\title{
Funktionelle Analysen deregulierter Signalwege transformierter B-Lymphozyten - \\ Das Epstein-Barr-Virus-Onkogen LMP1
}

\author{
DisSERTATION \\ zur Erlangung des Doktorgrades \\ der Mathematisch-Naturwissenschaftlichen Fakultäten \\ der Georg-August-Universität zu Göttingen
}

vorgelegt von

Diana Pinkert-Leetsch

geb. Pinkert

aus Merseburg

Göttingen 2007 
D 7

Referent: Prof. Dr. R. Hardeland

Korreferent: Prof. Dr. E. Wimmer

Tag der mündlichen Prüfung:04.05.2007 
Für meine große und kleine Familie 


\section{Inhaltsverzeichnis}

1 Abkürzungsverzeichnis $\quad$ VI

2 Einleitung 1

2.1 Das Epstein-Barr-Virus . . . . . . . . . . . . . . . 2

2.1.1 EBV-Infektion und -Latenz . . . . . . . . . . . . 2

2.1.2 EBV-assoziierte Erkrankungen . . . . . . . . . . . . . . 4

2.2 Das Latente Membranprotein $1 \ldots \ldots$. . . . . . . . . . . 7

2.2.1 Struktur und Aufbau von LMP1 . . . . . . . . . . . . . . 7

2.2.2 LMP1-aktivierte Signalwege . . . . . . . . . . . . . 10

2.3 Der Jak/STAT-Signalweg . . . . . . . . . . . . . . . . 12

2.3.1 Rückkopplungsmechanismen zur Hemmung des Jak/STAT-

Signalweges . . . . . . . . . . . . . . . . . . . 14

2.3.2 Der Jak/STAT-Signalweg in Tumoren . . . . . . . . . . . . 15

2.4 Aufgabenstellung . . . . . . . . . . . . . . . . . 17

$\begin{array}{llr}3 & \text { Material } & 18\end{array}$

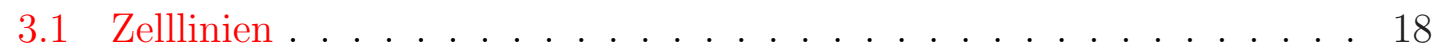

3.2 Geräte und Verbrauchsmaterialien . . . . . . . . . . . . 18

3.3 Chemikalien ........................... 20

3.4 Gebrauchsfertige Reaktionssysteme („Kits”) . . . . . . . . . . . . . 21

3.5 Antikörper . . . . . . . . . . . . . . . . . . 22

3.6 Zytokine und Inhibitoren . . . . . . . . . . . . . . . . . 23

3.7 Plasmide und Bakterienstämme . . . . . . . . . . . . . . 24

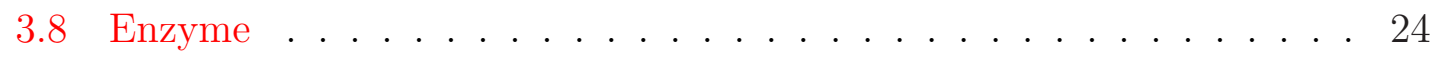


3.9 Oligonukleotide . . . . . . . . . . . . . . . . 25

4 Methoden 26

4.1 Zellbiologische Analysen . . . . . . . . . . . . . 26

4.1.1 Kultivierung von Suspensionszellen . . . . . . . . . . . . . 26

4.1.2 Kultivierung von adhärenten Zellen . . . . . . . . . . . . 26

4.1.3 Kryokonservierung und Auftauen von Zellen . . . . . . . . . . 27

4.1 .4 Zellzahlbestimmung . . . . . . . . . . . . . . 28

4.1.5 Einbringen von fremd-DNA in Zellen . . . . . . . . . . . . . . 28

4.1.6 Magnetische Zellseparation . . . . . . . . . . . . . . . . . 29

4.1.7 Manipulation der Zellen mit Inhibitoren . . . . . . . . . . . 30

4.1.8 Behandlung der Zellen mit Zytokinen und neutralisierenden Antikörpern ..................... 31

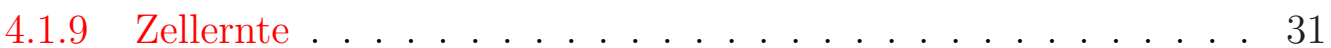

4.1 .10 Durchflusszytometrie . . . . . . . . . . . . . . 32

4.1 .11 Reportergenanalyse . . . . . . . . . . . . . . . 33

4.1 .12 Luciferaseassay . . . . . . . . . . . . . . . . 34

4.2 Proteinbiochemische Analysen . . . . . . . . . . . . . . . 35

4.2.1 Proteinisolation und Proteinbestimmung . . . . . . . . . 35

4.2.2 Western Blot-Analyse . . . . . . . . . . . . . . 36

4.2 .3 Immunpräzipitation . . . . . . . . . . . . . . . . . . . 39

4.2 .4 ELISA . . . . . . . . . . . . . . . . . . . 40

4.3 Molekularbiologische Analysen . . . . . . . . . . . . . . . . . . . 41

4.3.1 Transformation von E.coli-Zellen . . . . . . . . . . . . . . . 41

4.3.2 Isolierung von Plasmid-DNA . . . . . . . . . . . . . . . . . 41 
4.3.3 Isolation von Gesamt-RNA und reverse Transkription . . . . . 42

4.3.4 Konzentrationsbestimmung von Nukleinsäuren . . . . . . . . . 43

4.3.5 Quantitative Real-Time-PCR .............. 43

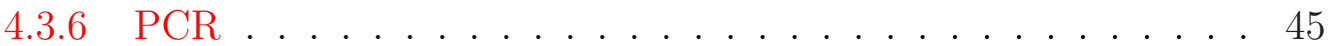

4.3.7 Agarose-Gelelektrophorese . . . . . . . . . . . . . . . 46

4.3 .8 Sequenzierung . . . . . . . . . . . . . . . . . 46

5 Ergebnisse 48

5.1 Der Jak/STAT-Signalweg in Lymphomen . . . . . . . . . . . . . . . . 48

5.1.1 STAT1 und STAT3 werden EBV-abhängig in Burkitt-Lymphomzellinien exprimiert . . . . . . . . . . . . . 48

5.1.2 EBV hat einen Einfluss auf die Aktivierung der Januskinasen in Burkitt-Lymphomzellinien . . . . . . . . . . . . 52

5.1.3 Die Januskinasen 2 und 3 sind in die Aktivierung des Jak/STATSignalweges involviert . . . . . . . . . . . . . 53

5.2 LMP1 ist für die STAT1- und STAT3-Aktivierung ausreichend . . . . 58

5.3 Die Analyse der SOCS3-Expression in Lymphomzelllinien . . . . . . . 61

5.3.1 SOCS3 wird in EBV-positiven Burkitt-Lymphomzelllinien exprimiert ........................... 61

5.3.2 Die Januskinasen 2 und 3 sind in die Aktivierung von SOCS3 involviert .................... . . . 65

5.3.3 SOCS3 wird in Hodgkin-Lymphomzellinien exprimiert . . . . 67

5.3.4 Die Expression von LMP1 ist ausreichend, um SOCS3 zu induzieren .............................. 69 
5.3.5 Die Überexpression von SOCS3 führt nicht zu einer vollständigen Hemmung von STAT3 in der EBV-positiven BurkittLymphomzellinie BL36 . . . . . . . . . . . . . . 70

5.4 Der LMP1-abhängig aktivierte p38/MAPK-Signalweg beeinflusst die Regulation des Chemokins IP-10 und des Jak/STAT-Signalweges in Burkitt-Lymphomzellinien . . . . . . . . . . . . . . . . . . 71

5.4.1 CD40 als funktionelles Homolog zu LMP1 reguliert NF- $\kappa$ Babhängig den Promotor des Chemokins IP-10 . . . . . . . 71

5.4.2 LMP1 reguliert p38/MAPK-abhängig die mRNA-Stabilität von $\mathrm{IP}-10 \ldots \ldots \ldots \ldots$. . . . . . . . . . . . . . . . . . . . .

5.4.3 Der p38/MAPK-Inhibitor SB202190 beeinflusst den Jak/STATSignalweg in Burkitt-Lymphomzelllinien . . . . . . . . . 76

5.4.4 Der p38/MAPK-Inhibitor SB202190 beeinflusst die LMP1-induzierte Phosphorylierung von STAT3 und die SOCS3-Expression ........................... 77

5.4.5 Die SOCS3-mRNA wird EBV-abhängig über p38/MAPK stabilisiert ....................... 79

5.5 Der Einfluss von LMP1 auf die Zytokinsignalwege transformierter B-

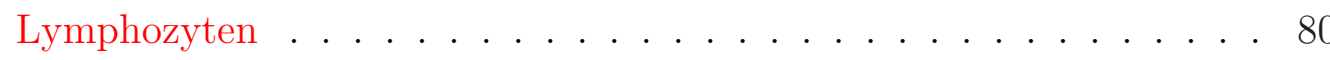

5.5.1 LMP1 aktiviert die IL-6- und IL-10-Produktion in BurkittLymphomzellinien . . . . . . . . . . . . . . . . . . 81

5.5.2 Die Wirkung von Zytokinen auf STAT3 und SOCS3 in Burkitt-Lymphomzellinien . . . . . . . . . . . . 83

5.5.3 Der Einfluss von neutralisierenden Antikörpern in EBV-positiven Burkitt-Lymphomzellinien . . . . . . . . . 86

6 Diskussion 
6.1 Der Jak/STAT-Signalweg wird EBV-abhängig in Burkitt-Lymphomzellen aktiviert . . . . . . . . . . . . . . . . . 90

6.2 Der Negativregulator SOCS3 wird in Abhängigkeit von EBV in Lymphomzellinien exprimiert . . . . . . . . . . . . . . . 93

6.3 LMP1 reguliert die mRNA-Stabilität von IP-10 und SOCS3 . . . . . 94

6.4 EBV beeinflusst den Jak/STAT-Signalweg durch Zytokine . . . . . . 96

6.5 Mögliche Funktionen von SOCS3 in EBV-positiven Burkitt-Lymphomzellen . . . . . . . . . . . . . . . . . . . . 98

6.6 Ausblick . . . . . . . . . . . . . . . . . . . . . . . 99

$\begin{array}{lll}7 & \text { Zusammenfassung } & 101\end{array}$

8 Veröffentlichungen 114

9 Danksagung 116 


\section{Abkürzungsverzeichnis}

A

Abb.

A.bidest

ABL

AG490

AIDS

ALL

Amp

APS

AS

BHK

BL

bp

BSA

bzw.

${ }^{\circ} \mathrm{C}$

ca.

CD

cDNA

CML

CTAR

Da

D-MEM

DMSO

DNA

DNase

dNTP

EBV

ECL

E.coli
Ampere

Abbildung

Wasser zweifach destilliert

engl.: Abelson murine leukemia viral oncogene homolog 1

$\alpha$-Cyano-(3,4-dihydroxy)-N-benzylcinnamid

engl.: Aquired Immune Deficiency Syndrom

akute lymphatische Leukämie

Ampicillin

Ammoniumpersulfat

Aminosäure

engl.: baby hamster kidney cells

Burkitt-Lymphom

Basenpaar

Rinderserumalbumin (engl.: bovine serum albumin)

beziehungsweise

Grad Celsius

circa

engl.: cluster of differentiation

komplementäre DNA (engl.: complementary DNA)

chronisch myeloische Leukämie

C-terminale Aktivierungsregion

Dalton

Dulbecco's modifiziertes Eagle Medium

Dimethylsulfoxid

Desoxyribonukleinsäure (engl.: desoxyribonucleic acid)

Desoxyribonuklease

Desoxynukleotidtriphosphat

Epstein-Barr-Virus

engl.: enhanced chemiluminescence

Escherichia coli 


\begin{tabular}{|c|c|}
\hline EDTA & Ethylendiamintetraessigsäure \\
\hline ELISA & engl.: enzyme-linked immuno sorbent assay \\
\hline et al. & und andere (lat.: et alii) \\
\hline etc. & und so weiter (lat.: et cetera) \\
\hline Fa. & Firma \\
\hline FACS & engl.: fluorescence activated cell sorting \\
\hline FITC & Fluoreszeinthiocyanat \\
\hline EtBr & Ethidiumbromid \\
\hline FBS & fetales Kälberserum (engl.: fetal bovine serum) \\
\hline g & Gramm \\
\hline GFP & grünfluoreszierendes Protein (engl.: green fluorescent protein) \\
\hline gp & Glykoprotein \\
\hline $\mathrm{h}$ & Stunde \\
\hline HEPES & N-2-Hydroxyethylpiperazin-N'-2-ethansulfonsäure \\
\hline HRP & Meerrettichperoxidase (engl.: horseradish peroxidase) \\
\hline IL & Interleukin \\
\hline IPTG & Isopropyl- $\beta$-D-thiogalactopyranosid \\
\hline $\mathrm{Jak}$ & Januskinase \\
\hline k- & kilo $\left(1 \times 10^{3}\right)$ \\
\hline Kan & Kanamycin \\
\hline 1 & Liter \\
\hline LB & Luria Bertani \\
\hline LCL & engl.: lymphoblastoid cell line \\
\hline LMP1 & Latentes Membranprotein 1 \\
\hline M & Molar \\
\hline m- & milli $\left(1 \times 10^{-3}\right)$ \\
\hline MACS & engl.: magnetic cell sorting \\
\hline MAPK & Mitogen-aktivierte Proteinkinase \\
\hline MG132 & Carbobenzoxy-L-leucyl-L-leucyl-L-leucinal \\
\hline $\min$ & Minute \\
\hline monokl. & monoklonal \\
\hline mRNA & Boten-RNA (engl.: messenger RNA) \\
\hline
\end{tabular}




$\begin{array}{ll}\mu- & \text { mikro }\left(1 \times 10^{-6}\right) \\ \text { n- } & \text { nano }\left(1 \times 10^{-9}\right) \\ \text { Neo } & \text { Neomycin } \\ \text { Nr. } & \text { Nummer } \\ \text { nt } & \text { Nukleotid } \\ \text { OD } & \text { optische Dichte } \\ \text { p- } & \text { pico }\left(1 \times 10^{-12}\right) \\ \text { P- } & \text { Phospho- } \\ \text { p.a. } & \text { zur Analyse }\end{array}$

PAGE Polyacrylamidgelelektrophorese

PBS Phosphat-gepufferte Kochsalzlösung (engl.: phosphate buffered saline)

PCR Polymerasekettenreaktion (engl.: polymerase chain reaction)

PE Phycoerythrin

pH negativer dekadischer Logarithmus der Hydroniumionenkonzentration

PMSF Phenylmethylsulfonylfluorid

polykl. polyklonal

RIP Rezeptor-interagierendes Protein

RLU relative Lichteinheiten (engl.: relative light units)

RNA Ribonukleinsäure (engl.: ribonucleic acid)

rpm Umdrehungen pro Minute (engl.: rounds per minute)

RPMI engl.: Roswell Park Memorial Institute

RT Raumtemperatur

s Sekunde

SB202190 4-(4-Fluorophenyl)-2-(4-hydroxyphenyl)-5-(4-pyridyl)1H-imidazol

SDS Natriumdodecylsulfat (engl.: sodium-dodecylsulfate)

SOCS $\quad$ engl.: suppressor of cytokine signaling

STAT engl.: signal transducer and activator of transcription

Tab. Tabelle

Taq Thermus aquaticus

TBE Tris-Borat-EDTA 
TBS Tris-gepufferte Kochsalzlösung (engl.: tris buffered saline)

TM engl.: Trademark

TEMED N,N,N',N'-Tetramethylendiamin

TNF Tumornekrosefaktor

TRADD Toll-like-Rezeptor-assoziierte Todesdomäne (engl:: Toll-likeRezeptor associated deathdomain)

TRAF Toll-like-Rezeptor-assoziierter Faktor

Tris Tris-hydroxymethyl-aminomethan

TritonX-100 Octylphenoxypolyethoxyethan

Tween Polyoxyethylensorbitanmonolaurat

Tyk2 Tyrosinkinase 2

U Unit

u.a. und anderes

üN über Nacht

V Volt

$\mathrm{v} / \mathrm{v} \quad$ Volumen/Volumen

WHI-P131 4-(4'-Hydroxyphenyl)amino-6,7-dimethoxyquinazolin

w/v Gewicht/Volumen (engl.: weight/volume)

$\mathrm{x}$-Gal 5-bromo-4-chloro-3-indolyl- $\beta$-D-galactopyranosid

z.B. $\quad$ zum Beispiel 


\section{Einleitung}

Nach den Herz-Kreislauf-Erkrankungen ist Krebs die zweithäufigste Todesursache in den westlichen Industrieländern. Als Krebs bezeichnet man bösartige Tumoren (lat.: Geschwulst, Schwellung). Kennzeichen bösartiger (maligner) Tumoren sind ein meist schnelles, infiltrierendes und invasives Wachstum. Es gibt keine scharfe Abgrenzung zum umgebenden Gewebe und maligne Tumoren besitzen die Fähigkeit, Metastasen zu bilden. Bei einer Metastase handelt es sich um eine Tochtergeschwulst des eigentlichen Tumors, die durch Streuung von Tumorzellen in entferntes Gewebe entstehen kann. In Abhängigkeit von ihrem zellulären Ursprung können maligne Tumoren näher charakterisiert werden. So werden Tumoren, die von hämatopoetischen bzw. lymphoiden Zellen abstammen, als Leukämien respektive Lymphome bezeichnet. Als Karzinome bezeichnet man Tumoren, die von epithelialen Zellen abstammen. Hingegen werden Tumoren, die sich von mesenchymalen Zellen herleiten, Sarkome genannt. Neben den bösartigen Tumoren gibt es auch gutartige (benigne) Tumoren. Diese Tumoren sind hochdifferenziert, scharf abgegrenzt und wachsen langsam und expansiv.

Die Entstehung von Krebs auf molekularer Ebene ist trotz intensiver Forschung noch weitgehend unverstanden. Ursachen für eine Krebsentstehung sind Veränderungen auf genetischer Ebene. So können beispielsweise Mutationsereignisse zur Überaktivierung von Genen, so genannten Proto-Onkogenen (z.B. MYC, MDM2, RAS, etc.), die insbesondere für Zellwachstum und Zellteilung verantwortlich sind, führen. Auch die Hemmung der Expression bestimmter Gene, so genannter Tumorsuppressorgene (z.B. TP53, RB1, BRCA1, etc.), die für das zelluläre Schicksal verantwortlich sind, kann zur Entartung der Zellen beitragen. Aber erst das Auftreten von mehreren genetischen Ereignissen kann schließlich zur malignen Transformation einer Zelle und somit zur Tumorentstehung führen. Auslöser für die Entwicklung eines Tumors kann beispielsweise die Exposition mit krebsauslösenden Stoffen, so genannten Karzinogenen, sein. Ebenso können virale Infekte zu einer Zelltransformation führen. Ein Virus, das in Zusammenhang mit der Entstehung von Tumoren gebracht wird, ist das Epstein-Barr-Virus (EBV). Denis Burkitt vermutete bereits 1958 einen Zusammenhang zwischen dem Auftreten des nach ihm benannten Burkitt-Lymphoms 
(siehe 2.1.2) und eines krankheitsassoziierten infektiösen Agenz, welches sich später als EBV herausstellte (Rickinson und Kieff et al., 1996). Die Entwicklung eines Zervikalkarzinoms steht ebenfalls im direkten Zusammenhang mit einer viralen Infektion, wobei es sich hier um den Humanen Papilloma-Virusstamm 16 handelt, der zur Krebsentstehung führt (Schulz et al., 2005).

\subsection{Das Epstein-Barr-Virus}

Benannt nach seinen Entdeckern Anthony Epstein und Yvonne Barr, wurde das Virus erstmals in Zelllinien entdeckt, die aus Burkitt-Lymphom-Biopsien etabliert worden waren (Epstein et al., 1964). Das Virus gehört zur Gruppe der $\gamma$-Herpesviren und wird auch als Humanes Herpesvirus 4 (HHV4) bezeichnet. Die Gruppe von DNA-Viren wird weiter unterteilt in Lymphokryptoviren und Rhadinoviren. Das Karposi's Sarkoma-assoziierte Herpesvirus, welches zur Gruppe der Rhadinoviren gehört, und das Epstein-Barr-Virus, das den Lymphokryptoviren angehört, sind die einzigen humanen Viren innerhalb der $\gamma$-Herpesviren (Kieff und Rickinson et al., 2001). Die verschiedenen Stämme der Epstein-Barr-Viren werden ihrerseits in zwei Gruppen unterteilt, die sich hauptsächlich in der Aminosäuresequenz der EBVnukleären Antigene (EBNA) unterscheiden. Stämme der Gruppe 1 findet man in den meisten Bevölkerungsgruppen, während Stämme der Gruppe 2 in Zentralafrika und Neu Guinea zu finden sind (Kieff und Rickinson et al., 2001). Das Epstein-Barr-Virus ist das erste beschriebene humane Tumor-assoziierte Virus.

\subsubsection{EBV-Infektion und -Latenz}

Eine Infektion mit EBV erfolgt in der Regel im Kindesalter und zumeist ohne Anzeichen von Krankheitssymptomen. Infiziert man sich hingegen im Jugend- oder Erwachsenenalter mit dem Virus, so kann man eine infektiöse Mononukleose, auch Pfeiffersches Drüsenfieber oder „kissing disease” genannt, entwickeln (Rickinson und Kieff et al., 1996). Die Symptome der Erkrankung sind denen einer Grippe ähnlich. Mehr als 90\% der erwachsenen Bevölkerung sind mit EBV infiziert (Schulz et al., 2005). Die Übertragung des Virus erfolgt über den Speichel, der dann Schleimhau- 
tepithelzellen in Mund- und Rachenraum sowie B-Lymphozyten infiziert. Die Reihenfolge der Infektion ist jedoch noch nicht vollständig geklärt (Rickinson und Kieff et al., 1996). Einmal infiziert, persistiert das Virus ein Leben lang in Gedächtnis-BLymphozyten, kann aber jederzeit reaktiviert werden und neue Viren in den Rachenraum und damit in den Speichel sekretieren. In den infizierten B-Lymphozyten liegt das 184kbp große EBV-Genom in Form einer zirkularisierten DNA, auch als Episom bezeichnet, vor. Hierbei wird die latente Infektion von einer in $10^{5}$ bis $10^{6}$ peripheren Blut-B-Lymphozyten getragen (Babcock et al., 2000). Charakteristischerweise befinden sich mehrere Kopien des Episoms in der Zelle, wobei es in sehr seltenen Fällen durchaus auch zur Integration in das Wirtsgenom kommen kann (Kieff und Rickinson et al., 2001).

Zur Zeit werden vier Latenztypen definiert, die sich in der Expression der viralen Latenzgene unterscheiden (Tab. 1). In den Gedächtnis-B-Lymphozyten von gesunden EBV-positiven Menschen kann der Latenztyp 0 nachgewiesen werden (Küppers et al., 2003). B-Zellen, die in vitro mit EBV transformiert wurden, und EBV-positive Zellkulturen weisen stets den Latenztyp III auf (Joseph et al., 2000). Zu den Latenzgenen gehören die sechs EBV-nukleären Antigene EBNA1, EBNA2, EBNA3A, EBNA3B, EBNA3C und EBNA-LP. Hierbei ist die Expression von EBNA1-Protein für die Beibehaltung des episomalen Zustandes von EBV essentiell (Kieff und Rickinson et al., 2001). EBNA1 wird mit Ausnahme des Latenztyps 0 in allen Latenztypen exprimiert, wohingegen nur in Latenz III alle sechs EBNAs vorkommen.

Tab. 1: Latenz

\begin{tabular}{lll}
\hline Latenztyp & exprimierte Gene & Vorkommen \\
\hline Latenz 0 & EBERs 1, 2; LMP2A & gesunde, seropositive Personen \\
Latenz I & EBERs 1, 2; EBNA1; BARTs & Burkitt-Lymphom \\
Latenz II & EBERs 1, 2; EBNA1; BARTs; LMP1; & Hodgkin-Lymphom; T-Zell-Lymphom; \\
& LMP2A; LMP2B & Nasopharynx-Karzinom \\
Latenz III & EBERs 1, 2; EBNA1; EBNA2; EBNA3A; & immunoblastische B-Zell-Lymphome \\
& EBNA3B; EBNA3C; EBNA-LP; BARTs; & \\
& LMP1; LMP2A; LMP2B & \\
\hline
\end{tabular}

Die Latenten Membranproteine 1 (LMP1, siehe 2.2), LMP2A und LMP2B werden in Latenz II und III exprimiert. Als virales Onkogen ist LMP1 essentiell für die Transformation von B-Lymphozyten. Auf den strukturellen Aufbau von LMP1 und 
dessen Bedeutung bei der Transformation von Zellen wird näher in Kapitel 2.2 eingegangen. Die Membranproteine LMP2A und LMP2B unterscheiden sich in einem verkürzten Exon1 in LMP2B und einem daraus folgenden anderen Translationsstartpunkt (Kieff und Rickinson et al., 2001). Die zwei kleinen, nicht polyadenylierten RNAs (EBER1 und EBER2) treten ebenfalls in allen Latenztypen auf und befinden sich als Komplex mit zellulären Proteinen (La, EAP) im Zellkern der infizierten Zelle (Kieff und Rickinson et al., 2001). Ihre Funktionen sind jedoch noch unklar.

Eine weitere Gruppe viraler Genprodukte, die sich in allen Latenzen nachweisen lässt, repräsentieren die erst kürzlich entdeckten mikroRNAs (miRNA). miRNAs sind ca. 22nt lange, nicht-kodierende, kleine RNAs, welche die Stabilität und Translation der mRNA beeinflussen und eine wichtige Rolle bei der Regulation zellulärer Prozesse spielen (Kloosterman et al., 2006). Während man die erste miRNA in C.elegans nachwies, wurden virale miRNAs erstmals in Epstein-Barr-Viren gefunden (Lee et al., 1993; Pfeffer et al., 2004). Je nach Lage im viralen Genom unterteilt man die miRNAs in die Gruppe der BHRF1- mikroRNAs (miR-BHRF1, Bam $H I \mathrm{H}$ rightward frame 1) und die der BART- mikroRNAs (miR-BART, Bam HI A rightward transcripts), wobei die Funktionen der einzelnen miRNAs noch nicht vollständig geklärt sind.

\subsubsection{EBV-assoziierte Erkrankungen}

In einem gesunden Menschen mit intaktem Immunsystem kommt es meist nicht zu einem klinisch manifestierten Auftreten einer lymphoproliferativen Erkrankung infolge einer EBV-Infektion. Dennoch gibt es eine Anzahl von Erkrankungen, deren Entstehung mit dem Epstein-Barr-Virus assoziiert ist. Zu nennen sind hier das Burkitt-Lymphom (siehe unten), das Nasopharynx-Karzinom (siehe unten), das Hodgkin-Lymphom (siehe unten) und T-Zell-Lymphome. Ein Zusammenhang zwischen Tumorentstehung und EBV kann auch bei Lymphomen, die bei immunsuppremierten Menschen oder durch erbliche Veranlagung auftreten, gefunden werden. Zur erstgenannten Gruppe gehören Patienten, die an AIDS erkrankt sind oder sich einer Transplantation unterzogen haben. 
Tab. 2: EBV-assoziierte Erkrankungen

\begin{tabular}{lll}
\hline Erkrankung & & EBV-positive Fälle \\
\hline Burkitt-Lymphom & endemisch & $100 \%$ \\
& sporadisch & $15-85 \%$ \\
& AIDS-assoziiert & $30-40 \%$ \\
Nasopharynx-Karzinom & & $100 \%$ \\
Hodgkin-Lymphom & mc/ld & $80-90 \%$ \\
T-Zell-Lymphome & ns & $30 \%$ \\
immunoblastische B-Zell-Lymphome & erblich veranlagt & $40-100 \%$ \\
& nach Transplantation & $100 \%$ \\
& AIDS-assoziiert & $70-80 \%$ \\
\hline
\end{tabular}

Quelle: Rickinson und Kieff et al. (1996)

Das Burkitt-Lymphom (BL). Das Burkitt-Lymphom ist eine besonders aggressive Erkrankung und gehört zur Gruppe der hochmalignen Non-Hodgkin-Lymphome. Es ist B-zellulären Ursprungs und wurde erstmals von Denis Burkitt beschrieben (Burkitt et al., 1958). Die Tumorzellen weisen eine sehr hohe Proliferationsrate auf und infiltrieren neben den Lymphknoten auch andere Organe. Es gibt drei Formen des Burkitt-Lymphoms: das endemische, das sporadische und das AIDSassoziierte. Allen gemeinsam ist eine Chromosomentranslokation, die den MYCGenlokus (8q24.1) mit einbezieht. Das häufigste Ereignis ist die durch die Translokation hervorgerufene Fusion mit dem Immunglobulin-Schwerkettenlokus (14q32). Weniger oft kommt es zur Fusion mit den Immunglobulin-Leichtkettenloci für die $\lambda$ (22q11)- oder $\kappa(2 \mathrm{p} 12)$-Leichte Kette (Schulz et al., 2005). Das translozierte MYCGen wird somit sehr stark aktiviert und stimuliert Zellwachstum, Proliferation, aber auch Apoptose (Boxer et al., 2001). Das endemische Burkitt-Lymphom findet man in Gebieten mit hoher Malariainfektion in Zentralafrika und Neu Guinea. In Zentralafrika ist es die am häufigsten auftretende Tumorerkrankung bei Kindern unter 15 Jahren (Inzidenz 10/10000). Alle endemisch auftretenden Burkitt-Lymphome sind zu 100\% EBV-positiv (Tab. 2). Das sporadische Burkitt-Lymphom ist dagegen in den westlichen Ländern zu finden (Rickinson und Kieff et al., 1996). Weitere Unterschiede zwischen endemischen und sporadischen Burkitt-Lymphomen sind das Alter der Patienten und die Ausprägung des Krankheitsbildes. Menschen mit der Im- 
munschwächekrankheit AIDS können ebenfalls an einem B-Zell-Lymphom (Immunoblastisches- oder Burkitt-Lymphom) erkranken. In den westlichen Gesellschaften entwickeln bis zu 10\% der AIDS-Kranken ein Burkitt-Lymphom. Das charakteristische EBV-Genexpressionsprofil ist das des Latenztyps I (Tab. 1). In allen EBVpositiven Burkitt-Lymphomen muss sich das Virus bereits in der B-Zelle befunden haben, bevor diese entartet ist. Dies gilt unabhängig davon, ob es sich um die endemische, sporadische oder AIDS-assoziierte Form des Burkitt-Lymphoms handelt, da alle Tumorzellen den gleichen EBV-Episom-Klon aufweisen (Neri et al., 1991).

Das Hodgkin-Lymphom (HL). Hodgkin-Lymphome stellen eine Untergruppe der Lymphomerkrankungen dar und sind eine der am häufigsten auftretenden malignen Lymphome in der westlichen Welt. Die Ursprungszelle für die Entstehung dieses Lymphoms kann eine T- oder eine B-Zelle sein, wobei Erkrankungen mit Bzellulärem Ursprung überwiegen. Kennzeichnend für das von Thomas Hodgkin beschriebene Lymphom ist das Auftreten einkerniger Hodgkin-Zellen und mehrkerniger Reed-Sternberg-Zellen. Über $98 \%$ der Tumormasse bilden allerdings verschiedene nicht-maligne infiltrierende Zellen. Hodgkin-Lymphome können in vier Klassen unterteilt werden: ein Lymphozyten-predominantes (lp), ein nodulär-sklerodisierendes (ns), eines mit gemischter Zellularität (mc) und ein Lymphozyten-armes (ld) Hodgkin-Lymphom (Rickinson und Kieff et al., 1996). Auch in den EBV-positiven Hodgkin-Reed-Sternberg-Zellen muss sich das virale Genom bereits vor Entartung der Zellen befunden haben. Der Anteil an EBV-positiven Fällen an den gesamten HLs ist in Tabelle 2 aufgeführt. Im Durchschnitt liegt der Anteil bei 40-50\% in der westlichen Welt (Jarrett et al., 1991). Die EBV-assoziierten Hodgkin-Lymphome weisen den Latenztyp II auf (Tab. 1).

Das Nasopharynx-Karzinom. Eine Infektion mit dem Epstein-Barr-Virus kann ebenfalls zur Entstehung eines Nasopharynx-Karzinoms führen. Wenn es zur Ausprägung dieser Tumorentität aufgrund einer EBV-Infektion kommen sollte, dann geschieht dies erst nach über 30 Jahren. 100\% der Tumoren sind EBV-positiv, sie besitzen den Latenztyp II (Tab. 1, 2) und weisen ein monoklonales Virusepisom auf (Rickinson und Kieff et al., 1996). Das Nasopharynx-Karzinom findet man 
hauptsächlich im südostasiatischen Raum, auf Grönland sowie in Nord- und Ostafrika. Das Auftreten der Erkrankung in diesen Regionen kann mit den Essgewohnheiten in Zusammenhang gebracht werden (Poirier et al., 1987). Auslöser hierfür können flüchtige Nitrosamine sein, die bei der Konservierung von Lebensmitteln entstehen.

Für die Transformation der Zellen stellt die Expression von LMP1 die entscheidende Komponente dar. Als wesentlicher Gegenstand dieser Arbeit wird der Aufbau und die Funktion des Moleküls im nächsten Kapitel eingehend beleuchtet.

\subsection{Das Latente Membranprotein 1}

Das Latente Membran Protein 1 (LMP1) des Epstein-Barr-Virus gehört zu den Latenzgenen und wird in den Latenztypen II und III nachgewiesen (Tab. 1). Es scheint eine besondere Rolle bei der Entstehung EBV-assoziierter Erkrankungen zu spielen: Die Expression von LMP1 ist essentiell für die Transformation von BLymphozyten. Daher wird LMP1 auch als virales Onkogen bezeichnet (Kaye et al., 1993). Wang et al. (1985) konnten zeigen, dass LMP1 in Nagerfibroblasten-Zelllinien (Rat-1) transformierende Effekte zeigt und die Zellen ihre Fähigkeit zur Kontaktinhibierung verlieren. Diese LMP1-exprimierenden Zellen führten in Nacktmäusen zur Tumorentstehung, während dies bei den LMP1-negativen Kontrollzellen nicht der Fall war.

\subsubsection{Struktur und Aufbau von LMP1}

Das LMP1-Protein ist 63kDa (386 Aminosäuren) groß und setzt sich aus einem 24 Aminosäuren langen zytoplasmatischen N-Terminus, sechs Transmembrandomänen, bestehend aus je 20 Aminosäuren langen $\alpha$-Helices, und einem 200 Aminosäuren langen zytoplasmatischen C-Terminus zusammen (Liebowitz et al., 1986) (Abb. 1). LMP1 ist in den zytoplasmatischen Membranen der Zellen lokalisiert, wobei sich ungefähr die Hälfte des zellulären LMP1 in der Zellmembran befindet (Liebowitz et al., 1986). Voraussetzung für die Aktivierung von Signalwegen durch LMP1 ist, dass diese in Form von Aggregaten in den sogenannten „Rafts” der Membranen der Zellen vorliegen. Dabei befinden sich die Moleküle sowohl in der Plasmamembran als 
auch in Membranen zellulärer Kompartimente (Liebowitz et al., 1986; Kaykas et al., 2001). Bei den Lipid-Rafts handelt es sich um Cholesterin- und Sphingolipid-reiche Bereiche der Zellmembran. Ein Teil der LMP1-Proteine kann mit Komponenten des Zytoskeletts interagieren, z.B. mit Vimentin (Liebowitz et al., 1987).

Der N-terminale Bereich von LMP1 ist für die Verankerung in der Membran, die Interaktion mit Komponenten des Zytoskeletts und den Abbau von LMP1 verantwortlich. Die Transmembrandomänen ermöglichen die Aggregation und Oligomerisierung von LMP1-Molekülen, die dann ohne Bindung eines Liganden aktiv sind und somit funktionell einem konstitutiv aktiven Rezeptor entsprechen (Gires et al., 1997). Eine natürlich vorkommende Mutante des LMP1-Proteins (D1LMP1), deren N-Terminus und die ersten vier Transmembrandomänen fehlen, kann nicht aggregieren und ist demzufolge nicht in der Lage, Zellen zu transformieren (Wang et al., 1988; Liebowitz et al., 1992). Obgleich LMP1 für eine Signaltransduktion in oligomerisierter Form vorliegen muss, ist der C-Terminus die für die Signaltransduktion entscheidende Komponente, da es ohne die letzten 200 Aminosäuren nicht zur Immortalisierung von B-Lymphozyten kommt (Kaye et al., 1995). Der zytoplasmatische C-Terminus (AS 187-386) wird funktionell in die C-terminalen Aktivierungsregionen 1 und 2 (CTAR1 und CTAR2) unterteilt (Abb. 1). In Mutationsanalysen wurde festgestellt, dass CTAR1 für die transformierenden Eigenschaften von LMP1 essentiell ist (Izumi et al., 1997a; Kaye et al., 1999). CTAR2 scheint hingegen für die Aufrechterhaltung dieses Phänotyps verantwortlich zu sein, da es ohne sie zwar zu einer Immortalisierung von B-Lymphozyten kommt, das Wachstum dieser Zellen aber endlich ist (Izumi et al., 1997b).

Da der C-Terminus von LMP1 der signalgebende Teil des Proteins ist, stellt dieser für eine Vielzahl von Proteinen den Bindungspartner dar. So konnte gezeigt werden, dass TNF-Rezeptor-assoziierte Faktoren (TRAFs) an CTAR1 (TRAF1, 2, 3, 5) und CTAR2 (TRAF2, 6) binden (Mosialos et al., 1995; Devergne et al., 1996; Brodeur et al., 1997; Schultheiss et al., 2001; Shirakata et al., 2001). Hierbei sind für die Bindung von TRAFs an CTAR1 die Aminosäuremotive PxQxT bzw. PxQxxD notwendig, wobei x für eine beliebige Aminosäure steht (Devergne et al., 1998; Ye et al., 1999). CTAR2 weist ebenfalls Interaktionspartner auf. An das Ami- 
nosäuremotiv YYD bindet der N-Terminus des TRADD (TNF-Rezeptor-assoziierte Todesdomäne)-Moleküls. Die Bindung der TRAF-Moleküle erfolgt über TRADD. Das Motiv YYD sowie ein weiterer Teil in Richtung des N-Terminus von LMP1 sind ebenfalls notwendig für die Bindung von RIP (Rezeptor-interagierendes Protein) (Izumi et al., 1999a). Gires et al. (1999) zeigten, dass sich zwischen den CTARs Bindestellen für die Januskinase 3 (Jak3) befinden und diese dort mit LMP1 interagiert. Die auch als CTAR3 bezeichnete Region hat aber keinen Einfluss auf die Transformation von B-Lymphozyten (Izumi et al., 1999b). Da die Jak3-Bindung an LMP1 in anderen Untersuchungen nicht bestätigt werden konnte, ist dies zur Zeit Gegenstand kontroverser Diskussionen (Higuchi et al., 2002).

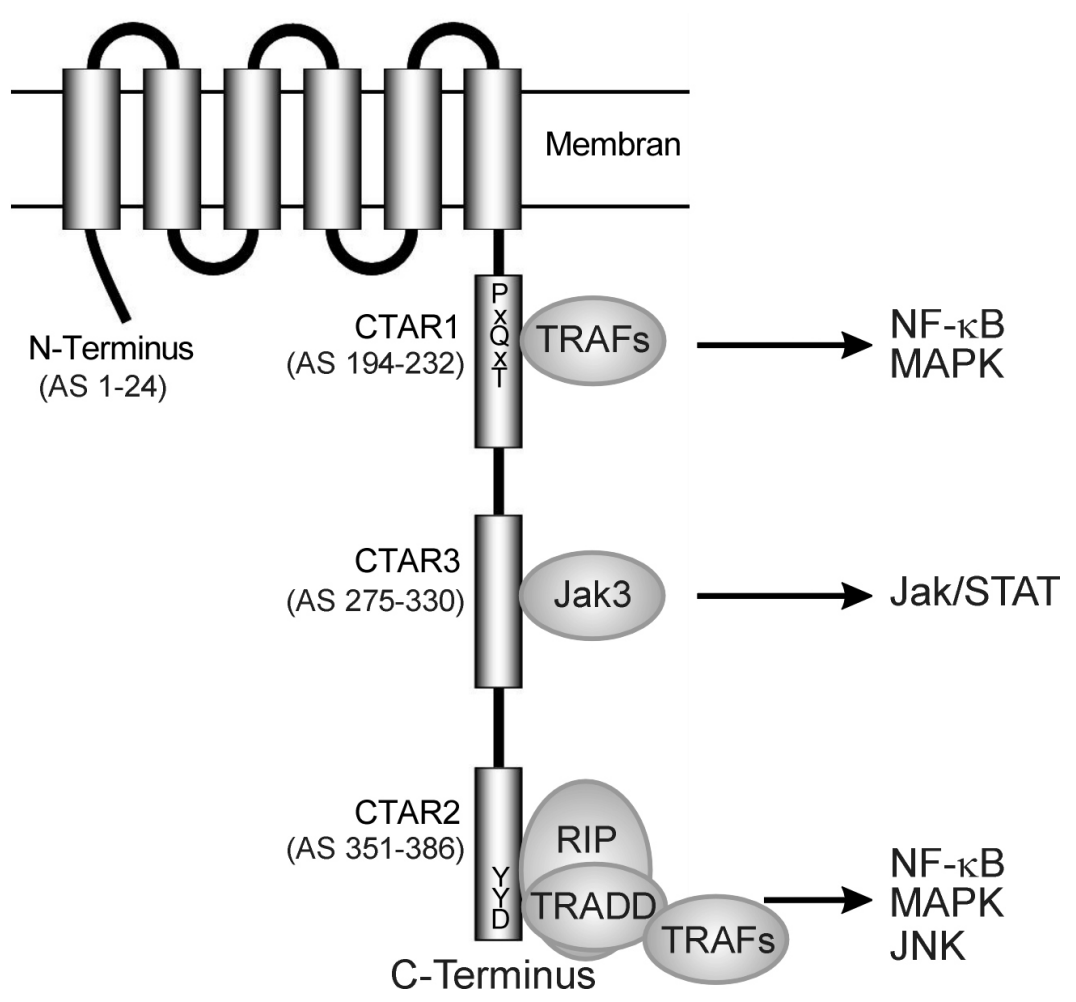

Abb. 1: Schematische Darstellung der Domänenstruktur von LMP1 und den aktivierten Signalwegen. Das Membranprotein LMP1 besteht aus sechs Transmembrandomänen, einem zytoplasmatischen N- und einem zytoplasmatischen C-Terminus. Funktionell wird der C-terminale Bereich in die Domänen CTAR1, CTAR2 und CTAR3 unterteilt. Diese sind durch die Konsensusmotive PxQxT in der CTAR1 und YDD in der CTAR2 Bindungspartner für unterschiedliche Moleküle und tragen so zur Aktivierung von Signalwegen bei. 


\subsubsection{LMP1-aktivierte Signalwege}

Der wohl am besten untersuchte, durch LMP1 aktivierte Signalweg ist der NF- $\kappa$ BSignalweg. Dieser spielt in Zellen eine wichtige Rolle bei der Regulation von Apoptose, Proliferation, Wachstum, Inflammation und Onkogenese. LMP1 induziert die Aktivierung von NF- $\kappa \mathrm{B}$ durch die direkt an CTAR1 oder indirekt über TRADD an CTAR2 gebundenen TRAF-Moleküle (Abb. 1). Somit tragen beide CTARs zur NF- $\kappa$ B-Aktivierung bei, wobei CTAR2 stärker involviert ist (Huen et al., 1995; Mitchell und Sugden, 1995). Infolge der NF- $\kappa$ B-Aktivierung kommt es zur Expression der anti-apoptotischen Gene A20 und cIAP, der Zelloberflächen-Antigene CD40 und CD54 sowie der Zytokine IL-6 und IL-8 (Eliopoulos und Young, 2001). Luftig et al. (2003) fanden heraus, dass die Aktivierung von NF- $\kappa$ B durch LMP1 in Abhängigkeit von TRAF6 und IRAK1 geschieht. Anhand ihrer Experimente in embryonalen Mäusefibroblasten (MEFs) konnten sie in TRAF6-knock out-MEFs keine Aktivierung von NF- $\kappa \mathrm{B}$ durch LMP1 wohl aber durch TNF zeigen. Eine direkte Bindung von TRAF6 an LMP1 wurde noch nicht nachgewiesen. Es wird daher vermutet, dass die Rekrutierung von TRAF6 über Adapterproteine an die CTAR2 erfolgt (Luftig et al., 2003). Schultheiss et al. (2001) postulieren ebenfalls eine indirekte Interaktion von LMP1 und TRAF6. Jedoch sehen sie TRAF6 als Bestandteil des signalgebenden Komplexes aggregierter LMP1-Moleküle.

Betrachtet man die Interaktionspartner und die Signalwege von LMP1, so kann man Gemeinsamkeiten mit den Rezeptoren der TNF-Familie feststellen. Funktionell wird LMP1 als CD40-Homolog gesehen, da auch hier TRAF-Moleküle an das gleiche Konsensusmotiv binden, wie sie es an CTAR1 im LMP1 tun (Uchida et al., 1999). Durch die neueren Erkenntnisse von Luftig et al. (2003) sind nun ebenfalls Gemeinsamkeiten mit den Signalkaskaden der Toll-like-Rezeptoren (TLR), im Speziellen des IL-1-Rezeptors, zu finden. Die durch LMP1 aktivierten Signalwege beinhalten Komponenten der Signalwege sowohl des TNF- als auch des TL-Rezeptors. LMP1 kann deshalb nicht mehr ausschließlich als TNF-Rezeptor-Homolog gesehen werden.

In der Literatur gib es Hinweise, dass LMP1 den Jak/STAT-Signalweg (siehe 2.3) aktivieren kann. So können Gires et al. (1999) eine direkte Interaktion von Jak3 mit LMP1 zeigen. In diesem Zusammenhang konnte ebenfalls eine erhöhte Bindungs- 
aktivität von STAT1 an die DNA nachgewiesen werden. Neben STAT1 kann aber auch STAT3 EBV-abhängig in lymphoblastoiden Zelllinien (LCL) von Patienten mit einer lymphoproliferativen Erkrankung infolge einer Transplantation konstitutiv aktiv vorliegen (Nepomuceno et al., 2002). Es wird vermutet, dass dies im Zusammenhang mit der autokrinen IL-10-Produktion dieser Zellen steht. Eine Aktivierung von STAT-Proteinen (STAT3, STAT5), die durch LMP1 verursacht wird, konnte ebenfalls in Nasopharynx-Karzinom-Zellinien beobachtet werden (Chen et al., 2003). Die Aktivierung von STAT3 ist hier im Zusammenhang mit einer von IL-6 abhängigen, positiv regulierten Feedbackschleife zu sehen.

Zu den Signalwegen, die durch LMP1 aktiviert werden, gehören auch die der Mitogen-aktivierten Proteinkinase (MAPK)-Familie. Diese Kinasen, zu denen die Gruppen der JNKs (c-Jun N-terminale Kinase), p38/MAPKs und ERKs (engl.: extracellular signal regulated kinase) gehören, werden infolge der MAPK-Kaskade aktiviert. Auslöser dieser Signalwege können Wachstumsfaktoren, Zytokine oder zellulärer Stress sein. Die Aktivierung von JNK durch LMP1 erfolgt ausschließlich über CTAR2, wobei TRAF2 involviert zu sein scheint (Eliopoulos et al., 1999a; Kieser et al., 1999). Dies führt zur Aktivierung von AP-1 (Kieser et al., 1997). Hierbei handelt es sich um Transkriptionsfaktoren, die in Form von Homo- oder Heterodimeren aus Komponenten der Transkriptionsfaktorfamilien ATF, Jun und Fos bestehen und eine Rolle bei der Zellproliferation und der Apoptose spielen (Shaulian et al., 2001). p38/MAPKs können innerhalb der MAPK-Kaskade durch die MAPKK MKK3 und MKK6 aktiviert werden. Für eine Induktion von p38 durch LMP1 ist sowohl die CTAR1 als auch die CTAR2 erforderlich (Eliopoulos et al. (1999b); Abb. 1). Über TRADD, TRAF2 und die Rekrutierung von TRAF6 in den signalgebenden Komplex aggregierter LMP1-Moleküle kommt es zur Aktivierung von p38 durch MKK6 (Schultheiss et al., 2001). Dies wiederum führt zur Aktivierung von ATF-2 und der Expression von Zytokinen wie IL-6 bzw. IL-8 in epithelialen Zellen (Eliopoulos et al., 1999b). Die p38/MAPK-abhängige Induktion von IL-10 konnte in LMP1-exprimierenden Burkitt-Lymphomzellen nachgewiesen werden (Vockerodt et al., 2001). Es wurde ebenfalls gezeigt, dass p38 eine Rolle in der posttranslationalen Modifikation spielt. Für das Chemokin IL-8, das ein AU-reiches cis-Element (ARE) im 3'-untranslatierten Bereich der mRNA besitzt, konnte eine Stabilisierung 
der mRNA in Abhängigkeit von p38 und MK2 (MAP-Kinase-aktivierte Proteinkinase 2) festgestellt werden (Winzen et al., 1999). MK2 ist ein direktes Ziel von p38 und wird durch Phosphorylierung aktiviert. Für die Stabilisierung der ARE-enthaltenden mRNAs durch p38 werden ARE-bindende Proteine benötigt. Es wurde bereits eine Vielzahl dieser Proteine identifiziert. Dennoch ist unklar, welches der identifizierten Proteine zusammen mit p38 eine Rolle bei der Stabilisierung der mRNA spielt (Dean et al., 2004). Aufbauend auf Vorarbeiten der Arbeitsgruppe zu p38 und IP-10 (IFN- $\gamma$ induzierbares Protein, 10kDa) werden in dieser Arbeit weitere Studien zu p38 im Zusammenhang mit der mRNA-Stabilisierung in Burkitt-Lymphomzellinien durchgeführt.

Es gibt Hinweise, die auf einen Zusammenhang zwischen der Expression des Onkogens LMP1 und der Aktivierung des Jak/STAT-Signalweges hindeuten. Demnach ist es wahrscheinlich, dass die Aktivierung des Jak/STAT-Signalweges eine wichtige Rolle bei der EBV-vermittelten Tumorentstehung spielt. Dennoch ist nicht vollkommen geklärt, wie die Aktivierung erfolgt. Dies näher zu untersuchen, ist Gegenstand dieser Arbeit. Im Folgenden wird daher der Jak/STAT-Signalweg näher erläutert.

\subsection{Der Jak/STAT-Signalweg}

Insbesondere Zellen des Immunsystems benötigen für die Übermittlung von Signalen Zytokine. Dies sind kleine Proteine (15-25kDa), die von den Zellen des Immunsystems sezerniert werden und somit Stärke und Dauer einer Immunreaktion steuern. Infolge ihrer Arginin- und Uracil-reichen Sequenzen im 3'-Bereich der mRNA besitzen sie eine geringe Halbwertszeit (Roitt et al., 1993). Das Auslösen einer Signalkaskade geschieht durch Bindung des Zytokins an seinen Rezeptor. Man unterscheidet zwei strukturell verwandte Zytokinrezeptorfamilien: Typ 1- und Typ 2Zytokinrezeptoren. Diese Rezeptoren besitzen keine intrinsische Kinaseaktivität wie beispielsweise Rezeptortyrosinkinasen und sind deshalb abhängig von Kinasen wie etwa den Januskinasen (Jaks). Neben Jak/STAT können aber auch noch andere Signalwege, beispielsweise MAPK- und PI3K-Signalwege, durch Zytokine aktiviert werden. Die Januskinasen sind eine Familie von Tyrosinkinasen mit den vier Mitgliedern Jak1, Jak2, Jak3 und Tyk2, welche mit den Zytokinrezeptoren assoziiert 
sind (Ortmann et al., 2000). Die Bindung an den Rezeptor erfolgt mit dem NTerminus der Jaks, die je nach Zytokinrezeptor in verschiedenen Kombinationen (z.B. Jak1/Jak2) an die Untereinheiten des Rezeptors binden. Die sich C-terminal befindende Kinasedomäne des Rezeptors ist für die weitere Signalübertragung durch Phosphorylierung verantwortlich. Die Pseudo-Kinasedomäne der Jaks ist für die Kinaseaktivität erforderlich und fördert die Bindung der STAT-Moleküle (engl.: signal transducer and activator of transcription) (Steelman et al., 2004). Diese Familie von Transkriptionsfaktoren besteht aus 7 Mitgliedern (STAT1, STAT2, STAT3, STAT4, STAT5a, STAT5b, STAT6). Zur Aktivierung der STATs müssen diese spezifisch phosphoryliert werden. Dies geschieht durch die Übertragung einer Phosphatgruppe auf Tyrosin durch die Januskinasen oder auf Serin durch MAPKinasen (Goh et al., 1999; Lim et al., 1999). Es gibt zwei DNA-Motive, an welche die STATMoleküle binden können: das Interferon-stimulierte DNS-Bindungsmotiv (ISRE) sowie das $\gamma$-aktivierte Sequenzelement (GAS).

Die Signaltransduktion durch den Jak/STAT-Signalweg ist in Abbildung 2 schematisch dargestellt. Die Bindung eines Zytokins an seine entsprechende Rezeptoruntereinheit führt zur Dimerisierung der Untereinheiten. Die an die Rezeptoruntereinheiten gebundenen Jaks kommen nun in räumliche Nähe zueinander, was eine
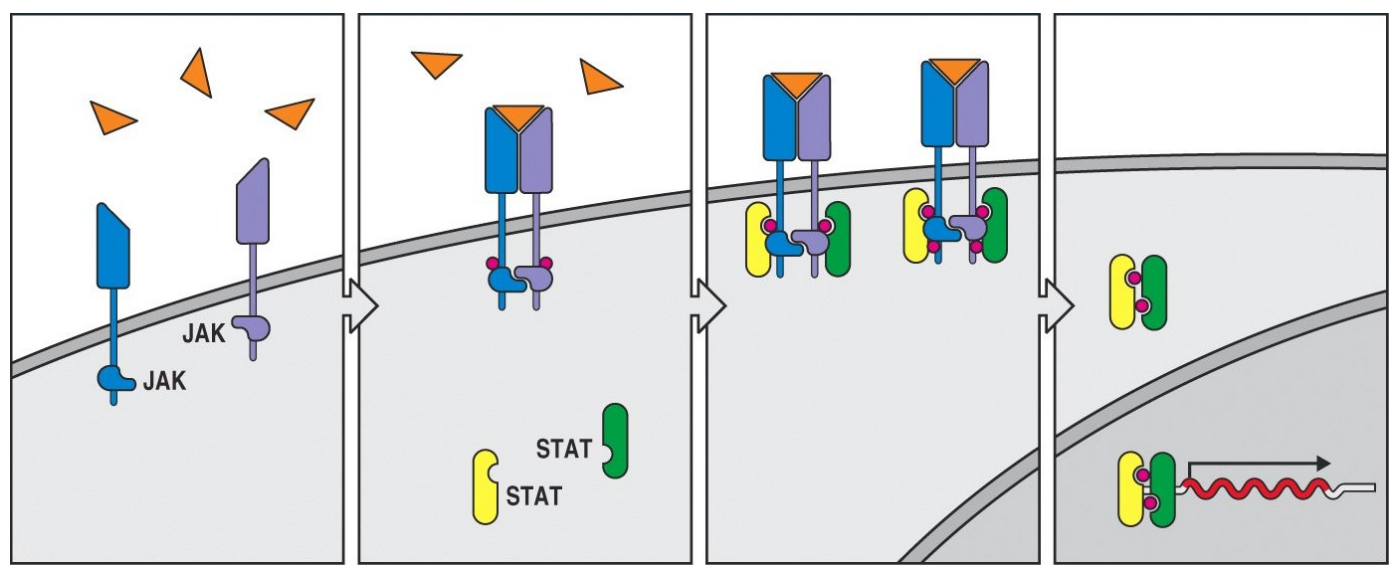

Abb. 2: Schematische Darstellung des Jak/STAT-Signalweges. Die Bindung von Zytokinen an ihre Rezeptoruntereinheiten führt zur Dimerisierung des Rezeptors. Die daran gebundenen Januskinasen werden autophosphoryliert und können daraufhin den Rezeptor phosphorylieren, an welchen dann die STAT-Moleküle mit ihrer SH2-Domäne binden können. Diese werden daraufhin ebenfalls von den Januskinasen phosphoryliert. In diesem aktivierten Zustand dissoziieren die STATs vom Rezeptor und wandern nach erfolgreicher Dimerisierung in den Zellkern, wo sie als Transkriptionsfaktoren verschiedene Zielgene aktivieren. Quelle: Janeway et al. (2005) 
Autophosphorylierung der Jaks zur Folge hat. Dies führt im weiteren Verlauf zur spezifischen Tyrosin-Phosphorylierung der Rezeptoruntereinheiten und damit zur Bildung von Bindestellen für die STATs. Diese binden mit ihrer SH2-Domäne an den Rezeptor und werden ebenfalls von den Januskinasen an Tyrosinen phosphoryliert. In diesem Zustand dissoziieren die STATs vom Rezeptor, bilden Homo- oder Heterodimere und wandern in den Zellkern, wo sie die Transkription verschiedener regulatorischer Gene etwa für Wachstum, Apoptose und Angiogenese der Zelle aktivieren (Bromberg et al., 2002).

\subsubsection{Rückkopplungsmechanismen zur Hemmung des Jak/STAT-Signal- weges}

Die Hemmung des Jak/STAT-Signalweges kann durch verschiedene Mechanismen erfolgen. Die wichtigste Gruppe der Negativregulatoren des Jak/STAT-Signalweges stellen die SOCS-Proteine (engl.: suppressor of cytokine signaling) dar. Diese werden von den STATs selbst aktiviert und sind somit Bestandteil einer negativen Rückkopplungsschleife (Feedbackloop) (Hilton et al., 1999). Diese Proteinfamilie, die durch Zytokine, Hormone und Wachstumsfaktoren innerhalb kürzester Zeit aktiviert werden kann, besitzt als strukturelles Merkmal ebenfalls eine SH2-Domäne (Krebs et al., 2000). Die Familie der SOCS-Proteine besteht aus acht Mitgliedern (CIS, SOCS1, SOCS2, SOCS3, SOCS4, SOCS5, SOCS6, SOCS7). Mit Hilfe der SH2-Domäne binden die SOCS-Moleküle entweder an die phosphorylierten Jaks oder die aktivierten Rezeptoren (Sasaki et al., 1999; Schmitz et al., 2000). Ein weiteres Strukturmerkmal ist die C-terminal gelegene SOCS-Box. Über die Bindung von Elongin $\mathrm{C}$ wird eine E3-Ligase rekrutiert, was zur Ubiquitinierung sowohl von SOCS-gebundenen Proteinen als auch von SOCS selber und dem damit verbundenen Proteinabbau im Proteasom führt (Kamura et al., 1998; Zhang et al., 1999). Die Bindung von Elongin $\mathrm{C}$ an SOCS könnte aber nicht nur mit dem Abbau sondern auch mit der Stabilisierung von SOCS in Zusammenhang stehen. So zeigten Haan et al. (2003), dass eine Phosphorylierung von SOCS3 zur Zerstörung des SOCS-Elongin C-Komplexes führt und SOCS3 dadurch schneller abgebaut wird.

Eine weitere Möglichkeit, um den Jak/STAT-Signalweg zu inhibieren, besteht in der 
Dephosphorylierung von Jaks und STATs durch Phosphatasen. Es handelt sich hierbei um SHP-1 und SHP-2 aus der Familie der SH-Phosphatasen (SHP). Diese binden mit ihrer N-terminalen SH2-Domäne die phosphorylierten Tyrosine von Januskinasen oder Zytokinrezeptoren und führen mit Hilfe ihrer C-terminalen Protein-TyrosinPhosphatase-Domäne zur Dephosphorylierung der gebundenen Tyrosine (Wormald et al., 2004). Für die Inhibierung des IL-6-Signalweges ist es unter anderem notwendig, dass SHP2 an ein spezifisches Tyrosin der gp130-Rezeptoruntereinheit bindet (Stahl et al., 1995). Chung et al. (1997) und Liu et al. (1998) konnten zeigen, dass die Transkriptionsaktivierung von STAT1 und STAT3 durch die Bindung von PIASMolekülen (engl.: protein inhibitor of activated STATs) inhibiert wird. Die Familie der PIAS-Proteine besteht mittlerweile aus 5 Mitgliedern: PIAS1, PIAS3, PIASx $\alpha$, PIASx $\beta$ und PIASy (Shuai et al., 2000). Alle Moleküle besitzen eine E3-SUMOLigase-Aktivität, was zur Sumoylierung der gebundenen Proteine führt. Bei SUMO (engl.: small ubiquitin-related modifier) handelt es sich um ein 11kDa-Protein, welches als posttranslationale Modifikation kovalent an Lysine gebunden wird. Innerhalb der PIAS-Familie gibt es unterschiedliche Strategien, um die Aktivität der STATs zu inhibieren. Für PIAS1 und PIAS3 wurde gezeigt, dass sie die Bindung von STAT1 und STAT3 an die DNA inhibieren (Wormald et al., 2004).

\subsubsection{Der Jak/STAT-Signalweg in Tumoren}

Kurz nach seiner Entdeckung wurde eine Fehlregulation des Jak/STAT-Signalweges mit verschiedenen Tumorentitäten in Zusammenhang gebracht. So kommt es beispielsweise durch chromosomale Veränderungen $\mathrm{zu}$ einem Fusionsprotein, bestehend aus Jak2 und der Oligomerisierungsdomäne des Ets-Transkriptionsfaktors (TelJak2), was eine Liganden-unabhängige, konstitutiv aktive Januskinase 2 zur Folge hat (Lacronique et al., 1997; Peeters et al., 1997). Dies führt dann zu einer permanenten Aktivierung von STAT-Proteinen, die durch die Aktivierung von antiapoptotischen, Wachstums- und Angiogenese-fördernden Genen zur malignen Entartung der Zellen beitragen. Das Tel-Jak-Fusionsprotein findet man besonders häufig in Leukämien (ALL, CML). Eine anormale Aktivierung von STAT-Proteinen, insbesondere von STAT3, STAT5 und STAT1, ist in einer Reihe von soliden Tumoren, 
Leukämien und Lymphomen nachgewiesen worden (Bromberg et al., 2002), wobei deren Aktivierung nicht allein auf die Januskinasen zurückzuführen ist. STAT3 und STAT1 sind auch deshalb von besonderem Interesse, weil sie sowohl Homoals auch Heterodimere bilden können. Auch andere Kinasen, wie Rezeptortyrosinkinasen (EGF, RET, KIT) und zytoplasmatische Kinasen (Src, Abl), spielen bei der Aktivierung der STATs eine Rolle und können bei Fehlregulation zu einer permanenten STAT-Aktivierung führen (Bromberg et al., 2002; Bowman et al., 2000). STAT3 ist das am häufigsten in Tumoren und Tumorzelllinien dereguliert vorliegende STAT-Protein. Es konnte gezeigt werden, dass Tumorzelllinien von einem konstitutiv aktiven STAT3 abhängig sind und dessen Inhibierung zu Zellarrest und Apoptose führt (Bromberg et al., 2002). Wie bereits erwähnt, darf aber nicht außer Acht gelassen werden, dass einer Deregulation von STAT-Proteinen eine Fehlregulation der aktivierenden Kinase vorausgehen kann.

Eine ständige Aktivierung von STAT-Proteinen kann auch durch eine Fehlregulation der Inhibitoren des Jak/STAT-Signalweges ausgelöst werden. So zeigten Yoshikawa et al. (2001), dass eine Methylierung des SOCS1-Gens und die damit verbundene Inhibierung der Transkription des Gens zu einer konstitutiven STAT3-Aktivierung in Leberzellkarzinom-Zelllinien führt. Die Hypermethylierung des SOCS3-Promotors führt ebenfalls zum Verlust der inhibierenden Funktion von SOCS3 in Mammakarzinom- und Lungenkarzinom-Zelllinien (He et al., 2003). Es wird auch vermutet, dass die Herunterregulation des STAT-Inhibitors PIAS3 im Anaplastisch-Großzelligen-Lymphom für die hohen Level an aktiviertem STAT3 verantwortlich sein könnte (Zhang et al., 2002). 


\subsection{Aufgabenstellung}

Die Expression des Latenten Membranproteins 1 (LMP1) des Epstein-Barr-Virus (EBV) ist für die Transformation einer mit EBV infizierten humanen B-Zelle essentiell. Im Zusammenspiel mit anderen viralen Faktoren trägt LMP1 durch die von ihm aktivierten Signalwege zur Immortalisierung und malignen Entartung von EBVinfizierten Zellen bei. Einer dieser Signalwege ist der Jak/STAT-Signalweg, wobei dessen Aktivierung bislang nur unzureichend geklärt ist.

Grundlage dieser Arbeit ist die Hypothese, dass der durch EBV aktivierte Jak/STAT-Signalweg auch zu einer Aktivierung der negativen Rückkopplungsmechanismen in Form von SOCS3 in Burkitt-Lymphomzellen führt.

Zur Klärung dieser Annahme soll die Beantwortung folgender Fragestellungen beitragen:

- Wie ist der Jak/STAT-Signalweg in EBV-positiven und -negativen BurkittLymphomzellen aktiviert?

- Ist die Expression des viralen Onkoproteins LMP1 ausreichend, um den Jak/STAT-Signalweg zu aktivieren?

- Führt die EBV/LMP1-vermittelte STAT3-Aktivierung zur Expression von SOCS3, eines Negativregulators des Jak/STAT-Signalweges?

- Welcher Mechanismus liegt der EBV-abhängigen Aktivierung des Jak/STATSignalweges und von SOCS3 zu Grunde?

a) Gibt es einen direkten Mechanismus, der den p38/MAPK-Signalweg und damit die Regulation der mRNA-Stabilität mit einbezieht?

b) Wird der Jak/STAT-Signalweg indirekt über EBV/LMP1-induzierte Zytokine aktiviert? 


\section{Material}

\subsection{Zellinien}

Die in dieser Arbeit verwendeten Zelllinien sind in Tabelle 3 aufgelistet.

Tab. 3: verwendete Zelllinien

\begin{tabular}{lll}
\hline Zelllinie & Zellursprung & Referenz \\
\hline BHK & Fibroblast, Baby-Hamsterniere & MacPherson et al. (1962) \\
BHK-CD40L & Fibroblast, Baby-Hamsterniere & Hess et al. (1995) \\
BL2 & B-Zelle, Burkitt-Lymphom & Bertrand et al. (1981) \\
BL2P3HR1 & B-Zelle, Burkitt-Lymphom & Calender et al. (1987) \\
BL2B95-8 & B-Zelle, Burkitt-Lymphom & Calender et al. (1987) \\
BL30 & B-Zelle, Burkitt-Lymphom & Calender et al. (1987) \\
BL30P3HR1 & B-Zelle, Burkitt-Lymphom & Calender et al. (1987) \\
BL30B95-8 & B-Zelle, Burkitt-Lymphom & Calender et al. (1987) \\
BL41 & B-Zelle, Burkitt-Lymphom & Lenoir et al. (1985) \\
BL41P3HR1 & B-Zelle, Burkitt-Lymphom & Calender et al. (1987) \\
BL41B95-8 & B-Zelle, Burkitt-Lymphom & Calender et al. (1987) \\
BL36 & B-Zelle, Burkitt-Lymphom & Lenoir et al. (1985) \\
BL74 & B-Zelle, Burkitt-Lymphom & Nilsson et al (1975) \\
BL60 & B-Zelle, Burkitt-Lymphom & Lenoir et al. (1985) \\
Ramos & B-Zelle, Burkitt-Lymphom & Klein et al. (1975) \\
L660 & B-Zelle, Burkitt-Lymphom & Lenoir et al. (1985) \\
IARC304 & B-Zelle, LCL & Lenoir et al. (1985) \\
L428 & B-Zelle, Hodgkin-Lymphom & Schaadt et al. (1979) \\
HDLM2 & T-Zelle, Hodgkin-Lymphom & Diehl et al. (1985) \\
L1236 & B-Zelle, Hodgkin-Lymphom & Wolf et al. (1996) \\
L540 & T-Zelle, Hodgkin-Lymphom & Diehl et al. (1981) \\
L591 & B-Zelle, Hodgkin-Lymphom & Diehl et al. (1982) \\
KM-H2 & B-Zelle, Hodgkin-Lymphom & Kamesaki et al. (1986) \\
\hline
\end{tabular}

\subsection{Geräte und Verbrauchsmaterialien}

Nachstehend (Tab. 4) sind alle regelmäßig verwendeten Geräte und deren Hersteller aufgeführt. Artikel des täglichen Laborbedarfs, wie Pipettenspitzen, Reaktionsgefäße, Zellkulturflaschen, Röntgenfilme, Sterilfilter, etc. wurden von den Firmen GE Healthcare (München), Braun (Melsungen), Eppendorf (Hamburg), Bec- 
ton Dickinson (Heidelberg), Greiner (Nürtingen), Nunc (Wiesbaden) und Sarstedt (Nümbrecht) bezogen.

Tab. 4: Geräte

\begin{tabular}{|c|c|}
\hline Geräte & Hersteller \\
\hline Biofuge pico & Heraeus Instruments, Hanau \\
\hline Brutschrank Cytoperm & Heraeus Instruments, Hanau \\
\hline Brutschrank BBD 6220 & Heraeus Instruments, Hanau \\
\hline Consort E734 Power Supply & Schütt Labortechnik, Göttingen \\
\hline Elektrophoreseeinheit & BioRad, München \\
\hline Elektroporationsgerät Easyject & Geneflow Ltd, Staffordshire, UK \\
\hline FACScan Gerät & Becton Dickinson, Heidelberg \\
\hline Heizblock Thermostat 5320 & Eppendorf, Hamburg \\
\hline Hera-Freez $-80{ }^{\circ} \mathrm{C}$ Kühleinheit & Heraeus Instruments, Hanau \\
\hline IKAMAG RCT Magnetrührer/Heizplatte & IKA, Staufen \\
\hline Incudrive Inkubator & Schütt Labortechnik, Göttingen \\
\hline Inkubator Certomat $^{\circledR} \mathrm{H}$ & B. Braun Biotech International, Göttingen \\
\hline Inverses Durchlichtmikroskop (Telaval 31) & Zeiss, Jena \\
\hline Inverses Fluoreszenzmikroskop (Leitz DM IL) & Leica, Wetzlar \\
\hline Microflow Laminar Downflow Workstation & Bioquell, Andover, UK \\
\hline Multifuge $3 \mathrm{~L}-\mathrm{R}$ & Heraeus Instruments, Hanau \\
\hline Power Pac 300 Power Supply & BioRad, München \\
\hline Spektrometer & Eppendorf, Hamburg \\
\hline TaqMan 7900HT Real-Time-PCR-System & Applied Biosystems, Foster City, USA \\
\hline Tischzentrifuge $1-15 \mathrm{k}$ & SIGMA-Laborzentrifugen, Osterode \\
\hline Tischzentrifuge $5415 \mathrm{C}$ & Eppendorf, Hamburg \\
\hline Trio-Thermoblock mit Deckelheizung & Biometra, Göttingen \\
\hline Überkopfmischer & Heidolph Instruments, Schwabach \\
\hline Ultra Low $-152{ }^{\circ} \mathrm{C}$ Kühleinheit & Sanyo, Gunma, Japan \\
\hline Ultraschallbad Branosonic 220 & Lab Extreme Inc, Kent City, USA \\
\hline Vortex Genie 2 & Schütt Labortechnik, Göttingen \\
\hline Wasserbad & Kötterman Labortechnik, Hänigsen \\
\hline
\end{tabular}




\subsection{Chemikalien}

In Tabelle 5 sind die in dieser Arbeit verwendeten Chemikalien aufgelistet.

Tab. 5: Chemikalien

\begin{tabular}{|c|c|}
\hline Chemikalien & Hersteller \\
\hline Acrylamid/Bisacrylamid 40\% & BioRad, München \\
\hline Actinomycin D & Merck, Darmstadt \\
\hline Agar & Sigma-Aldrich, Taufkirchen \\
\hline Agarose & Roth, Karlsruhe \\
\hline Ammoniumpersulfat & Sigma-Aldrich, Taufkirchen \\
\hline Ampicillin & Sigma-Aldrich, Taufkirchen \\
\hline Borsäure & Sigma-Aldrich, Taufkirchen \\
\hline Bradford-Reagenz & BioRad, München \\
\hline Brij97 & Sigma-Aldrich, Taufkirchen \\
\hline Bromphenolblau & Sigma-Aldrich, Taufkirchen \\
\hline BSA & Serva, Heidelberg \\
\hline BSA (Zellkultur getestet) & Sigma-Aldrich, Taufkirchen \\
\hline Complete Mini & Roche, Mannheim \\
\hline D-MEM & Sigma-Aldrich, Taufkirchen \\
\hline DMSO & Sigma-Aldrich, Taufkirchen \\
\hline DTT & Serva, Heidelberg \\
\hline dNTP-Mix (dATP, dTTP, dGTP, dCTP) & Promega, Mannheim \\
\hline EDTA & Sigma-Aldrich, Taufkirchen \\
\hline Essigsäure (p.a.) & Sigma-Aldrich, Taufkirchen \\
\hline Ethanol 96\% (p.a.) & J.T. Baker, Deventer, Holland \\
\hline Ethidiumbromid & Serva, Heidelberg \\
\hline Facs Flow & Becton Dickinson, Heidelberg \\
\hline FBS & Sigma-Aldrich, Taufkirchen \\
\hline Ficoll 400 & Pharmacia, Uppsala, Schweden \\
\hline Geneticin & Invitrogen, Karlsruhe \\
\hline Gentamycin & Invitrogen, Karlsruhe \\
\hline Glycerin & Sigma-Aldrich, Taufkirchen \\
\hline Glycin & Roth, Karlsruhe \\
\hline Hefeextrakt & Invitrogen, Karlsruhe \\
\hline HEPES-Puffer & Sigma-Aldrich, Taufkirchen \\
\hline Hygromycin B & Invitrogen, Karlsruhe \\
\hline Isopropanol & Roth, Karlsruhe \\
\hline Kaliumchlorid & Merck, Darmstadt \\
\hline L-Glutamin-Penicillin-Streptomycin-Lösung & Sigma-Aldrich, Taufkirchen \\
\hline MACSelect LNGFR MicroBeads & Miltenyi Biotec, Bergisch Gladbach \\
\hline
\end{tabular}




\begin{tabular}{ll}
\hline Chemikalien & Hersteller \\
\hline Magermilchpulver & BioRad, München \\
Membrane Blocking Agent & GE Healthcare, München \\
$\beta$-Mercaptoethanol & Sigma-Aldrich, Taufkirchen \\
Methanol 100\% (p.a.) & J.T. Baker, Deventer, Holland \\
$\mu$ MACS Protein A MicroBeads & Miltenyi Biotec, Bergisch Gladbach \\
Natriumacetat & Serva, Heidelberg \\
Natriumchlorid & Merck, Darmstadt \\
Natriumdeoxycholat & Merck, Darmstadt \\
Natriumdodecylsulfat & Merck, Darmstadt \\
Natriumfluorid & Roth, Karlsruhe \\
Natriumvanadat & Sigma-Aldrich, Taufkirchen \\
Nonidet P40 & Sigma-Aldrich, Taufkirchen \\
PBS & Invitrogen, Karlsruhe \\
PMSF & Sigma-Aldrich, Taufkirchen \\
Ponceau S & Sigma-Aldrich, Taufkirchen \\
RPMI-1640 Zellkulturmedium & Sigma-Aldrich, Taufkirchen \\
Protein-Standard für SDS-PAGE & GE Healthcare, München \\
Re-Blot Plus Mild & Chemicon International, Hofheim \\
Salzsäure 37\% & Merck, Darmstadt \\
SB202190 & Merck, Darmstadt \\
Schwefelsäure & J.T. Baker, Deventer, Holland \\
TEMED & Sigma-Aldrich, Taufkirchen \\
Tris & Sigma-Aldrich, Taufkirchen \\
Trypsin-EDTA-Lösung & PAA, Cölbe \\
Trypton & Becton Dickinson, Heidelberg \\
Tween 20 & Serva, Heidelberg \\
Xylencyanol & Sigma-Aldrich, Taufkirchen \\
100bp DNA Leiter & Invitrogen, Karlsruhe \\
1kbp DNA Leiter & Invitrogen, Karlsruhe \\
\hline & \\
\hline & \\
\hline &
\end{tabular}

\subsection{Gebrauchsfertige Reaktionssysteme („Kits”)}

Nachstehend (Tab. 6) sind die verwendeten Kits aufgeführt.

Tab. 6: Reaktionssysteme

\begin{tabular}{ll}
\hline Kits & Hersteller \\
\hline BigDye Terminator Cycle Sequencing Kit v1.1 & Applied Biosystems, Foster City, USA \\
ECL ${ }^{\text {TM }}$-Western Blotting Reagenz & GE Healthcare, München \\
\hline
\end{tabular}




\begin{tabular}{ll}
\hline Kits & Hersteller \\
\hline EndoFree Plasmid Maxi Kit & Qiagen, Hilden \\
CD4-Multi Sort Kit & Miltenyi Biotec, Bergisch-Gladbach \\
Dual-Luciferase ${ }^{\circledR}$ Reporter Assay System & Promega, Mannheim \\
IL-6 Eli-pair ELISA Kit & Diaclone, Giessen \\
IL-10 Eli-pair ELISA Kit & Diaclone, Giessen \\
PathDetect ${ }^{\circledR}$ in Vivo Signal Transduction Path- & Promega, Mannheim \\
way trans-Reporting Systems & \\
QIAprep Spin Miniprep Kit & Qiagen, Hilden \\
QIAquick Gel Extraction Kit & Qiagen, Hilden \\
RNeasy Mini Kit & Qiagen, Hilden \\
Taqman Reverse Transcriptase Kit & Applied Biosystems, Foster City, USA \\
Taqman Universal PCR Mastermix & Applied Biosystems, Foster City, USA \\
TOPO -TA Cloning Kit & Invitrogen, Karlsruhe \\
\hline
\end{tabular}

\subsection{Antikörper}

Die Primär- und Sekundärantikörper für die Proteindetektion im Immunoblot sowie die Antikörper zur Analyse zellbiologischer Parameter, die in dieser Arbeit Verwendung fanden, sind in den Tabellen 7 und 8 aufgelistet.

Tab. 7: Antikörper für die Proteindetektion im Immunoblot

\begin{tabular}{|c|c|c|c|}
\hline Antigen & Artikel-Nr. & Spezifität & Hersteller \\
\hline Aktin & MAB1501 & monokl. Maus IgG & Chemicon International, Hofheim \\
\hline Jak1 & sc-277 & polykl. Kaninchen IgG & Santa Cruz Biotechnology, Heidelberg \\
\hline Jak2 & sc-294 & polykl. Kaninchen $\lg G$ & Santa Cruz Biotechnology, Heidelberg \\
\hline Jak3 & sc-513 & polykl. Kaninchen IgG & Santa Cruz Biotechnology, Heidelberg \\
\hline LMP1 & M 0897 & monokl. Maus lgG & Dako, Hamburg \\
\hline P-STAT1 & 9172 & polykl. Kaninchen IgG & $\begin{array}{l}\text { Cell Signaling Technologies, Frankfurt } \\
\text { a.M. }\end{array}$ \\
\hline P-STAT3 & 9131 & polykl. Kaninchen IgG & $\begin{array}{l}\text { Cell Signaling Technologies, Frankfurt } \\
\text { a.M. }\end{array}$ \\
\hline P-Tyrosin & 05-321 & monokl. Maus IgG & Upstate, Lake Placid, USA \\
\hline P-Tyk2 & 9321 & polykl. Kaninchen IgG & $\begin{array}{l}\text { Cell Signaling Technologies, Frankfurt } \\
\text { a.M. }\end{array}$ \\
\hline STAT1 & 9171 & polykl. Kaninchen IgG & $\begin{array}{l}\text { Cell Signaling Technologies, Frankfurt } \\
\text { a.M. }\end{array}$ \\
\hline STAT3 & 9132 & polykl. Kaninchen $\lg G$ & $\begin{array}{l}\text { Cell Signaling Technologies, Frankfurt } \\
\text { a.M. }\end{array}$ \\
\hline SOCS3 & sc-7009 & polykl. Ziege & Santa Cruz Biotechnology, Heidelberg \\
\hline
\end{tabular}




\begin{tabular}{|c|c|c|c|}
\hline Antigen & Artikel-Nr. & Spezifität & Hersteller \\
\hline SOCS3 & 18395 & polykl. Kaninchen IgG & IBL, Gunma, Japan \\
\hline Tyk2 & sc-169 & polykl. Kaninchen IgG & $\begin{array}{l}\text { Cell Signaling Technologies, Frankfurt } \\
\text { a.M. }\end{array}$ \\
\hline $\begin{array}{l}\text { Kaninchen- } \\
\text { HRP }\end{array}$ & sc-2313 & polykl. Esel lgG & Santa Cruz Biotechnologies, Heidelberg \\
\hline Maus-HRP & sc-2005 & polykl. Ziege IgG & Santa Cruz Biotechnologies, Heidelberg \\
\hline Ziege-HRP & P0449 & polykl. Kaninchen $\lg G$ & Dako, Hamburg \\
\hline
\end{tabular}

Tab. 8: Antikörper für die Anwendung in der Zellkultur

\begin{tabular}{|c|c|c|c|}
\hline Antigen & Artikel-Nr. & Spezifität & Hersteller \\
\hline CD4-PE & A07751 & monokl. Maus & Beckman Coulter, Krefeld \\
\hline CD54-FITC & MCA1616F & polykl. Maus IgG & Serotec, Düsseldorf \\
\hline CD126-FITC & 852.031 .010 & monokl. Maus IgG (B-R6) & Diaclone, Giessen \\
\hline CD130-FITC & 852.061 .010 & monokl. Maus IgG (B-R3) & Diaclone, Giessen \\
\hline gp130 & 852.060 .000 & monokl. Maus IgG & Diaclone, Giessen \\
\hline IL-10 & 855.100 .005 & monokl. Maus IgG & Diaclone, Giessen \\
\hline Isotyp-Kontrolle & 857.080 .000 & monokl. Maus IgG & Diaclone, Giessen \\
\hline $\begin{array}{l}\text { Isotyp-Kontrolle } \\
\text { PE/FITC }\end{array}$ & 342409 & monokl. Maus IgG & Diaclone, Giessen \\
\hline LNGFR-FITC & 130-091-917 & monokl. Maus IgG & $\begin{array}{l}\text { Miltenyi Biotec, Bergisch Glad- } \\
\text { bach }\end{array}$ \\
\hline Maus $\lg G / \lg M$ & $115-005-068$ & polykl. Ziege & Dianova, Hamburg \\
\hline
\end{tabular}

\subsection{Zytokine und Inhibitoren}

Die in dieser Arbeit verwendeten Zytokine und Hemmstoffe sind in Tabelle 9 aufgeführt.

Tab. 9: Zytokine/Inhibitoren

\begin{tabular}{ll}
\hline Zytokin/Inhibitor & Hersteller \\
\hline AG490 & Merck, Darmstadt \\
Actinomycin D & Merck, Darmstadt \\
Interleukin 6 & PeproTech Inc., Rocky Hill, USA \\
Interleukin 10 & PeproTech Inc., Rocky Hill, USA \\
MG-132 & Merck, Darmstadt \\
SB 202190 & Merck, Darmstadt \\
WHI-P131 & Merck, Darmstadt \\
\hline
\end{tabular}




\subsection{Plasmide und Bakterienstämme}

Zur Transformation der Plasmide, die in Tabelle 10 aufgeführt sind, wurde der Bakterienstamm E. coli XL1-Blue (Genotyp: recA1 endA1 gyrA96 thi-1 hsdR17 supE44 relA1 lac $\left[F^{\prime}\right.$ proAB lacl ${ }^{\mathrm{Z}} \mathrm{Z} \Delta \mathrm{M} 15$ Tn10 $\left.\left.\left(\mathrm{Tet}^{\mathrm{r}}\right)\right]\right)$ aus der Stammsammlung der Arbeitsgruppe verwendet.

Tab. 10: Plasmide

\begin{tabular}{lll}
\hline Plasmid & Resistenz & Bezugsquelle \\
\hline pCR 2.1-TOPO & Amp, Kan & Invitrogen, Karlsruhe \\
EGFP C1 GFP & Kan, Neo & Clontech, Heidelberg \\
pcDNA3.1 & Amp, Neo & Invitrogen, Karlsruhe \\
pcDNA-hSOCS3 & Amp & S. Haan; Hörtner et al. (2002) \\
pFACHOP & Kan, Neo & Stratagene, Amsterdam \\
pFRLUC & Amp & Stratagene, Amsterdam \\
pGL2basic & Amp & Promega, Mannheim \\
pGL3control & Amp & Promega, Mannheim \\
pMACS4.1 & Amp & Miltenyi Biotec, Bergisch Gladbach \\
pRL0 & Amp & Promega, Mannheim \\
pSG5 & Amp & Stratagene, Amsterdam \\
pSG5-LMP1 & Amp & E. Kieff; Devergne et al. (1996) \\
pSG5-LMP1 CTAR1mut & Amp & M. Vockerodt; Vockerodt et al. (2001) \\
pSG5-LMP1 CTAR2mut & Amp & M. Vockerodt; Vockerodt et al. (2001) \\
pSG5-LMP1 CTAR1/2mut & Amp & M. Vockerodt; Vockerodt et al. (2001) \\
TGL-IP10 & Amp & R.M. Ransohoff; Majumder et al. (1998) \\
TGL-IP10 $\kappa$ B2mut & Amp & R.M. Ransohoff; Majumder et al. (1998) \\
\hline
\end{tabular}

\subsection{Enzyme}

Folgende Enzyme wurden in dieser Arbeit eingesetzt.

Tab. 11: Enzyme

\begin{tabular}{ll}
\hline Enzym & Hersteller \\
\hline DNAse I & Qiagen, Hilden \\
Bam HI & Roche, Mannheim \\
Superscript II Reverse Transcriptase & Invitrogen, Karlsruhe \\
Taq Polymerase & Promega, Mannheim \\
\hline
\end{tabular}




\subsection{Oligonukleotide}

In Tabelle 12 sind die in dieser Arbeit verwendeten Sequenzen der Oligonukleotide und deren Bezugsquellen aufgeführt.

Tab. 12: Primersequenzen

\begin{tabular}{llll}
\hline Name & Sequenz 5'-3' & Orientierung & Hersteller \\
\hline ABL fw & GGCCAGTAGCATCTGACTTTG & sense & IBA, Göttingen \\
ABL rv & ATGGTACCAGGAGTGTTTCTCC & antisense & IBA, Göttingen \\
GL1 fw & TGTATCTTATGGTACTGTAACTG & sense & Eurogentec, Köln \\
GL2 rv & CTTTATGTTTTTGGCGTCTTCC & antisense & Eurogentec, Köln \\
hSOCS3 fw & ATGGTCACCCACAGCAAGTTTC & sense & IBA, Göttingen \\
hSOCS3 rv & GTTAAAGCGGGGCATCGTACT & antisense & IBA, Göttingen \\
T7 & GTAATACGACTCACTATAGGGC & sense & IBA, Göttingen \\
\hline
\end{tabular}




\section{Methoden}

\subsection{Zellbiologische Analysen}

\subsubsection{Kultivierung von Suspensionszellen}

Die Anzucht der eukaryotischen Zellen erfolgte in RPMI-1640-Medium und je nach Zelldichte in $25 \mathrm{~cm}^{2}-, 75 \mathrm{~cm}^{2}$ - oder $175 \mathrm{~cm}^{2}$-Zellkulturflaschen mit Belüftungskappe. Die Dichte betrug je nach Art der Zellen zwischen $3 \times 10^{5}$ und $5 \times 10^{5}$ Zellen $/ \mathrm{ml}$. Die Kultivierung der in Suspension wachsenden Zellen fand steril in einem Inkubator bei $37^{\circ} \mathrm{C}, 5 \% \mathrm{CO}_{2}$ und $95 \%$ Luftfeuchtigkeit statt. Da die Zellen nicht-adhärent auf dem Boden der Kulturflasche wuchsen, konnten sie ohne den sonst erforderlichen Trypsinierungsschritt durch Zugabe von frischem Medium oder durch einfaches Umsetzen in eine neue Kulturflasche versorgt werden. Die Häufigkeit, mit der das Medium erneuert wurde, richtete sich nach der Proliferationsrate und der Stoffwechselaktivität der jeweiligen Zelllinie.

Nährmedium: RPMI-1640

$10 \%$ FBS

200U/ml Penicillin

$200 \mu \mathrm{g} / \mathrm{ml}$ Streptomycin

4mM L-Glutamin

\subsubsection{Kultivierung von adhärenten Zellen}

Die Anzucht der adhärent wachsenden Zellen erfolgte weitestgehend analog zu der in Abschnitt 4.1.1 beschriebenen Methode. Allerdings mussten die Zellen bei jedem Umsetzen vom Boden der Zellkulturflaschen gelöst werden. Hierfür wurde das Medium abgesaugt und die Zellen mit PBS gewaschen. Anschließend wurde für fünf Minuten bei $37^{\circ} \mathrm{C}$ mit einer Trypsin-EDTA-Lösung (Trypsin 0,5mg/ml; EDTA 0,22mg/ml [Verhältnis 1:250]) inkubiert. Der Prozess des Ablösens der Zellen wurde mikroskopisch überprüft. Nach erfolgreicher Ablösung wurde die Reaktion durch Zugabe von DMEM gestoppt. Nach einem Zentrifugationsschritt (5min, 800rpm) 
wurde das Zellpellet in frischem Medium resuspendiert und die Zellen abschließend im gewünschten Verhältnis in neue Flaschen umgesetzt.

Nährmedium: DMEM

\author{
$10 \%$ FBS \\ 200U/ml Penicillin \\ $200 \mu \mathrm{g} / \mathrm{ml}$ Streptomycin \\ $4 \mathrm{mM}$ L-Glutamin
}

\title{
4.1.3 Kryokonservierung und Auftauen von Zellen
}

Bevor Zellen zur Langzeitaufbewahrung, der sogenannten Kryokonservierung, eingefroren werden können, müssen sie sich in einem guten Allgemeinzustand und der logarithmischen Wachstumsphase befinden. War diese Voraussetzung erfüllt, wurden ca. $5 \times 10^{6}$ Zellen bei $4^{\circ} \mathrm{C}$ und $750 \mathrm{rpm}$ für $5 \mathrm{~min}$ zentrifugiert, das Medium abgenommen und die Zellen in 1,5ml Einfriermedium resuspendiert. Die Zellsuspension wurde in Einfrierröhrchen überführt und in einer Einfrierbox für $24 \mathrm{~h}$ bei $-80^{\circ} \mathrm{C}$ eingefroren. Das in der Einfrierbox enthaltene Isopropanol ermöglicht das Abkühlen der Zellsuspension um $1^{\circ} \mathrm{C}$ pro Minute und verhindert zusammen mit dem im Einfriermedium enthaltenen DMSO eine Zerstörung der Zellen durch zu schnelle Eiskristallbildung. Die Langzeitlagerung der Zellen erfolgte dann bei $-150^{\circ} \mathrm{C}$.

Zum Auftauen wurden die Zellen in ein Wasserbad bei $37^{\circ} \mathrm{C}$ gestellt, anschließend in $10 \mathrm{ml}$ Zellkulturmedium überführt und $5 \mathrm{~min}$ bei 750rpm zentrifugiert. Dieser Waschschritt und das schnelle Auftauen der Zellen verhindern zytotoxische Effekte, die durch DMSO entstehen können. Nach der Sedimentation der Zellen wurde das Medium abgenommen und die Zellen zur Kultivierung in einer entsprechenden Menge Kulturmedium resuspendiert und in eine Zellkulturflasche überführt.

Einfriermedium: $\quad 90 \%$ FBS

$10 \%$ DMSO 


\subsubsection{Zellzahlbestimmung}

Zur Bestimmung der Zellzahl wurden 10 $\mu$ l Zellsuspension 1:1 mit Trypanblau-Lösung versetzt und $10 \mu \mathrm{l}$ davon in eine Neubauer-Zählkammer gegeben. Dieses System ermöglicht die Bestimmung der Zellzahl pro ml bei bekanntem Volumen der Zählkammer. Das Auszählen der Zellen erfolgte unter Zuhilfenahme eines Mikroskops. Durch die Färbung mit Trypanblau-Lösung kann man lebende von toten Zellen gut unterscheiden, da die Zellmembran toter Zellen im Gegensatz zu der der lebenden für den Farbstoff Trypanblau permeabel ist.

\subsubsection{Einbringen von fremd-DNA in Zellen}

Das Einbringen von DNA in eukaryotische Zellen wird Transfektion genannt und wurde mit Hilfe der Elektroporation durchgeführt. Hierbei wird die DNA mittels elektrischer Impulse in die Zellen eingebracht. 24h vor der Transfektion wurden die Zellen mit einer Zelldichte von $3 \times 10^{5}-5 \times 10^{5}$ Zellen/ml in frisches Medium eingestreut. Am folgenden Tag wurden sie dann zentrifugiert $\left(750 \mathrm{rpm}, 4^{\circ} \mathrm{C}, 5 \mathrm{~min}\right)$ und das Zellpellet in Medium resuspendiert. Ein Aliquot dieser Zellsuspension wurde entnommen, um die Zellzahl zu ermitteln. Nach erneuter Zentrifugation wurde eine Zelldichte von 4x107 Zellen/ml mit RPMI-1640-Medium, das 25mM HEPES enthielt, eingestellt. Alle Reagenzien hatten eine Temperatur von $4^{\circ} \mathrm{C}$. Die Elektroporationsküvetten wurden für die Transfektion ebenfalls auf Eis vorgekühlt. Für einen

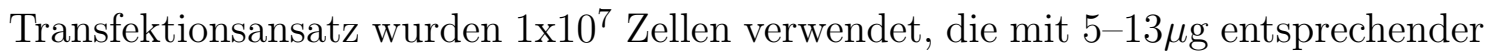
Plasmid-DNA vermischt (maximal $20 \mu \mathrm{g}$ Gesamt-DNA-Menge) und entsprechend den in Tab. 13 angegebenen Bedingungen elektroporiert wurden. Sollten die Zellen später einer Anreicherung unterzogen werden, dann enthielten die 20 $\mu \mathrm{g}$ DNA zusätzlich $7 \mu \mathrm{g}$ pMACS 4.1, ein Plasmid um die Zellen für die Separation zu markieren (siehe 4.1.6). Nach der Transfektion wurden die Zellen direkt in 10ml RPMI1640-Medium mit 10mM HEPES transferiert und für 24h kultiviert. Um die Effizienz der Transfektion zu bestimmen, wurde bei allen Reaktionen ein Ansatz mit $5 \mu \mathrm{g}$ EGFP-Plasmid transfiziert und die Proteinexpression nach 24h im Durchflusszytometer analysiert. 
Tab. 13: Elektroporationsbedingungen

\begin{tabular}{lllll}
\hline Zelllinie & Zellzahl/Ansatz & Volumen/Ansatz & Spannung & Kapazität \\
\hline BL2 & $1 \times 10^{7}$ & $250 \mu \mathrm{l}$ & $250 \mathrm{~V}$ & $1350 \mu \mathrm{F}$ \\
BL36 & $1 \times 10^{7}$ & $500 \mu \mathrm{l}$ & $270 \mathrm{~V}$ & $1800 \mu \mathrm{F}$ \\
L428 & $1 \times 10^{7}$ & $500 \mu \mathrm{l}$ & $250 \mathrm{~V}$ & $1650 \mu \mathrm{F}$ \\
\hline
\end{tabular}

\subsubsection{Magnetische Zellseparation}

Um die Anzahl der transfizierten Zellen zu erhöhen und damit eine Analyse zu ermöglichen, wurde das Prinzip der magnetischen Zellseparation (engl.: MACS magnetic cell separation) angewandt. Bei der Transfektion wurden daher in die Zellen neben dem gewünschten Plasmid auch das pMACS 4.1-Plasmid kotransfiziert, so dass auf der Zelloberfläche die extrazelluläre Domäne des CD4-Antigens exprimiert werden kann. Bei CD4 handelt es sich um einen T-Zellmarker, der auf humanen B-Zellen natürlicherweise nicht vorkommt. Somit kann spezifisch zwischen transfizierten und nicht-transfizierten Zellen unterschieden werden. Die spezifisch markierten Zellen werden an einen gegen CD4 gerichteten Antikörper gekoppelt, der seinerseits an einen superparamagnetischen Partikel gebunden ist. In einem Magnetfeld können nun die markierten von den nicht-markierten Zellen getrennt werden. Dafür wurden 24h nach der Transfektion die Zellen zentrifugiert (750rpm, $4^{\circ} \mathrm{C}, 5 \mathrm{~min}$ ) und einmal mit MACS-Puffer gewaschen. Anschließend wurden $1 \times 10^{7}$ Zellen mit 20 $\mu$ l CD4 Multisort Beads und 80 $\mu$ l entgastem MACS-Puffer für 15min bei $4^{\circ} \mathrm{C}$ inkubiert. Die Zellen wurden daraufhin mit dem 10fachen Färbevolumen an entgastem MACS-Puffer gewaschen und das Zellpellet nach der Sedimentation in $500 \mu \mathrm{l}$ MACS-Puffer resuspendiert und auf die sich in einem Magnetfeld befindende, bereits mit $500 \mu$ l entgastem MACS-Puffer äquilibrierte Separationssäule mit Vorfilter gegeben. Nach dreimaligem Waschen der Säule (einmal mit und zweimal ohne Vorfilter) mit jeweils $500 \mu \mathrm{l}$ entgastem MACS-Puffer wurden anschließend außerhalb des Magnetfeldes die markierten Zellen mit 500 $\mu$ l entgastem MACS-Puffer eluiert. Die Anreicherung wurde durch eine CD4-Färbung im FACScan (siehe 4.1.10) analysiert. Je nach experimentellem Ansatz wurden die Zellen in definierter Zellzahl bis zur Zellernte weiterkultiviert. 
MACS-Puffer: $\quad$ 1xPBS (pH7,4)

$$
\begin{aligned}
& 0,5 \%(\mathrm{w} / \mathrm{v}) \text { BSA } \\
& \text { 2mM EDTA (pH8,0) } \\
& \text { sterilfiltrieren des Puffers }
\end{aligned}
$$

\subsubsection{Manipulation der Zellen mit Inhibitoren}

Für die Behandlung der Zellen mit dem p38-Inhibitor SB202190 wurden diese sedimentiert und in einer Dichte von $3 \times 10^{5}$ Zellen $/ \mathrm{ml}$ in frisches Medium eingestreut. Es erfolgte die Zugabe des Hemmstoffes in einer Konzentration von $1 \mu \mathrm{M}$. Als Kontrollansatz wurde das gleiche Volumen an Lösungsmittel, hier DMSO, zu den Zellen gegeben. Dadurch kann man unspezifische Effekte, die durch DMSO hervorgerufen werden könnten, ausschließen. Im Anschluss an eine 24stündige Kultivierung wurden die Zellen als Trockenpellet geerntet (siehe 4.1.9). Um zu klären, wie die Stabilität der mRNA spezifischer Gene mit der von p38/MAPK zusammenhängt, wurde folgender Versuch durchgeführt. Die Zellen wurden wie bereits beschrieben für $24 \mathrm{~h}$ mit SB202190 bzw. DMSO behandelt. Anschließend wurde der Transkriptionsinhibitor Actinomycin D zu den Zellen gegeben und diese dann nach definierten Zeitpunkten geerntet.

Für einen weiteren experimentellen Ansatz wurden die Zellen mit den Kinase-Inhibitoren AG490 (Jak2-Inhibitor) und WHI-P131 (Jak3-Inhibitor) behandelt. Am Tag vor der Zugabe der Hemmstoffe wurden die Zellen pelletiert und mit einer Zelldichte von $3 \times 10^{5}$ Zellen $/ \mathrm{ml}$ in frisches Medium eingestreut. Die Behandlung erfolgte dann für einen vordefinierten Zeitraum mit 100 $\mu \mathrm{M}$ AG490 bzw. $200 \mu \mathrm{M}$ WHI-P131. Da beide Hemmstoffe in DMSO gelöst worden waren, diente auch hier der experimentelle Ansatz mit DMSO als Kontrolle. Die Ernte der Zellen erfolgte, wie unter Abschnitt 4.1.9 beschrieben. 


\subsubsection{Behandlung der Zellen mit Zytokinen und neutralisierenden An- tikörpern}

Für den Stimulierungsversuch mit Zytokinen wurden die Zellen am Vortag mit einer Zelldichte von $4 \times 10^{5}$ Zellen/ml in frisches Medium in eine 24-Loch-Zellkulturplatte eingestreut. Die Zugabe der Zytokine IL-6 oder IL-10 erfolgte in einer Konzentration von $100 \mathrm{ng} / \mathrm{ml}$ für einen definierten Zeitraum (30min bis $6 \mathrm{~h}$ ). Die Ernte der Zellen als Trockenpellet für die RNA- bzw. Proteinisolation wurde, wie unter Abschnitt 4.1.9 beschrieben, durchgeführt.

Um eine Signaltransduktion durch die Zytokine zu verhindern, wurden die Zellen mit neutralisierenden Antikörpern behandelt. Die Zugabe der Antikörper zu den Zellen erfolgte für 24h, nachdem diese mit definierter Zellzahl in frisches Medium in eine 24-Loch-Zellkulturplatte eingestreut worden waren. Der neutralisierende, gegen die $\beta$-Untereinheit des IL-6-Rezeptors (gp130) gerichtete Antikörper wurde mit einer Konzentration von $200 \mu \mathrm{g} / \mathrm{ml}$ eingesetzt; ebenso der neutralisierende Antikörper gegen IL-10. Etwaige unspezifische Effekte wurden mit Hilfe der sogenannten IsotypKontrolle $(200 \mu \mathrm{g} / \mathrm{ml})$ ausgeschlossen. Hierbei handelt es sich um einen Antikörper, der unspezifisch gegen IgG gerichtet ist und somit Aufschluss über unspezifische Effekte der neutralisierenden Antikörper gibt.

\subsubsection{Zellernte}

Die Zellen wurden am Tag vor der Ernte mit einer definierten Zellzahl zwischen $3 \times 10^{5}$ und $5 \times 10^{5}$ Zellen/ml in frisches Medium eingestreut. Je nach experimentellem Ansatz wurden die Zellen zusätzlich mit Hemmstoffen, Zytokinen, etc. behandelt. Erfolgte die Ernte der Zellen mit dem Ziel der RNA-Isolation, so wurden diese zentrifugiert (750rpm, $\left.4^{\circ} \mathrm{C}, 5 \mathrm{~min}\right)$, das Zellpellet mit Waschpuffer gewaschen und als sogenanntes Trockenpellet bis zum Zellaufschluss bei $-80^{\circ} \mathrm{C}$ gelagert.

Sollte aus den Zellen hingegen Protein isoliert werden, so wurden diese für $3 \mathrm{~h}$ mit einem Proteasomeninhibitor (MG132 10 $\mathrm{MM}$ ) inkubiert. Dies dient der Proteinstabilisierung (insbesondere von SOCS3) durch die Inhibierung des Proteinabbaus durch das Proteasom. Die weitere Ernte der Zellen erfolgte wie oben beschrieben. 
Waschpuffer: $\quad$ 1xPBS $(\mathrm{pH} 7,4)$

$1 \mathrm{mM}$ Natriumorthovanadat

\subsubsection{Durchflusszytometrie}

Die Durchflusszytometrie, auch FACS (engl.: fluorescense activated cell sorting) genannt, ermöglicht das Sichtbarmachen von Zellen durch deren Anfärbung mit Fluorochrom-markierten Antikörpern bzw. durch deren Expression von fluoreszierenden Proteinen. Das zur Analyse genutzte FACScan-Gerät detektiert neben der Größe und Granularität der Zellen auch die durch einen Laser angeregten Signale der Fluorochrome. Von den zu untersuchenden Zellen wurde ein Aliquot entnommen und zusammen mit 2ml FACS-Puffer in speziell für die FACS-Analyse notwendige 5ml-Rundbodenröhrchen überführt und zentrifugiert (750rpm, $\left.4^{\circ} \mathrm{C}, 5 \mathrm{~min}\right)$. Der Überstand wurde abgenommen und die Zellen anschließend für 15min mit einem Fluorochrom-markierten Antikörper in einer 1:10-Verdünnung bei $4^{\circ} \mathrm{C}$ im Dunkeln inkubiert. Danach wurden die Zellen mit 2ml FACS-Puffer gewaschen, um nicht gebundene Antikörper zu entfernen. Nach einem Zentrifugationsschritt wurde das Zellpellet in $500 \mu \mathrm{l}$ FACS-Puffer resuspendiert und bis zur Analyse im FACScan bei $4^{\circ} \mathrm{C}$ in Dunkelheit aufbewahrt. Zellen, die bereits einen fluoreszierenden Marker tragen, wie etwa GFP-exprimierende Zellen, wurden wie oben beschrieben pelletiert und anschließend direkt in $500 \mu \mathrm{l}$ FACS-Puffer resuspendiert. Vor der Analyse im FACScan wurde den Proben im Verhältnis 1:100 Propidiumjodid ( $2 \mu \mathrm{g} / \mathrm{ml}$ in PBS) zugefügt. Propidiumjodid interkaliert mit den Nukleinsäuren einer Zelle und färbt somit spezifisch tote Zellen an, da deren Zellmembran permeabel für diesen Farbstoff ist. Der FACScan ist in der Lage, mehrere Fluoreszenzen gleichzeitig zu detektieren, was Doppelfärbungen mit Antikörpern gekoppelt an unterschiedliche Fluorochrome ermöglicht.

FACS-Puffer: $\quad$ 1xPBS $(\mathrm{pH} 7,4)$

$0,5 \%(\mathrm{w} / \mathrm{v}) \mathrm{BSA}$

sterilfiltrieren des Puffers 


\subsubsection{Reportergenanalyse}

Um den Einfluss verschiedener Faktoren auf bestimmte Gene bzw. Proteine nachzuweisen, macht man sich die Expression von Reportergenkonstrukten zunutze. Diese Konstrukte bestehen aus dem zu untersuchenden Gen oder Genabschnitt und einem Reportergen. Die Aktivität des Konstruktes in den Zellen wird anhand des leicht detektierbaren Reportergens nachgewiesen und gibt so Aufschluss über die Aktivität des zu untersuchenden Gens. Man verwendet diese Technik insbesondere bei der Analyse von Promotoren. In dieser Arbeit wurden Konstrukte verwendet, um den IP-10-Promotor zu untersuchen: das Plasmid TGL-IP10, welches Abschnitte des IP-10-Promotors mit einer Bindestelle für NF- $\kappa$ B enthält sowie das Plasmid TGL$\mathrm{IP} 10 \kappa \mathrm{B} 2 \mathrm{mut}$, in welchem eine mutierte NF- $\kappa \mathrm{B}$-Bindestelle vor dem Reportergen Luciferase vorliegt. Das Enzym Luciferase des Glühwürmchens weist eine besonders hohe Sensitivität auf und kann deshalb auch zur Untersuchung schwächerer Promotoren herangezogen werden. Zur Analyse wurden BL2-Zellen mit den Konstrukten

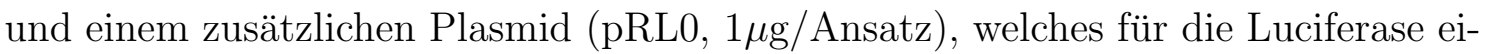
ner Quallenart kodiert, transfiziert (siehe 4.1.5). Dieses System der Expression zweier Luciferasen (Dual-Luciferase Reporter Assay der Fa. Promega), die unterschiedliche Substrate umsetzen, ermöglicht das Mitführen eines internen Standards. Zur Untersuchung der unterschiedlichen IP-10-Promotorkonstrukte (10 $\mu \mathrm{g} /$ Ansatz) wurden diese in Anwesenheit von pSG5 (100ng/Ansatz) bzw. pSG5-LMP1 (100ng/Ansatz) transfiziert. Zur Untersuchung des CD40-Signalweges wurden BL2-Zellen mit jeweils einem IP-10-Promotorkonstrukt transfiziert und in Anwesenheit von BHKbzw. BHK-CD40L-Zellen kultiviert. Als Positivkontrolle für die Funktion der Luciferase wurde ein Kontrollansatz mit dem pGL3control-Plasmid (10 $\mu \mathrm{g} /$ Ansatz) und als Negativkontrolle mit dem pGL2basic-Plasmid (10 $\mathrm{g} /$ Ansatz) transfiziert.

Eine weitere Möglichkeit, Gene mit Hilfe von Luciferase-Reportergenen zu untersuchen, bietet das Pathfinder-System (PathDetect ${ }^{\circledR}$ in Vivo Signal Transduction Pathway trans-Reporting Systems, Promega). Hierbei wird die Funktion eines Gens/Proteins (z.B. pSG5-LMP1, 100ng/Ansatz) über die indirekte Analyse eines spezifischen Substrats dieses Gens untersucht. Die Gensequenz des Substrats liegt als zweiter Teil eines Fusionsproteins mit GAL4dbd im sogenannten Transaktivierungs- 
plasmid pFA (pFA-CHOP, 500ng/Ansatz) vor. Wird dieses Fusionsprotein durch Phosphorylierung aktiviert, bindet es als Dimer mit GAL4dbd an seinen Promotor GAL4. Dieser befindet sich im Reporterplasmid pFR-Luc (10 $\mu \mathrm{g} /$ Ansatz) und kontrolliert die Transkription des Luciferasegens. Auch hier wird als interner Standard pRL0 $(1 \mu \mathrm{g} /$ Ansatz) in allen Ansätzen mitgeführt sowie pGL2basic (10 $\mu \mathrm{g} /$ Ansatz) als Negativ- und pGL3control (10 $\mathrm{g} /$ Ansatz) als Positivkontrolle.

\subsubsection{Luciferaseassay}

24h nach der Transfektion wurden die Zellen zentrifugiert und das Zellpellet pro

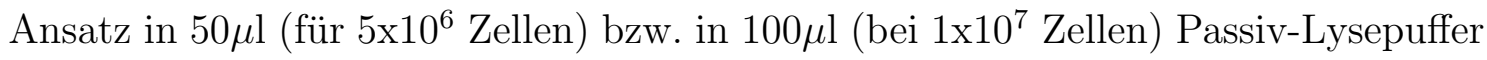
(1fach konzentriert) resuspendiert. Nach kräftigem Mischen wurden die Proben bis zum Vermessen, jedoch mindestens für $24 \mathrm{~h}$, bei $-20^{\circ} \mathrm{C}$ gelagert. Zur Ermittlung der Luciferaseaktivität wurden die Proben langsam auf Eis aufgetaut und mehrfach kräftig gemischt. Anschließend erfolgte ein Zentrifugationsschritt bei $4^{\circ} \mathrm{C}$ und 3000rpm für 15min. $16 \mu \mathrm{l}$ des Überstandes wurden in eine 96-well-Platte zur Messung von Fluoreszenz (Polysorb-Platte der Fa. NUNC) pipettiert. Dem zur Messung vorbereiteten Luminometer wurden dann automatisch die nach den Herstellerangaben gemischten Reagenzien zur Bestimmung der Enzymaktivität hinzugefügt. Hierbei wird zuerst das Substrat des Glühwürmchen-Luciferase-Enzyms zugegeben und die resultierende Lichtemission gemessen. Die Lichtemission ist dabei proportional zur Luciferasemenge. Danach wird das Substrat für die Quallen-Luciferase hinzugefügt, welches gleichzeitig die Reaktion der Glühwürmchen-Luciferase stoppt. Abschließend wird der Quotient aus den gemessenen Werten von Glühwürmchen- und Quallen-Luciferase gebildet. Die so gewonnenen Daten spiegeln die unterschiedlichen Aktivitäten der Luciferasekonstrukte wider. 


\subsection{Proteinbiochemische Analysen}

\subsubsection{Proteinisolation und Proteinbestimmung}

Für die Proteinisolation wurden die als Pellet geernteten Zellen in einem entsprechenden Volumen RIPA-Puffer resuspendiert und für 15min auf Eis inkubiert. Die Volumina richteten sich hierbei nach der Größe der Zellpellets und schwankten zwischen $30 \mu \mathrm{l}$ und $150 \mu \mathrm{l}$. Nach erneutem Durchmischen wurden die Proben zweimal für jeweils $5 \mathrm{~min}$ im Ultraschallbad bei $4^{\circ} \mathrm{C}$ beschallt. Zwischen den Beschallungen erfolgte ein 5minütiger Inkubationsschritt auf Eis. Im Anschluss daran wurden die Proben $15 \mathrm{~min}$ bei $14000 \mathrm{rpm}$ und $4^{\circ} \mathrm{C}$ zentrifugiert. Der Überstand wurde in ein neues Gefäß überführt und die Konzentration der darin enthaltenen Proteine bestimmt. Die Lagerung der Proteine erfolgte bei $-80^{\circ} \mathrm{C}$.

Zur Bestimmung der Proteinkonzentration wurde der Bradford-Test durchgeführt. Hierzu wurden im Doppelbestimmungsverfahren $2 \mu$ l Proteinlösung mit A.bidest 1:500 verdünnt und anschließend im Verhältnis 5:1 mit einem Farbstoff-Konzentrat (Protein-Assay, Bio-Rad, München) gemischt. Nach einer Inkubationszeit von 10min wurde die Absorption bei einer Wellenlänge von 595nm photometrisch bestimmt. Die Ermittlung der Proteinkonzentration erfolgte mit Hilfe einer Standardkurve, die zuvor mit BSA bestimmt worden war.

RIPA-Puffer: $\quad$ 1xPBS (pH7,4)

$1 \%(\mathrm{v} / \mathrm{v})$ Nonidet P-40

$0,5 \%(\mathrm{w} / \mathrm{v})$ Natriumdeoxycholat

$0,1 \%(\mathrm{w} / \mathrm{v}) \operatorname{SDS}$

frisch zugeben: $10 \mu \mathrm{M}$ PMSF

$1 \mathrm{mM}$ Natriumvanadat

Proteaseinhibitoren-Mix (complete mini, Fa. Roche) 


\subsubsection{Western Blot-Analyse}

Gelelektrophorese und Proteintransfer. Die Auftrennung der Proteine nach ihrer Größe erfolgte mittels diskontinuierlicher SDS-PAGE. Trenn- und Sammelgel hatten eine Dicke von $0,75 \mathrm{~mm}$. Ihre Zusammensetzung ist in Tab. 14 aufgeführt. Zur Analyse wurden 30 $\mu$ g Protein aufgetragen, welches zuvor 1:1 mit SDS-LämmliPuffer bzw. bei größeren Volumina 1:3 mit 4fach-Probenpuffer (Roti ${ }^{\circledR}$-Load, Roth, Karlsruhe) versetzt und $5 \mathrm{~min}$ bei $95^{\circ} \mathrm{C}$ denaturiert worden war. Die Proben wurden aufgetragen und die SDS-PAGE bei einer konstanten Stromstärke von 35mA, einer maximalen Spannung von $180 \mathrm{~V}$ und einer Laufzeit von ca. 1,5h durchgeführt. Es wurden je nach Größe des zu untersuchenden Proteins Gele zwischen 10\% und 15\% Acrylamidkonzentration verwendet. Zum späteren Größenvergleich der Proteinbanden wurde ein Protein-Molekulargewichtsstandard (Full Range Rainbow Molecular Weight Marker, GE Healthcare, München) mitgeführt.

Tab. 14: Ein Beispiel für die Zusammensetzung von Trenn- und Sammelgel

\begin{tabular}{lll}
\hline & Trenngel $11 \%$ & Sammelgel 5\% \\
\hline Trenngelpuffer & $2,5 \mathrm{ml}$ & - \\
Sammelgelpuffer & - & $1,25 \mathrm{ml}$ \\
Acrylamid/Bisacrylamid 40\% & $2,8 \mathrm{ml}$ & $0,625 \mathrm{ml}$ \\
A.bidest & $4,7 \mathrm{ml}$ & $3,125 \mathrm{ml}$ \\
$10 \%$ SDS & $0,1 \mathrm{ml}$ & $0,045 \mathrm{ml}$ \\
$10 \%$ APS & $0,04 \mathrm{ml}$ & $0,02 \mathrm{ml}$ \\
TEMED & $0,013 \mathrm{ml}$ & $0,008 \mathrm{ml}$ \\
\hline
\end{tabular}

SDS-Lämmli-Puffer (2x): 100mM Tris/HCL pH 6,8

$100 \mathrm{mM}$ DTT

$4 \%(\mathrm{w} / \mathrm{v}) \mathrm{SDS}$

20\%(v/v) Glycerol

0,05\%(w/v) Bromphenolblau

Trenngelpuffer: $\quad$ 1M Tris $\mathrm{pH} 8,8$

Sammelgelpuffer: $\quad$ 1M Tris $\mathrm{pH} 6,8$ 


$$
\begin{aligned}
& \text { Laufpuffer(1x): } \quad 25 \mathrm{mM} \text { Tris } \\
& \text { 192mM Glycin } \\
& 1 \%(\mathrm{w} / \mathrm{v}) \mathrm{SDS}
\end{aligned}
$$

Der Transfer der aufgetrennten Proteine auf eine Nitrozellulosemembran (HybondC-extra, GE Healthcare, München) wurde mittels Nassblot-Verfahren durchgeführt. Hierzu wurden die folgenden, in Transferpuffer getränkten Komponenten auf ein Trägergestell in der angegebenen Reihenfolge geschichtet, wobei Lufteinschlüsse zu vermeiden waren.

Kathode (Minuspol)

Schwamm

drei Lagen Filterpapier

SDS-Gel

Nitrozellulosemembran

drei Lagen Filterpapier

Schwamm

Anode (Pluspol)

Anschließend wurden die Proteine in einer mit Transferpuffer gefüllten Kammer mit voreingestellten Geräteparametern (Stromstärke: 300mA, Spannung: 100V, Leistung: 300W) im elektrischen Feld innerhalb von 4 h auf die Membran übertragen. Puffer und Kühlaggregat wurden hierbei nach $2 \mathrm{~h}$ erneuert, um die Temperatur konstant bei $4^{\circ} \mathrm{C}$ zu halten. Nach Beendigung des Blots wurde die Membran mit Ponceau S-Lösung angefärbt, um die Transfereffizienz und eventuelle Konzentrationsunterschiede bei den Proteinen vorab zu überprüfen. Hierfür wurde die Membran ca. 3min mit Ponceau S-Lösung inkubiert und danach mehrmals mit A.bidest gewaschen bis der Hintergrund entfärbt war. Die vollständige Entfärbung der Membran wurde durch das Waschen mit TBS-Tween erreicht.

Transferpuffer(1x) pH8,3: $\quad 25 \mathrm{mM}$ Tris

192mM Glycin

$15 \%$ (v/v) Methanol 
$\begin{array}{ll}\text { Ponceau S-Lösung: } & 5 \%(\mathrm{v} / \mathrm{v}) \text { Eisessig } \\ & 0,5 \%(\mathrm{w} / \mathrm{v}) \text { Ponceau S }\end{array}$

Proteinnachweis mittels spezifischer Antikörper. Die Nitrozellulosemembran wurde nach dem Blotvorgang in 5\% Milchpulver-TBS-Tween bzw. 5\% Blocking Agent-TBS-Tween für 1h bei Raumtemperatur geblockt, um unspezifische Bindungen der Antikörper zu reduzieren. Anschließend wurde die Primärantikörperverdünnung zugegeben und zusammen mit der Membran, wie in Tabelle 15 angegeben, schüttelnd inkubiert. Danach wurde dreimal mit TBS-Tween für jeweils 10min gewaschen. Die Sekundärantikörperverdünnung wurde zugegeben und die Membran für 1h bei Raumtemperatur schüttelnd inkubiert. Es schlossen sich drei weitere Waschschritte für jeweils 15min mit TBS-Tween an. Um die spezifisch gefärbten Proteinbanden sichtbar machen zu können, wurde für 1min ECL-Western Blotting-Reagenz A und B im Verhältnis 1:1 auf die Membran gegeben. Hierbei handelt es sich um das Substrat für die an den Sekundärantikörper gekoppelte Peroxidase. Die Detektion der Chemilumineszenz, die durch die Enzymreaktion entsteht, erfolgte durch Auflegen und Entwickeln von autoradiographischen Filmen. Die Belichtungszeit richtete sich hierbei nach der Stärke der zu erwartenden Proteinbanden.

Tab. 15: Antikörperverdünnungen

\begin{tabular}{|c|c|c|c|}
\hline Antikörper & Verdünnung & Lösungsmittel & Inkubation \\
\hline Aktin & $1: 20000$ & $1 \%$ Milchpulver-TBS-T & 1h, RT \\
\hline Jak1 & $1: 1000$ & $5 \%$ BSA-TBS-T & üN, $4^{\circ} \mathrm{C}$ \\
\hline Jak2 & $1: 1000$ & $5 \%$ BSA-TBS-T & $\ddot{\mathrm{u} N}, 4^{\circ} \mathrm{C}$ \\
\hline Jak3 & $1: 1000$ & $5 \%$ BSA-TBS-T & üN, $4^{\circ} \mathrm{C}$ \\
\hline LMP1 & $1: 100$ & $1 \%$ Milchpulver-TBS-T & üN, $4^{\circ} \mathrm{C}$ \\
\hline P-STAT1 & $1: 1000$ & $5 \%$ BSA-TBS-T & $\ddot{\mathrm{u} N}, 4^{\circ} \mathrm{C}$ \\
\hline P-STAT3 & $1: 1000$ & $5 \%$ BSA-TBS-T & $\ddot{\mathrm{u} N}, 4^{\circ} \mathrm{C}$ \\
\hline P-Tyrosin & $1: 1000$ & 1\% Milchpulver-TBS-T & üN, $4^{\circ} \mathrm{C}$ \\
\hline P-Tyk2 & $1: 1000$ & $5 \%$ BSA-TBS-T & üN, $4^{\circ} \mathrm{C}$ \\
\hline STAT1 & $1: 1000$ & $5 \%$ BSA-TBS-T & $\ddot{\mathrm{u} N}, 4^{\circ} \mathrm{C}$ \\
\hline STAT3 & $1: 1000$ & $5 \%$ BSA-TBS-T & $\ddot{\mathrm{u} N}, 4^{\circ} \mathrm{C}$ \\
\hline SOCS3 (Santa Cruz) & $1: 750$ & $5 \%$ BSA-TBS-T & $\ddot{\mathrm{u} N}, 4^{\circ} \mathrm{C}$ \\
\hline SOCS3 (IBL) & $1: 100$ & $5 \%$ BSA-TBS-T & üN, $4^{\circ} \mathrm{C}$ \\
\hline
\end{tabular}




\begin{tabular}{llll}
\hline Antikörper & Verdünnung & Lösungsmittel & Inkubation \\
\hline Tyk2 & $1: 1000$ & $5 \%$ BSA-TBS-T & üN, $4^{\circ} \mathrm{C}$ \\
Kaninchen-HRP & $1: 2000$ & $5 \%$ BSA-TBS-T & $1 \mathrm{~h}, \mathrm{RT}$ \\
Maus-HRP & $1: 2000$ & $1 \%$ Milchpulver-TBS-T & $1 \mathrm{~h}, \mathrm{RT}$ \\
Ziege-HRP & $1: 2000$ & $5 \%$ BSA-TBS-T & $1 \mathrm{~h}, \mathrm{RT}$ \\
\hline
\end{tabular}

Wiederverwendung der Membran. Um eine Membran mit mehreren Antikörpern zu testen, mussten die bereits gebundenen Antikörper wieder entfernt werden. Hierzu wurde die Membran für 30min bei Raumtemperatur mit einer Lösung bestehend aus Re-Blot plus Mild (Chemicon, Hofheim) und A.bidest im Verhältnis 1:10 schüttelnd inkubiert. Die Membran wurde danach 15min mit TBS-Tween gewaschen. Bis zur weiteren Verwendung wurde die Membran in TBS-Tween im Kühlschrank bei $4^{\circ} \mathrm{C}$ oder im getrockneten Zustand bei Raumtemperatur aufbewahrt.

TBS(1x) pH7,6: $\quad$ 20mM Tris Base

$137 \mathrm{mM}$ Natriumchlorid

TBS-Tween $(1 \mathrm{x}) \mathrm{pH} 7,6$ : 1xTBS

$$
0,1 \%(\mathrm{v} / \mathrm{v}) \text { Tween-20 }
$$

\subsubsection{Immunpräzipitation}

Um ein Protein aus der Gesamtheit aller zellulären Proteine zu isolieren und anzureichern, nutzt man das Prinzip der Immunpräzipitation. Hierfür wurden aus einem Zellpellet, das mindestens $1 \times 10^{7}$ Zellen enthält, die Proteine isoliert. Das Zellpellet wurde in $500 \mu \mathrm{l}$ Jak-Immunpräzipitationspuffer resuspendiert und 30min auf Eis inkubiert. Nach erneutem Mischen folgte für 15min ein Zentrifugationsschritt bei $14000 \mathrm{rpm}$ und $4^{\circ} \mathrm{C}$. Den Überstand überführte man in ein neues Gefäß und entnahm $4 \mu \mathrm{l}$ für die Proteinbestimmung (siehe 4.2.2). Anschließend wurde $1 \mu \mathrm{g}$ Antikörper zugegeben und das Gemisch über Nacht rotierend inkubiert. Nach ca. 16h wurden 50 $\mu$ l Protein A MicroBeads (Miltenyi Biotec, Bergisch Gladbach) zugegeben und für 30min auf Eis inkubiert. Das Protein A, welches an den Fc-Teil 
des Antikörpers bindet, ist an paramagnetische Partikel gekoppelt und ermöglicht so eine Isolierung des gewünschten Proteins mittels magnetischer Separation. Die dafür ebenfalls notwendigen Säulen ( $\mu$ Columns, Miltenyi Biotec, Bergisch Gladbach) wurden in die Magnethalterung gegeben ( $\mu M A C S^{T M}$ Separator, Miltenyi Biotec, Bergisch Gladbach) und mit $200 \mu \mathrm{l}$ Jak-Immunpräzipitationspuffer äquilibriert. Die nachfolgenden Schritte fanden im Kühlraum bei $4^{\circ} \mathrm{C}$ statt. Das Gemisch aus Protein, Antikörper und Protein A wurde auf die Säulen gegeben und nach dem Durchlaufen viermal mit $200 \mu$ l Jak-Immunpräzipitationspuffer gewaschen. Die Apparatur wurde aus dem Kühlraum unter einen Abzug bei Raumtemperatur verbracht. Anschließend wurden $20 \mu$ l SDS-Lämmli-Puffer $\left(2 \mathrm{x}, 95^{\circ} \mathrm{C}\right)$ auf die Säulen gegeben, um die Antikörper-Protein A-Bindung zu lösen. Nach einer Inkubationszeit von 5min wurde mit $50 \mu \mathrm{l}$ SDS-Lämmli-Puffer $\left(2 \mathrm{x}, 95^{\circ} \mathrm{C}\right)$ das gewünschte Protein in ein neues Gefäß eluiert. Zur weiteren Analyse wurden die Proben einer SDS-PAGE mit anschließendem Transfer und Immunfärbung mit spezifischen Antikörpern unterzogen (siehe 4.2.2).

Jak-Immunpräzipitationspuffer: $\quad$ 200mM Tris/HCL pH7,6

$150 \mathrm{mM}$ Natriumchlorid

10mM Natriumfluorid

$1 \mathrm{mM}$ EDTA

$1 \%(\mathrm{v} / \mathrm{v}) \operatorname{Brij} 97$

frisch zugeben:

$10 \mu \mathrm{M}$ PMSF

$1 \mathrm{mM}$ Natriumvanadat

Proteaseinhibitoren-Mix (complete mini,

Fa. Roche)

\subsubsection{ELISA}

Die Methode der ELISA (enzyme-linked immuno sorbent assay)-Analyse wurde angewendet, um im Zellkulturüberstand das von den Zellen sekretierte Zytokin Interleukin 6 nachzuweisen. Dafür wurde von den entsprechenden experimentellen 
Ansätzen zellfreies Kulturmedium entnommen und bis zur Analyse bei $-80^{\circ} \mathrm{C}$ gelagert. Die Durchführung des ELISAs erfolgte nach den Angaben des Herstellers.

\subsection{Molekularbiologische Analysen}

\subsubsection{Transformation von E.coli-Zellen}

Um Plasmid-DNA zu vermehren, wird diese in E.coli-Zellen eingebracht. Für die Transformation wurden chemisch kompetente Zellen genutzt. 50 $\mu$ l der Zellsuspension wurden auf Eis langsam aufgetaut, mit ca. 100ng Plasmid-DNA vorsichtig vermischt und für $30 \mathrm{~min}$ auf Eis inkubiert. Es folgte ein Hitzeschock bei $42^{\circ} \mathrm{C}$ für $50 \mathrm{~s}$. Danach wurden die Zellen für weitere 3min auf Eis gelagert. Anschließend wurden $250 \mu \mathrm{l}$ LB-Medium auf die Zellen gegeben und für eine Stunde bei $37^{\circ} \mathrm{C}$ schüttelnd inkubiert. Das Ausplattieren des Transformationsansatzes $(25 \mu \mathrm{l}$ und $75 \mu \mathrm{l})$ erfolgte auf LB-Selektionsagar (Ampicillin 50ng/ml bzw. Kanamycin 20ng/ml) mit anschließender Inkubation bei $37^{\circ} \mathrm{C}$ über Nacht.

\subsubsection{Isolierung von Plasmid-DNA}

Von der bewachsenen Agarplatte wurden einzelne Kolonien entnommen und für eine Vorkultur in 5ml LB-Medium mit entsprechendem Antibiotikum gegeben. Die Vorkulturen wurden dann für $6-8 \mathrm{~h}$ bei $37^{\circ} \mathrm{C}$ schüttelnd $(200 \mathrm{U} / \mathrm{min})$ kultiviert. Die Hauptkultur (120ml LB-Medium mit Antibiotikum) wurde mit 1ml der Vorkultur angeimpft. Die Anzucht der Bakterien erfolgte schüttelnd bei $37^{\circ} \mathrm{C}$ über Nacht (ca. 16h). Von der Hauptkultur wurde ein Aliquot als Glycerol-Stock (20\% Glycerol $(\mathrm{v} / \mathrm{v})$ ) bei $-80^{\circ} \mathrm{C}$ eingelagert. Die Plasmide wurden mit Hilfe des EndoFree Plasmid Maxi-Kits nach den Angaben der Fa. Qiagen isoliert. Die präzipitierte Plasmid-DNA wurde dann in Abhängigkeit der Größe des Präzipitats in einem entsprechenden Volumen Endotoxin-freien Wassers aufgenommen und ihre Konzentration ermittelt (siehe 4.3.4). 


\subsubsection{Isolation von Gesamt-RNA und reverse Transkription}

Um die Gesamt-RNA aus den zuvor geernteten Zellpellets (siehe 4.1.9) zu isolieren, wurde das RNeasy Mini-Kit der Fa. Qiagen verwendet. Die Isolation erfolgte entsprechend der Vorgaben des Herstellers. Im Anschluss an die Isolation wurde die Konzentration der RNA bestimmt (siehe 4.3.4) und diese dann bei $-80^{\circ} \mathrm{C}$ gelagert.

Die isolierte Gesamt-RNA wurde mit Hilfe der reversen Transkription in cDNA umgeschrieben. Die Synthese erfolgte mittels reverser Transkriptase, einer DNAPolymerase, die von einer Einzelstrang-RNA oder -DNA einen komplementären DNA-Strang synthetisiert. In dieser Arbeit wurden zwei Protokolle für die cDNASynthese angewandt. Das Umschreiben der RNA erfolgte mit dem Superscript II-Kit von Invitrogen, wobei pro $20 \mu \mathrm{l}$-Ansatz $12 \mu \mathrm{l}$ RNA mit $0,2 \mu \mathrm{l}$ Random Hexamer Primern $(50 \mathrm{mM})$ für $10 \mathrm{~min}$ bei $70^{\circ} \mathrm{C}$ inkubiert wurden. Danach kam die Probe auf Eis und wurde mit $4 \mu \mathrm{l}$ First Strand-Puffer (5x), $1 \mu \mathrm{l}$ dNTP (10mM), $2 \mu$ l DTT $(0,1 \mathrm{M})$ und $1 \mu \mathrm{l}$ reverser Transkriptase (Superscript II) versetzt (Tab. 16). Es folgten der Syntheseschritt bei $42^{\circ} \mathrm{C}$ für $1 \mathrm{~h}$, die Inaktivierung bei $65^{\circ} \mathrm{C}$ für $10 \mathrm{~min}$ und das Herunterkühlen der Probe auf $4^{\circ} \mathrm{C}$.

Tab. 16: Reaktionsansatz für die reverse Transkription

\begin{tabular}{ll}
\hline RNA & $12 \mu \mathrm{l}$ \\
Random Hexamere $(50 \mathrm{mM})$ & $0,2 \mu \mathrm{l}$ \\
$5 x$ Erststrang-Puffer & $4 \mu \mathrm{l}$ \\
dNTP $(10 \mathrm{mM})$ & $1 \mu \mathrm{l}$ \\
DTT $(0,1 \mathrm{M})$ & $2 \mu \mathrm{l}$ \\
reverse Transkriptase (Superscript II) & $1 \mu \mathrm{l}$ \\
\hline
\end{tabular}

Das zweite Protokoll, das Verwendung fand, war das Taqman Reverse TranscriptaseKit der Fa. Applied Biosystems. Hierfür wurden für einen 10 $\mu$ l-Ansatz $1 \mu \mathrm{l}$ Puffer (10x), 2,2 $\mu$ l Magnesiumchlorid (25mM), 0,4 $\mu$ l Random Hexamer Primer, 0,1 $\mu \mathrm{l}$ Oligo-dT Primer und $3,7 \mu \mathrm{l}$ RNA $(1 \mu \mathrm{g})$ vermischt und für $30 \mathrm{~s}$ bei $90^{\circ} \mathrm{C}$ sowie für $7 \mathrm{~min}$ bei $70^{\circ} \mathrm{C}$ inkubiert. Während des nächsten Schrittes $\left(10 \mathrm{~min}, 25^{\circ} \mathrm{C}\right)$ wurde dem Ansatz $2 \mu \mathrm{l}$ dNTP, $0,2 \mu \mathrm{l}$ RNase-Inhibitor (RNasin) und 0,25 $\mu$ l reverse Transkriptase hinzugefügt. Es folgten $30 \mathrm{~min}$ bei $48^{\circ} \mathrm{C}, 5 \mathrm{~min}$ bei $94^{\circ} \mathrm{C}$ und abschließend das Herunterkühlen der Probe auf $4^{\circ} \mathrm{C}$. Die so gewonnenen cDNAs konnten dann sowohl 
für konventionelle als auch Real-Time-PCR-Reaktionen verwendet werden. Die Lagerung der Proben erfolgte bei $-20^{\circ} \mathrm{C}$.

\subsubsection{Konzentrationsbestimmung von Nukleinsäuren}

Die Menge und die Reinheit der isolierten Nukleinsäuren wurden durch Messung der Extinktion bei 260nm und 280nm mit Hilfe eines Photospektrometers ermittelt. Hierfür wurden die Proben 1:50 verdünnt und gegen den Leerwert des Lösungsmittels gemessen. Der Quotient beider OD-Werte $\left(\mathrm{OD}_{260 \mathrm{~nm}} / \mathrm{OD}_{280 \mathrm{~nm}}\right)$ der jeweiligen Probe zeigt, ob eine Verunreinigung mit Proteinen vorliegt. Werte zwischen 1,8 und 2 weisen auf einen besonders hohen Reinheitsgrad hin. Die Konzentration der RNA ergibt sich aus folgender Beziehung: Eine $\mathrm{OD}_{260 \mathrm{~nm}}$ von 1 entspricht einer RNAKonzentration von $40 \mu \mathrm{g} / \mathrm{ml}$. Die Konzentration der DNA wird wie folgt ermittelt: Eine OD $_{260 \mathrm{~nm}}$ von 1 entspricht einer DNA-Konzentration von $50 \mu \mathrm{g} / \mathrm{ml}$.

\subsubsection{Quantitative Real-Time-PCR}

Diese Methode dient der Quantifizierung von Nukleinsäuren. Die Menge an spezifischer mRNA wurde mittels Real-Time-PCR bestimmt, indem diese zuerst in cDNA umgeschrieben (siehe 4.3.3) und daraufhin nach dem Taqman-Prinzip analysiert wurde. Der Reaktionsansatz und die Reaktionsbedingungen für die Real-Time-PCR sind in den Tabellen 17 und 18 dargestellt.

Tab. 17: Reaktionsansatz für die Real-Time-PCR

$\begin{array}{ll}\text { TaqMan Universal PCR Master-Mix (2-fach konzentriert) } & 5 \mu \mathrm{l} \\ \text { genspezifischer Primer/Sonden-Mix } & 0,5 \mu \mathrm{l} \\ \beta 2 M-P r i m e r / S o n d e n-M i x & 0,5 \mu \mathrm{l} \\ \text { cDNA } & 1 \\ \text { A.bidest } & \text { ad } 10 \mu \mathrm{l}\end{array}$

\footnotetext{
${ }^{1}$ Es wurden $4 \mu \mathrm{l}$ einer 1:4 verdünnten cDNA aus der reversen Transkription nach dem Protokoll der Fa. Applied Biosystems (siehe 4.3.3) oder $1 \mu \mathrm{l}$ einer 1:10 bzw. 1:20 verdünnten cDNA nach dem konventionellen cDNA-Synthese-Protokoll (siehe 4.3.3, Tab. 16) eingesetzt.
}

Das Taqman-Prinzip beruht darauf, in der PCR neben den Standardprimern auch Oligonukleotide einzusetzen, an denen sich am 5' - und 3'- Ende je ein Fluoro- 
Tab. 18: Reaktionsbedingungen für die Real-Time-PCR

\begin{tabular}{llll}
\hline Schritt & Temperatur & Zeit & Zyklen \\
\hline Denaturierung & $50^{\circ} \mathrm{C}$ & $2 \mathrm{~min}$ & 1 \\
Primer-Anlagerung & $95^{\circ} \mathrm{C}$ & $10 \mathrm{~min}$ & 1 \\
Synthese & $95^{\circ} \mathrm{C}$ & $15 \mathrm{~s}$ & 55 \\
Denaturierung & $60^{\circ} \mathrm{C}$ & $1 \mathrm{~min}$ & 55 \\
\hline
\end{tabular}

chrom mit unterschiedlichem Anregungs- und Emissionsspektrum befindet. Diese markierten Primer werden auch als Sonden bezeichnet. Die Emissionswellenlänge des einen Fluorochroms entspricht dabei der Anregungswellenlänge des anderen Fluorochroms. Man nennt dieses Prinzip Fluoreszenz-Resonanz-Energie-Transfer. Wird nun infolge der Polymerasekettenreaktion und der 5'-3' - Exonukleaseaktivität der Polymerase das Fluorochrom-markierte Oligonukleotid abgebaut, kommt es zu einer räumlichen Trennung beider Fluorochrome. Bei gleichbleibender Anregungswellenlänge ändert sich nun die detektierbare Emissionswellenlänge. Die Stärke der Signale nimmt mit der Menge an synthetisierter DNA zu. Analog zur konventionellen PCR ist die Menge an Nukleotiden und Enzym limitierend und es wird nach einer exponentiellen Phase eine Plateauphase erreicht. Mit der Real-Time-PCR kann jedoch nicht die absolute Menge an entstandenem PCR-Produkt bestimmt werden. Man macht sich daher die Kinetik dieser Reaktion zunutze. In dem Bereich, in dem die Amplifikation exponentiell verläuft, werden die sogenannten $\mathrm{C}_{T}$-Werte bestimmt, die der Zyklenzahl bei einem deutlichen Fluoreszenzsignal entsprechen. Die Anwendung dieser Methode erfordert die Mitführung eines internen Standards. Für diesen wurde hier $\beta 2 \mathrm{M}$ verwendet. Unter Berücksichtigung dieses internen Standards konnten die für das zu untersuchende spezifische Gen bestimmten $\mathrm{C}_{T}$-Werte anhand der nachfolgenden Berechnung untereinander verglichen werden.

$$
\begin{aligned}
\Delta C_{T} & =C_{T_{\text {Zielgen }}}-C_{T_{\text {Standard }}} \\
\Delta \Delta C_{T} & =\Delta C_{T_{t}}-\Delta C_{T_{t=0}}
\end{aligned}
$$

Der $\Delta \Delta C_{T}$-Wert wird hierbei vor dem Auftrag im Diagramm (siehe Abbildungen 30 und 25) normiert (Berechnung von $2^{-\Delta \Delta C_{T}}$ ), um die prozentuale Abnahme der mRNA-Menge und somit auch deren Halbwertszeit bestimmen zu können.

Entsprechend dem in Tab. 17 angegebenen Schema wurden die 10 $\mu$ l-Ansätze in eine 
384-Loch-Platte pipettiert sowie das PCR-Programm und die Messung der Fluoreszenz im TaqMan (Applied Biosystems, Foster City, USA) durchgeführt. Mit der Software SDS2.1 wurden die erhaltenen Werte anschließend analysiert.

\subsubsection{PCR}

Neben der Real-Time-PCR wurde auch das Standard-PCR-Verfahren zur Analyse der cDNA (siehe 4.3.3) angewandt. Der Reaktionsansatz und die Reaktionsbedingungen für die SOCS3-PCR sind in den Tabellen 19 und 20 aufgeführt. Neben der SOCS3-PCR wurde auch eine ABL-PCR durchgeführt. Die Amplifikation des ABL-Gens (Abelson murine leukemia viral oncogene homolog 1), ein sogenanntes „housekeeping”-Gen, diente als Positivkontrolle und zum späteren Vergleich der Proben untereinander. Der Reaktionsansatz und die Reaktionsbedingungen für die ABL-PCR sind mit Ausnahme der Primer-Anlagerungstemperatur, welche bei $60^{\circ} \mathrm{C}$ liegt, identisch zu denen der SOCS3-PCR.

Tab. 19: Reaktionsansatz für die SOCS3-PCR

\begin{tabular}{ll}
\hline $5 \times$ Reaktionspuffer & $10 \mu \mathrm{l}$ \\
$\mathrm{MgCl}_{2}(25 \mathrm{mM})$ & $4 \mu \mathrm{l}$ \\
$\mathrm{dNTP}(2,5 \mathrm{mM})$ & $4 \mu \mathrm{l}$ \\
hSOCS3 fw $(10 \mathrm{mM})$ & $1 \mu \mathrm{l}$ \\
hSOCS3 rv $(10 \mathrm{mM})$ & $1 \mu \mathrm{l}$ \\
Taq Polymerase $(5 \mathrm{U} / \mu \mathrm{l})$ & $0,2 \mu \mathrm{l}$ \\
cDNA & $500 \mathrm{ng}$ \\
A.bidest & ad $50 \mu \mathrm{l}$ \\
\hline
\end{tabular}

Tab. 20: Reaktionsbedingungen für die SOCS3-PCR

\begin{tabular}{llll}
\hline Schritt & Temperatur & Zeit & Zyklen \\
\hline Denaturierung & $95^{\circ} \mathrm{C}$ & $5 \mathrm{~min}$ & 1 \\
Primer-Anlagerung & $58^{\circ} \mathrm{C}$ & $3 \mathrm{~min}$ & 1 \\
Synthese & $72^{\circ} \mathrm{C}$ & $3 \mathrm{~min}$ & 1 \\
Denaturierung & $95^{\circ} \mathrm{C}$ & $1 \mathrm{~min}$ & 34 \\
Primer-Anlagerung & $58^{\circ} \mathrm{C}$ & $1 \mathrm{~min}$ & 34 \\
Synthese & $72^{\circ} \mathrm{C}$ & $1 \mathrm{~min}$ & 34 \\
Renaturierung & $72^{\circ} \mathrm{C}$ & $10 \mathrm{~min}$ & 1 \\
Kühlung & $4^{\circ} \mathrm{C}$ & & \\
\hline
\end{tabular}




\subsubsection{Agarose-Gelelektrophorese}

Zur optischen Begutachtung wurden die PCR-Produkte und die Plasmide auf ein 1\%iges Agarosegel aufgetragen, welches Ethidiumbromid (0,5ng/ml) enthielt. Vor dem Auftragen wurde das PCR-Produkt bzw. Plasmid in DNA-Auftragspuffer aufgenommen. Die Elektrophorese erfolgte in TBE-Puffer (1x). Um die Größe der Banden abschätzen zu können, wurde ein 100bp- bzw. 1kbp-DNA-Längenstandard aufgetragen. Nach dem Gellauf konnten die Banden unter UV-Licht analysiert werden, da Ethidiumbromid mit Nukleinsäuren interagiert und durch UV-Licht angeregt werden kann.

$\operatorname{TBE}(1 \mathrm{x})$ :

$89 \mathrm{mM}$ Tris

$89 \mathrm{mM}$ Borsäure

2mM EDTA pH8,0

DNA-Auftragspuffer (10x): $\quad 18 \%(\mathrm{w} / \mathrm{v})$ Ficoll400

0,25\% (w/v) Bromphenolblau

$0,25 \%(\mathrm{w} / \mathrm{v})$ Xylencyanol

\subsubsection{Sequenzierung}

Um die Sequenz der Plasmide zu überprüfen, wurde eine Sequenzierungsreaktion unter Verwendung von Fluoreszenz-markierten 2'3'-Desoxynukleotiden (BigDye Terminator Cycle Sequencing-Kit v1.1) durchgeführt. Der 10 $\mu$ l-Ansatz wurde nach den Angaben des Herstellers pipettiert. So wurden $2 \mu$ l Sequenzierungspuffer (5-fach konzentriert), 1,5 $\mu$ l Sequenzierungsmix, 5pmol spezifischer Primer sowie 500ng PlasmidDNA gemischt und soweit erforderlich mit A.bidest auf das entsprechende Volumen aufgefüllt. Nach der PCR (siehe Tab. 21) musste die Sequenzierungsreaktion aufgereinigt werden. Dies erfolgte durch Zugabe von $40 \mu$ l A.bidest und $150 \mu$ l Ethanol (100\%), kräftigem Durchmischen und einem Zentrifugationsschritt von 20min bei 13000rpm und Raumtemperatur. Nach der Fällung des PCR-Produkts wurde der Überstand abgenommen und das Pellet nach dem Trocknen in $20 \mu$ l A.bidest resuspendiert. $10 \mu \mathrm{l}$ dieses Ansatzes wurden daraufhin mit $10 \mu \mathrm{l}$ Formamidpuffer versetzt 
und zur Analyse in den Sequenzer (3130 Genetic Analyzer, Applied Biosystems, Foster City, USA) überführt.

Tab. 21: Reaktionsbedingungen für die Sequenzierungs-PCR

\begin{tabular}{llll}
\hline Schritt & Temperatur & Zeit & Zyklen \\
\hline Denaturierung & $96^{\circ} \mathrm{C}$ & $30 \mathrm{~s}$ & 25 \\
Primer-Anlagerung & $50^{\circ} \mathrm{C}$ & $15 \mathrm{~s}$ & 25 \\
Synthese & $60^{\circ} \mathrm{C}$ & $4 \mathrm{~min}$ & 25 \\
Kühlung & $4^{\circ} \mathrm{C}$ & & \\
\hline
\end{tabular}




\section{$5 \quad$ Ergebnisse}

Im Rahmen dieser Arbeit sollte der noch unzureichend erforschte EBV-aktivierte Jak/STAT-Signalweg näher untersucht werden. Grundlage ist dabei die Hypothese, dass der durch EBV aktivierte Jak/STAT-Signalweg auch zu einer Aktivierung der negativen Rückkopplungsmechanismen in Form von SOCS3 in BurkittLymphomzellen führt.

\subsection{Der Jak/STAT-Signalweg in Lymphomen}

Die STAT-Moleküle, die unter anderem durch Januskinasen aktiviert werden, spielen als Transkriptionsfaktoren bei der Regulation von Wachstum und Differenzierung von Zellen eine essentielle Rolle (siehe 2.3). In verschiedenen Tumorentitäten wurde eine permanente Aktivierung unterschiedlicher STAT-Moleküle nachgewiesen (siehe 2.3.2). Zur Beantwortung der eingangs gestellten Fragen werden in diesem Kapitel zunächst STAT1, STAT3 und Januskinasen auf ihre Expression in EBV-positiven und -negativen Burkitt-Lymphomzelllinien untersucht.

\subsubsection{STAT1 und STAT3 werden EBV-abhängig in Burkitt-Lymphom- zelllinien exprimiert}

Die Untersuchung der zwei STAT-Proteine hinsichtlich ihrer Expression und Aktivierung wurde mittels Western Blot-Analyse durchgeführt. Bei den analysierten Tumorzellinien handelte es sich um verschiedene Burkitt-Lymphomzellinien. Die Zelllinie Ramos ist eine primär-EBV-negative Burkitt-Lymphomzellinie, wohingegen BL60 eine EBV-positive Zelllinie ist, die eine nicht suffiziente LMP1-Expression aufweist. L660, BL74 und BL36 sind primär-EBV-positive Burkitt-Lymphomzelllinien, die LMP1 exprimieren. Bei IARC304 handelt es sich um die zu der Burkitt-Lymphomzelllinie BL2 analoge lymphoblastoide Zelllinie (LCL).

In Abbildung 3 ist das Ergebnis der Untersuchung für STAT3 dargestellt. Die Zelllinien BL60 und Ramos zeigen keine Tyrosin-Phosphorylierung und somit keine Aktivierung des STAT3-Proteins. Die Zelllinien L660, BL74, BL36 und IARC304 


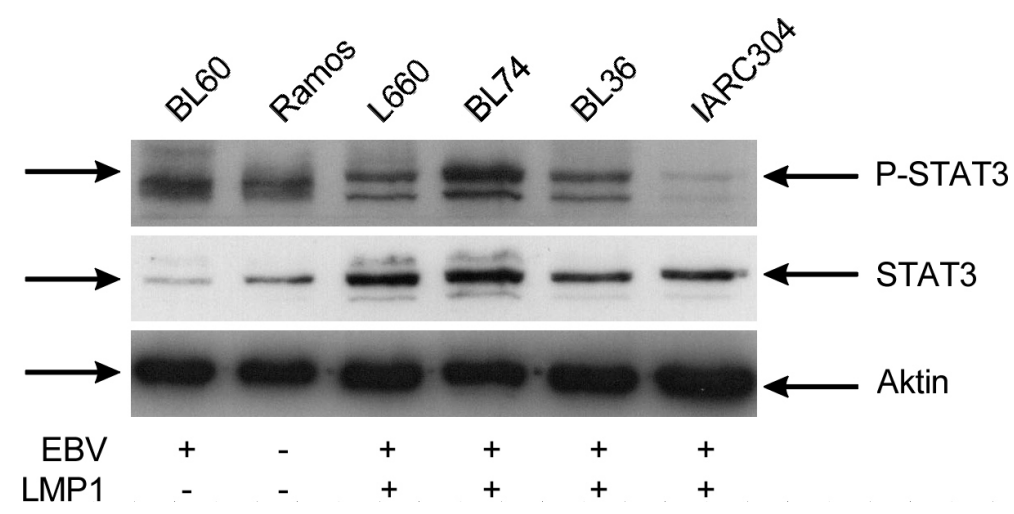

Abb. 3: STAT3-Expression in verschiedenen Burkitt-Lymphomzellinien. Aus den Burkitt-Lymphomzelllinien BL60, Ramos, L660, BL74, BL36 und der LCL IARC304 wurde nach der Zellernte das Gesamtprotein isoliert und mittels Western Blot-Verfahren analysiert. Die Immunfärbung wurde mit den spezifischen Antikörpern gegen P-STAT3, STAT3 (86kDa) und Aktin (43kDa) durchgeführt.

zeigen hingegen eine deutliche Tyrosin-Phosphorylierungsbande von STAT3, wenngleich sich deren Intensität zwischen den Zelllinien unterscheidet. Bei der unteren der beiden Banden, die mit dem P-STAT3-Antikörper nachgewiesen wurden, könnte es sich um den unspezifischen Nachweis einer Isoform von STAT3, vermutlich STAT3- $\beta$ handeln. Ein Vergleich der ebenfalls in den Zelllinien untersuchten STAT3-ProteinExpression zeigt minimale Unterschiede zwischen den Zelllinien. Dies könnte auf eine ineffiziente Immunfärbung zurückzuführen sein, da die Aktinfärbung, welche als interner Standard fungiert, einen Vergleich der Proben untereinander zulässt. In Abhängigkeit von EBV sind deutliche Unterschiede in der Aktivierung und Expression von STAT3 zu erkennen.

Analog zu STAT3 wurden die zuvor genannten Zelllinien hinsichtlich der Expression und Aktivierung von STAT1 untersucht. Der in Abbildung 4 dargestellte Western Blot zeigt eine deutliche Tyrosin-Phosphorylierung in den Zelllinien L660, BL74, BL36 und IARC304, die alle LMP1 exprimieren. Die stärkste STAT1-Aktivierung zeigt BL74, während sowohl BL60 als auch Ramos keinerlei STAT1-Aktivierung erkennen lassen. Auch die Menge an exprimiertem STAT1-Protein ist bei den untersuchten Burkitt-Lymphomzellinien unterschiedlich. So weisen die Zelllinien BL60 und Ramos eine wesentlich geringere Proteinexpression von STAT1 auf als die Zelllinien L660, BL74, BL36 und IARC304. Auch hier kennzeichnet die obere Bande den Nachweis von STAT1. Die zusätzlichen Proteine, die der P-STAT1- und der STAT1- 


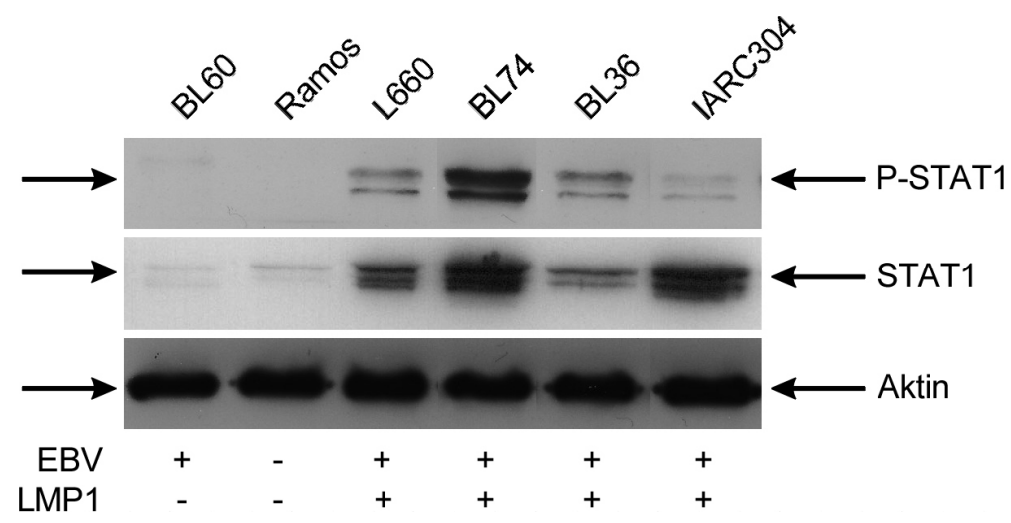

Abb. 4: STAT1-Expression in verschiedenen Burkitt-Lymphomzellinien. Aus den Burkitt-Lymphomzelllinien BL60, Ramos, L660, BL74, BL36 und der LCL IARC304 wurde nach der Zellernte das Gesamtprotein isoliert und mittels Western Blot-Verfahren analysiert. Die Immunfärbung wurde mit den spezifischen Antikörpern gegen P-STAT1, STAT1 (91kDa) und Aktin (43kDa) durchgeführt.

Antikörper detektieren, können eine Isoform von STAT1 darstellen (STAT1- $\beta$ ). Sowohl die Phosphorylierung von STAT3 als auch die Proteinexpression von STAT1 in den untersuchten Burkitt-Lymphomzellinien lassen sich mit der Expression des Epstein-Barr-Virus-Onkoproteins LMP1 assoziieren.

Dieser Zusammenhang wird anhand von Abbildung 5 weiter verdeutlicht, in welcher EBV-positive Zellen mit unterschiedlicher LMP1-Expression aber gleichem genetischen Ursprung verglichen werden. Die primär-EBV-negativen Burkitt-Lymphomzelllinien BL2 und BL30 zeigen hierbei keine Phosphorylierung von STAT3.

a)
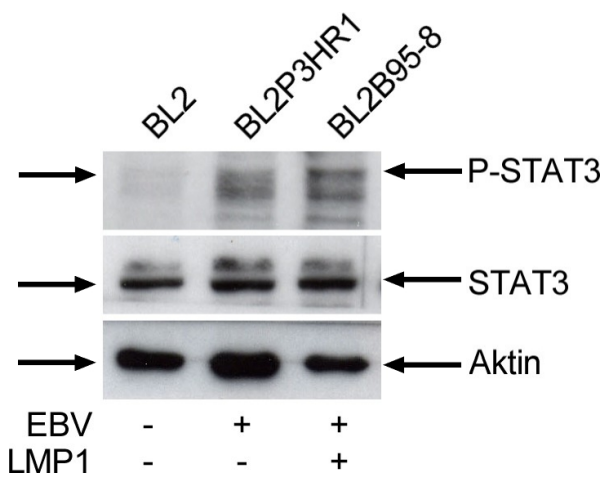

b)

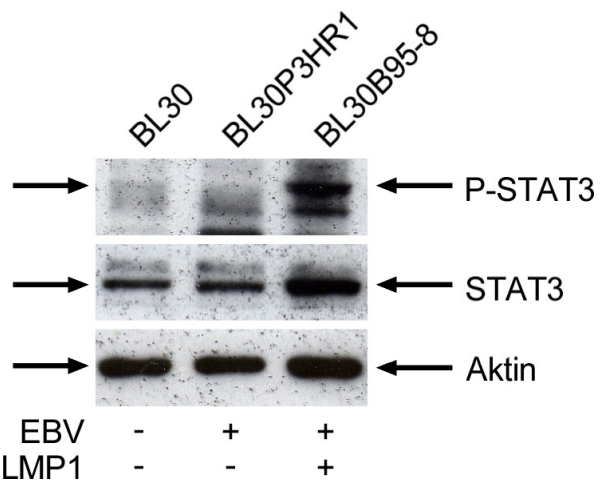

Abb. 5: STAT3-Expression in den Burkitt-Lymphomzelllinien BL2 und BL30 sowie ihren EBV-infizierten Analoga. Das Gesamtprotein der Zellen wurde mittels Western Blot analysiert. Die Detektion der Proteine erfolgte mit den spezifischen Antikörpern gegen P-STAT3, STAT3 und Aktin. In a) ist diese Analyse für BL2, BL2P3HR1 und BL2B95-8 dargestellt, in b) für BL30, BL30P3HR1 und BL30B95-8. 
Auch die mit dem EBV-Stamm P3HR1 infizierten Zellen weisen keine STAT3Phosphorylierungsbande auf. Der Virusstamm P3HR1 ist durch eine Deletion von EBNA2 und EBNA-LP im Virusgenom gekennzeichnet, aufgrund dessen LMP1 nicht mehr suffizient exprimiert werden kann. Demgegenüber stehen die mit dem als Wildtyp-Stamm bezeichneten EBV-Stamm B95-8 infizierten BL2- und BL30-Zellen. Diese exprimieren LMP1 und zeigen im Western Blot eine Aktivierung von STAT3. Die Analyse der Proteinexpression von STAT3 und Aktin diente der Kontrolle.

Zusätzlich zur Analyse von STAT3 wurde auch STAT1 hinsichtlich seiner Abhängigkeit von der LMP1-Expression in diesen Zellen untersucht. In Abbildung 6 ist zu erkennen, dass STAT1 in allen Zellen exprimiert wird. Bei vergleichbarer AktinProteinexpression zeigen die Zelllinien BL2B95-8 und BL30B95-8 eine größere Menge an STAT1-Protein als BL2, BL2P3HR1, BL30 und BL30P3HR1. In diesen beiden Zelllinien ist auch die Phosphorylierungsbande von STAT1 am intensivsten.
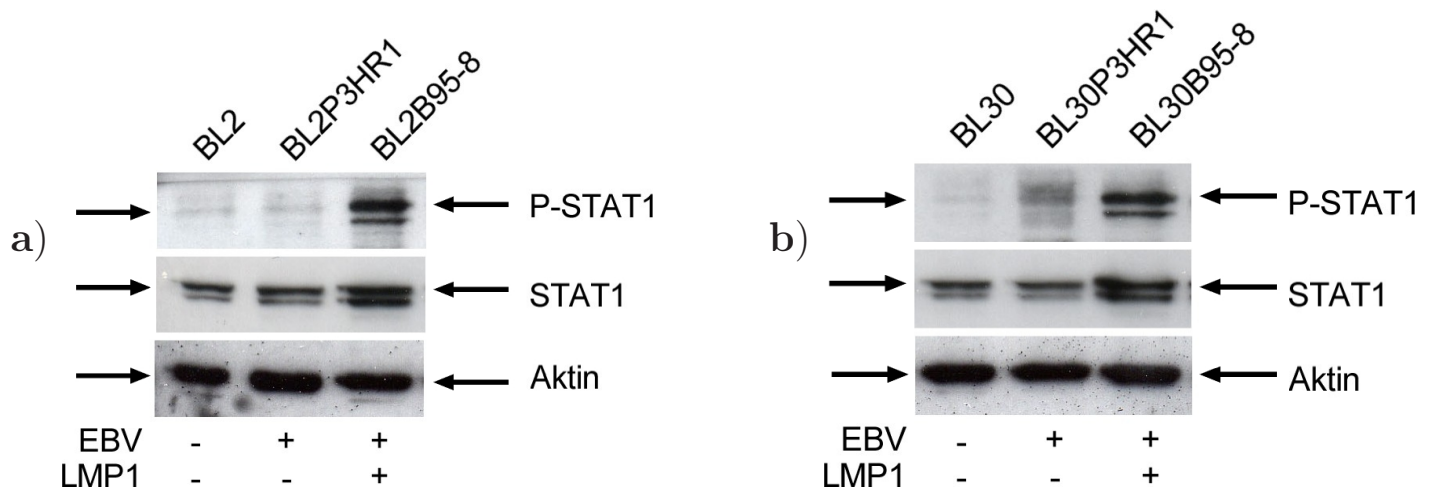

Abb. 6: STAT1-Expression in den Burkitt-Lymphomzellinien BL2 und BL30 sowie ihren EBV-infizierten Analoga. Das Gesamtprotein der Zellen wurde mittels Western Blot analysiert. Die Detektion der Proteine erfolgte mit den spezifischen Antikörpern gegen P-STAT1, STAT1 und Aktin. In a) ist diese Analyse für BL2, BL2P3HR1 und BL2B95-8 dargestellt, in b) für BL30, BL30P3HR1 und BL30B95-8. 


\subsubsection{EBV hat einen Einfluss auf die Aktivierung der Januskinasen in Burkitt-Lymphomzelllinien}

Als wesentlicher Bestandteil des Jak/STAT-Signalweges wurden die Januskinasen Jak1, Jak2, Jak3 und Tyk2 im Hinblick auf ihren Expressionsstatus untersucht. Die dafür verwendeten Zelllinien waren die EBV-negative Burkitt-Lymphomzelllinie BL2, deren mit dem EBV-Stamm B95-8 transformiertes Äquivalent BL2B95-8 sowie die primär-EBV-positive Zelllinie BL36. Die für die Analyse notwendige Anreicherung der Januskinasen erfolgte durch eine Immunpräzipitation mit Hilfe spezifischer Antikörper (siehe 4.2.3). Der Nachweis der Phosphorylierung und damit der Aktivierung der unterschiedlichen Januskinasen erfolgte mit einem spezifischen, gegen phosphorylierte Tyrosine in Proteinen gerichteten Antikörper.

Die Ergebnisse der Analyse sind in Abbildung 7 dargestellt. Für die Januskinase 2 (Abb. 7a) ergeben sich bei gleichbleibender Jak2-Proteinkonzentration deutliche Intensitätsunterschiede hinsichtlich der Tyrosin-Phosphorylierung zwischen den un-

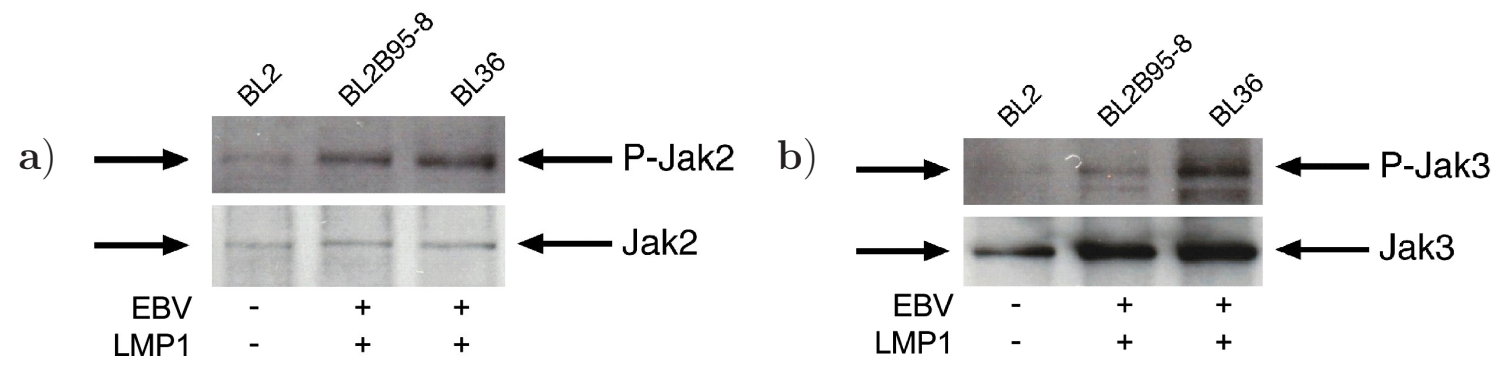

c)

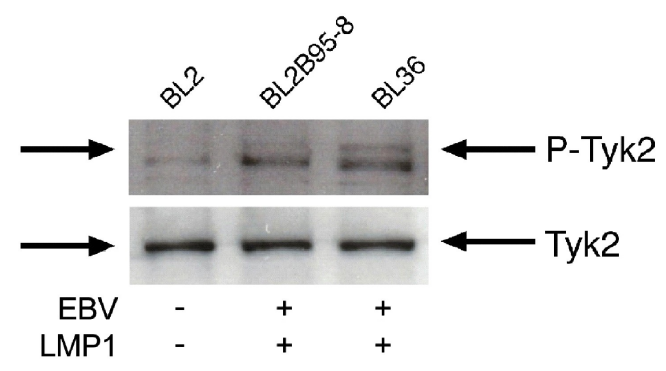

Abb. 7: Erhöhte Aktivität der Januskinasen in EBV-positiven Burkitt-Lymphomzelllinien. Zur Analyse der Januskinasen wurden die Zellen für 24h kultiviert und die Januskinasen durch Immunpräzipitation angereichert. Der Nachweis der Aktivierung erfolgte mit einem Phosphotyrosin-spezifischen Antikörper im Western Blot. Abbildung a) zeigt die Analyse der Januskinase 2, Abbildung b) die der Januskinase 3 und Abbildung c) die von Tyk2. 
tersuchten Zelllinien. Die EBV-positiven Zelllinien BL2B95-8 und BL36 zeigen im Vergleich zur EBV-negativen BL2 ein erhöhtes Niveau an phosphoryliertem Jak2. Die ebenfalls analysierten Januskinasen Jak3 (Abb. 7b) und Tyk2 (Abb. 7c) zeigen in den Zelllinien BL2B95-8 und BL36 gleichfalls ein höheres Phosphorylierungsniveau im Vergleich zu BL2. Von den beiden untersuchten EBV-positiven Zelllinien weist BL36 die intensivere Tyrosin-Phosphorylierung auf und scheint daher stärker aktiviert zu sein. Sowohl bei dem aktivierten Jak3 als auch bei dem aktivierten Tyk2 handelt es sich jeweils um die obere der beiden Banden. Die zweite Bande ist als Unspezifität der Antikörper zu betrachten. Aufgrund eines insuffizienten Antikörpers konnte die Analyse der Januskinase 1 noch nicht durchgeführt werden.

Da die Januskinasen 2 und 3 in den untersuchten Zelllinien hinsichtlich ihrer Aktivierung von den drei analysierten Januskinasen am stärksten beeinflusst scheinen, galt es zu klären, wie sich ein gezieltes Ausschalten der Jaks auf die nachfolgenden Komponenten im Jak/STAT-Signalweg, die STATs, auswirkt.

\subsubsection{Die Januskinasen 2 und 3 sind in die Aktivierung des Jak/STAT- Signalweges involviert}

Um den Einfluss der Januskinasen auf den Jak/STAT-Signalweg und die Aktivierung von STAT3 in EBV-positiven Burkitt-Lymphomzelllinien genauer zu beleuchten, wurden die Januskinasen mit spezifischen Inhibitoren gehemmt (siehe 4.1.7). Dies erfolgte mit Hilfe von chemischen Substanzen. Die Januskinase 2 wurde durch Zugabe des Tyrphostins AG490 gehemmt. In einem zweiten experimentellen Ansatz wurde die Januskinase 3 mit Hilfe von WHI-P131 inhibiert. Die Analyse wurde mit den EBV-positiven Burkitt-Lymphomzelllinien BL74 und BL36 durchgeführt. Die Hemmstoffe wurden für eine, drei bzw. sechs Stunden zu den Zellen gegeben. Letztere wurden anschließend geerntet und RNA bzw. Protein daraus isoliert. In den Abbildungen 8 und 9 ist die Western Blot-Analyse der STAT3-Expression nach Behandlung der Zelllinien BL74 und BL36 mit dem Jak2-Inhibitor AG490 dargestellt. In beiden Abbildungen wird deutlich, dass es durch die Zugabe des Jak2-Inhibitors AG490 im Vergleich zu den Kontrollansätzen (DMSO-behandelte Zellen) in den Burkitt-Lymphomzelllinien BL74 und BL36 innerhalb von sechs Stunden zu einer 


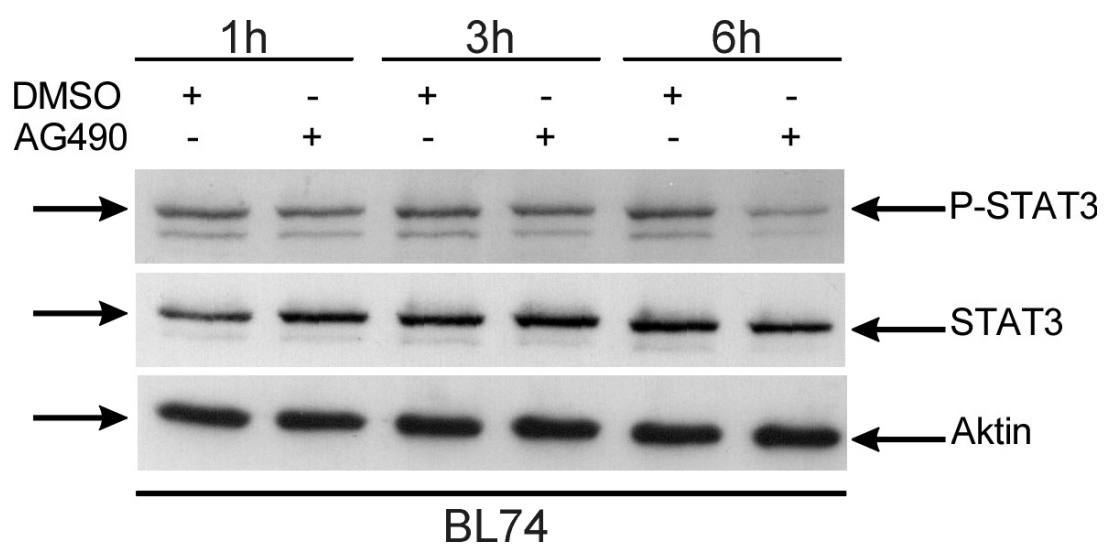

Abb. 8: Die Hemmung der Januskinase 2 durch AG490 in BL74. Die BurkittLymphomzelllinie BL74 wurde für eine, drei bzw. sechs Stunden mit dem Tyrphostin AG490 bzw. dessen Lösungsmittel DMSO behandelt. Nach der Ernte der Zellen wurde das Protein isoliert und im Western Blot mittels spezifischer Antikörper analysiert.

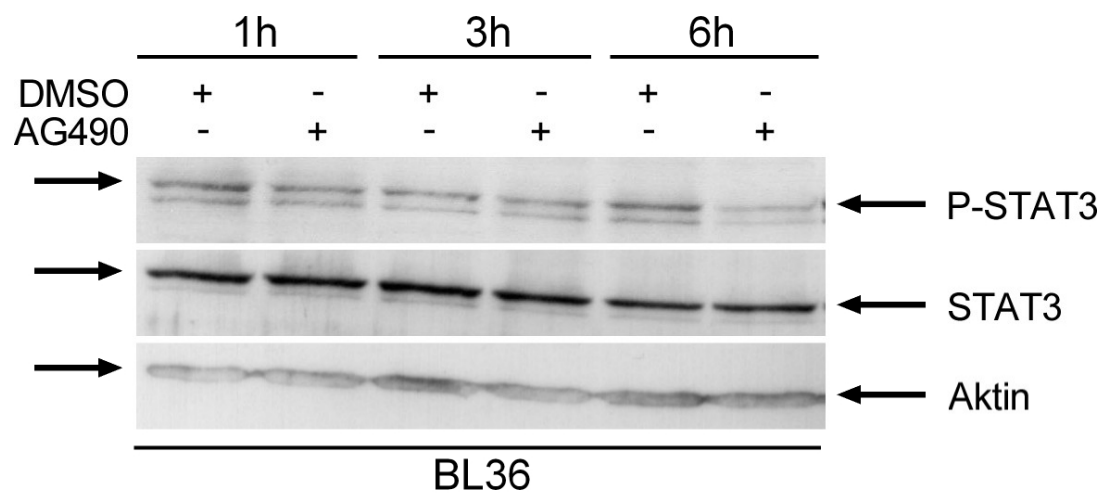

Abb. 9: Die Hemmung der Januskinase 2 durch AG490 in BL36. Die BurkittLymphomzelllinie BL36 wurde für eine, drei bzw. sechs Stunden mit dem Tyrphostin AG490 bzw. dessen Lösungsmittel DMSO behandelt. Nach der Zellernte wurde das Protein isoliert und nach der Western Blot-Analyse im Immunoblot mittels spezifischer Antikörper analysiert.

stufenweisen Reduktion der Tyrosin-Phosphorylierung von STAT3 kommt. Die Abnahme der Intensität der Phosphorylierungsbande war nach sechs Stunden am ausgeprägtesten. Die mit DMSO behandelten Proben zeigen hingegen keine Veränderung der Aktivierung von STAT3. Die Proteinexpression von STAT3 bleibt in allen untersuchten Proben von BL74 und BL36 unverändert. Ein gleichmäßiger Auftrag der Proben wurde überprüft, indem mittels Immunoblot auch die Menge an exprimiertem Aktin nachgewiesen wurde.

Um zu untersuchen, in wie weit das Tyrphostin AG490 spezifisch auf die Januskinase 2 in den Burkitt-Lymphomzelllinien BL36 und BL74 wirkt, wurden die Ja- 
nuskinasen nach dreistündiger Behandlung der Zellen mittels Immunpräzipitation angereichert und deren Phosphorylierungsstatus durch eine Immunfärbung mit einem phospho-spezifischen Antikörper nachgewiesen. Die in Abb. 10 gezeigte Immunpräzipitation der AG490-behandelten Zellen wurde für Jak2 und Jak3 durchgeführt. Bei beiden Zelllinien ist zu beobachten, dass die Tyrosin-Phosphorylierung der Januskinase 2 nach der Tyrphostinbehandlung abnimmt, wobei bei BL74 eine stärkere Abnahme der Signalintensität festzustellen ist als bei BL36. Die TyrosinPhosphorylierung der Januskinase 3 bleibt nach der Behandlung mit AG490 in BL36 weitgehend unverändert, scheint sich jedoch in BL74 etwas zu intensivieren. Die Menge der Jak-Proteine bleibt in allen Proben unverändert. Eine Analyse der Proteinproben vor der Immunpräzipitation zeigt ebenfalls eine deutliche Reduktion der

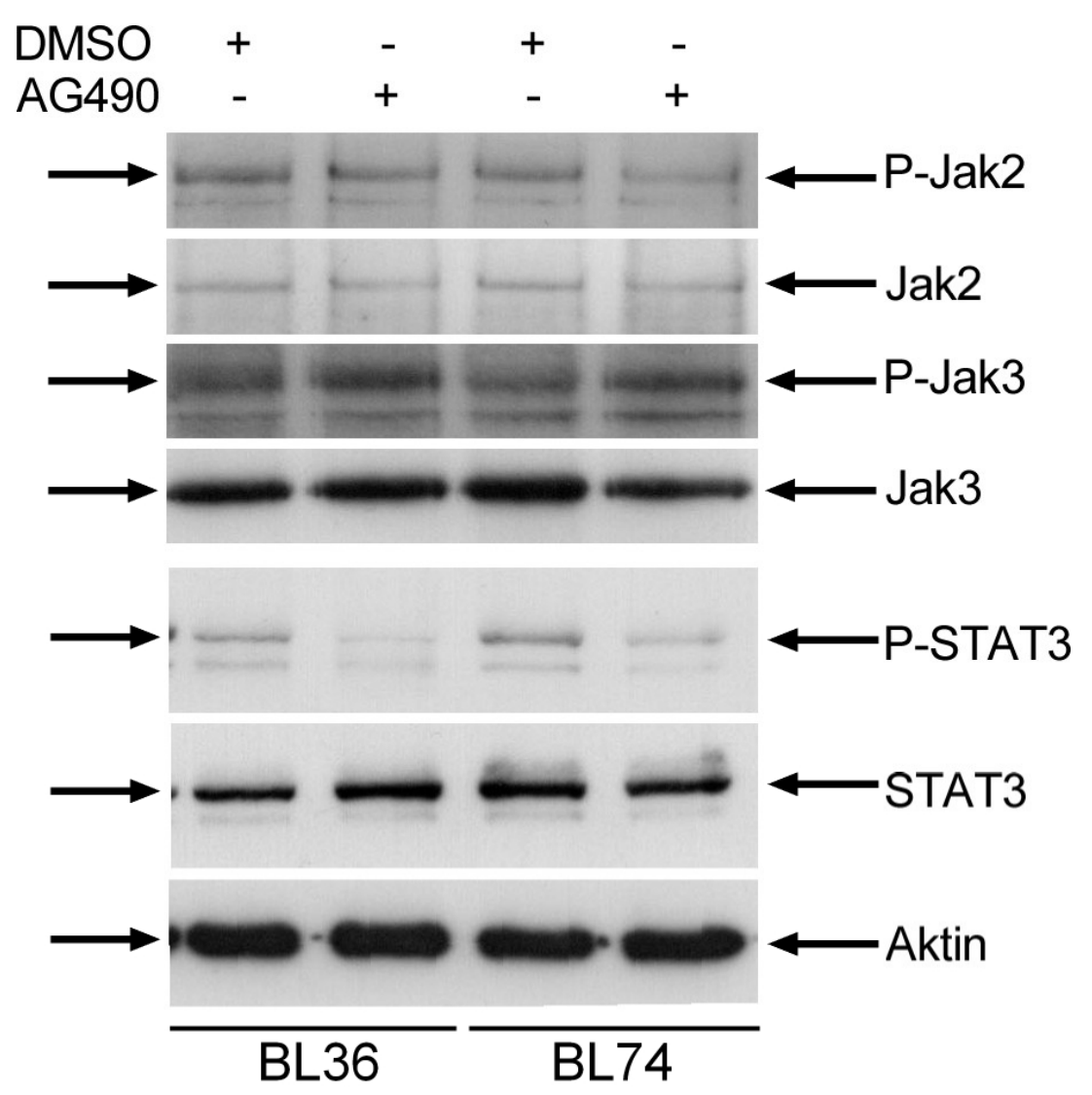

Abb. 10: Jak-Immunpräzipitation AG490-behandelter Burkitt-Lymphomzellinien. Nach dreistündiger Behandlung der Burkitt-Lymphomzelllinien wurde das daraus isolierte Protein für die Jak2- und Jak3-Immunpräzipitation eingesetzt. Im Anschluss erfolgte die Western Blot-Analyse mit spezifischen Antikörpern. 
STAT3-Phosphorylierung bei gleichbleibenden STAT3- und Aktin-Mengen, was den Einfluss von AG490 auf den Aktivierungszustand von STAT3 nochmals bestätigt. Allerdings scheint das Tyrphostin AG490 die Signalwege in den Zellen nicht ausschließlich über die Hemmung von Jak2 zu beeinflussen, da Jak2 durch AG490 nicht ausreichend inhibiert wird.

Für das spezifische Ausschalten der Funktion der Januskinase 3 wurde der Jak3Inhibitor WHI-P131 eingesetzt. Die Kultivierung der Burkitt-Lymphomzelllinien BL36 und BL74 wurde für eine, drei oder sechs Stunden in Anwesenheit des Inhibitors bzw. dessen Lösungsmittel DMSO durchgeführt. Die Analyse der STAT3Expression erfolgte mittels spezifischer Antikörper. In Abb. 11 sind die Ergebnisse für die EBV-positive Burkitt-Lymphomzelllinie BL74 dargestellt. Es ist zu erken-

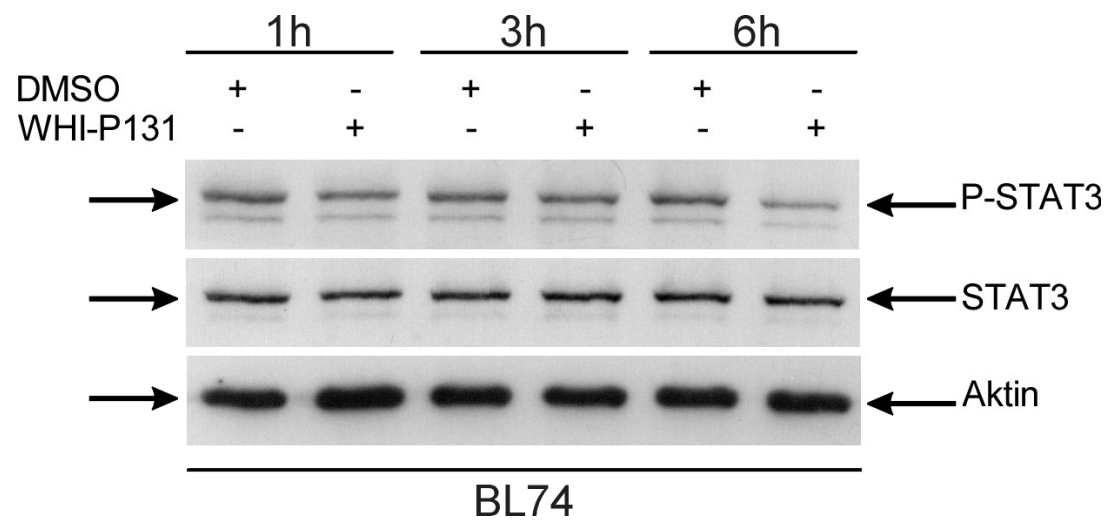

Abb. 11: Die Hemmung der Januskinase 3 durch WHI-P131 in BL74. Die BurkittLymphomzelllinie BL74 wurde für eine, drei bzw. sechs Stunden mit dem Jak3-Inhibitor oder dem Lösungsmittel DMSO behandelt. Anschließend wurde das zelluläre Protein isoliert und mittels Western Blot analysiert.

nen, dass es infolge der Zugabe von WHI-P131 zu einer Abnahme der TyrosinPhosphorylierung von STAT3 kommt, wobei die STAT3-Proteinexpression unverändert bleibt. Der Effekt der reduzierten Phosphorylierung ist nach sechs Stunden am ausgeprägtesten. Der Nachweis von Aktin und dessen unveränderte Expression in allen Proben bestätigte einen gleichmäßigen Probenauftrag. Auch die EBV-positive Burkitt-Lymphomzelllinie BL36 zeigt bei gleichbleibender STAT3-Proteinexpression eine Reduktion der STAT3-Tyrosin-Phosphorylierung nach WHI-P131-Behandlung (Abb. 12). Der Nachweis von Aktin diente hier ebenfalls der Überprüfung eines 


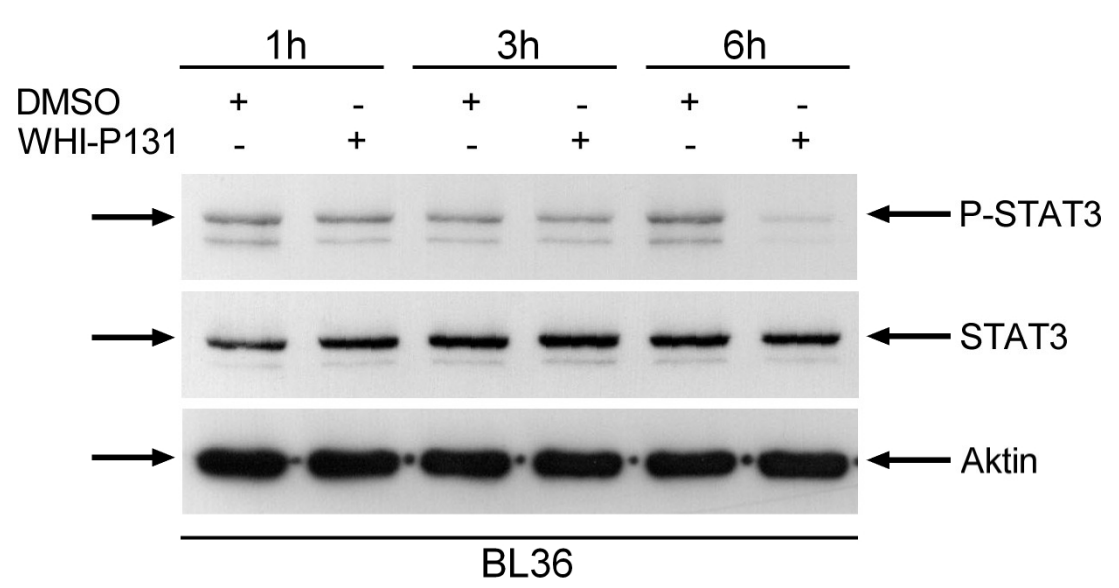

Abb. 12: Die Hemmung der Januskinase 3 durch WHI-P131 in BL36. Die BurkittLymphomzelllinie BL36 wurde für eine, drei bzw. sechs Stunden mit dem Jak3-Inhibitor oder dem Lösungsmittel DMSO behandelt. Anschließend wurde das zelluläre Protein isoliert und mittels Western Blot analysiert.

gleichmäßigen Probenauftrags.

In wie weit der Jak3-Inhibitor WHI-P131 in diesen Zellen spezifisch auf die Januskinase 3 wirkt, wird anhand von Abb. 13 verdeutlicht. Im Anschluss an eine dreistündige Behandlung der Burkitt-Lymphomzelllinien BL36 und BL74 mit WHIP131 erfolgte die Anreicherung der Januskinase 3 mittels Immunpräzipitation. Durch die Immunfärbung mit spezifischen Antikörpern konnte bei gleichbleibender Jak3Proteinexpression gezeigt werden, dass unter WHI-P131-Behandlung die TyrosinPhosphorylierung von Jak3 nach drei Stunden deutlich abnimmt. Die Färbung der Proben vor der Immunpräzipitation zeigt eine Abnahme der Phosphorylierung von STAT3 bei gleichbleibenden STAT3- und Aktin-Proteinmengen und ist somit ebenfalls als Kontrolle für die Wirksamkeit des Inhibitors zu betrachten. 


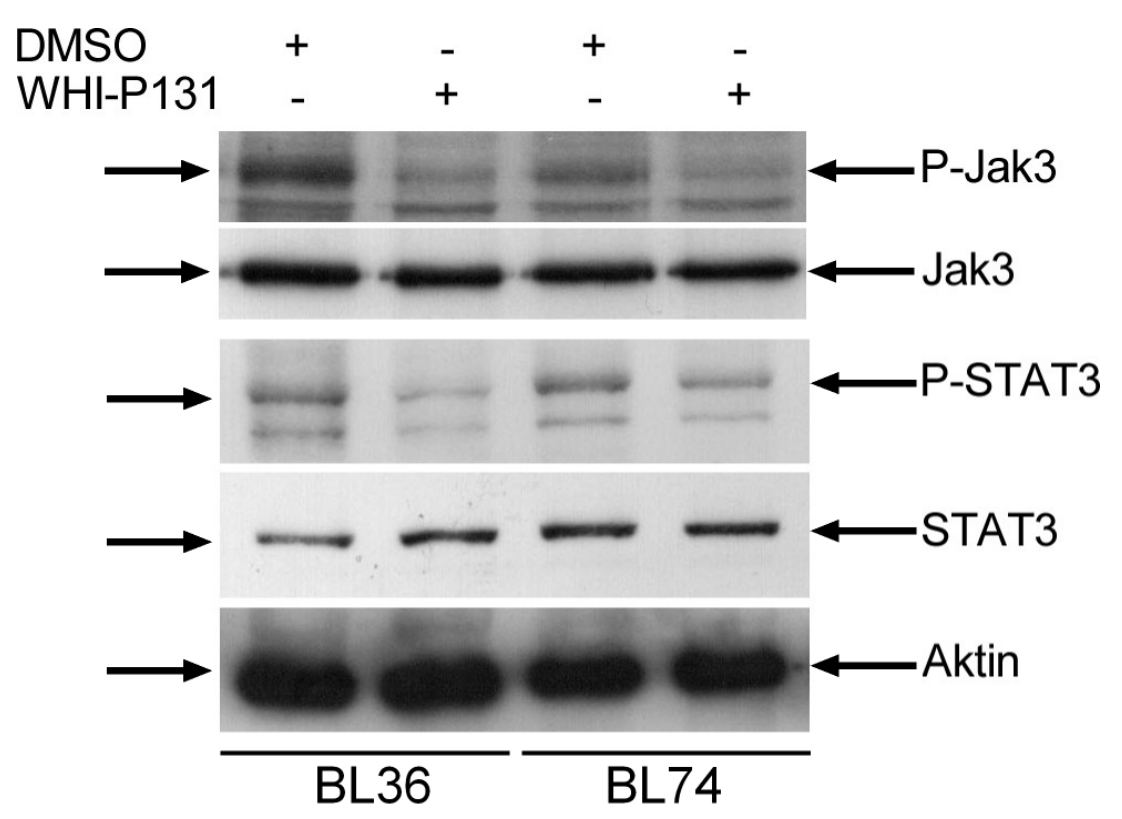

Abb. 13: Jak-Immunpräzipitation WHI-P131-behandelter Burkitt-Lymphomzelllinien. Die Burkitt-Lymphomzelllinien BL36 und BL74 wurden für drei Stunden mit dem Jak3Inhibitor WHI-P131 behandelt. Die Januskinase 3 wurde mittels Immunpräzipitation angereichert und ihr Phosphorylierungsstatus im Western Blot analysiert.

\subsection{LMP1 ist für die STAT1- und STAT3-Aktivierung aus- reichend}

Der C-terminale Bereich von LMP1 ist für die Aktivierung von Signalwegen in der EBV-positiven Lymphomzelle verantwortlich. Man kann den C-Terminus funktionell in die C-terminalen Aktivierungsregionen CTAR1 und CTAR2 unterteilen. Beide Bereiche sind für die Aktivierung bestimmter Signalwege in der Zelle verantwortlich. Es galt daher zu untersuchen, ob LMP1 bei der Aktivierung von STAT3 und STAT1 eine Rolle spielt und welche CTAR in diesen Prozess involviert ist. Um diese Frage zu klären, wurde die EBV-negative Burkitt-Lymphomzellinie BL2 mit verschiedenen Plasmiden transfiziert, die entweder für den Wildtyp LMP1 (pSG5 LMP1), LMP1 mit mutierter CTAR1 (pSG5 LMP1 CTAR1mut), LMP1 mit mutierter CTAR2 (pSG5 LMP1 CTAR2mut) oder LMP1 mit mutierter CTAR1 und CTAR2 (pSG5 LMP1 CTAR1/2mut) kodierten. Als Kontrolle wurde pSG5 als Leerplasmid mitgeführt. Die Zellen wurden 24h nach der Transfektion angereichert (siehe 4.1.5 und 4.1.6) und für weitere 24h kultiviert. Nach der Zellernte und der Pro- 
teinisolation wurde die Western Blot-Analyse durchgeführt.

Die Immunfärbung der Proben auf STAT3 ist in Abbildung 14 dargestellt. Ein Vergleich der Proben untereinander zeigt, dass nur bei BL2, welche Wildtyp-LMP1 exprimiert, phosphoryliertes STAT3 nachgewiesen werden kann. Die als Kontrolle dienende Transfektion mit dem Leervektor sowie die Proben, die mutiertes LMP1 exprimieren, weisen keine Phosphorylierungsbande von STAT3 auf. Allerdings findet man in allen Proben zusätzlich eine durch den Antikörper verursachte unspezifische Bande. Das STAT3-Proteinlevel weist leichte Schwankungen auf. Die Aktinfärbung ist mit Ausnahme der Probe pSG5 LMP1 CTAR1/2mut, welche eine schwächere Bande aufweist als die anderen Proben, vergleichbar. Dies untermauert die Aussage, dass nur Wildtyp-LMP1 STAT3 aktivieren kann. Die Immunfärbung auf LMP1 zeigt, dass die pSG LMP1 CTAR2mut- und pSG LMP1 CTAR1/2mut-exprimierenden Zellen ein höheres Niveau an LMP1-Protein aufweisen.

Die Analyse der LMP1-Mutanten erfolgte ebenfalls für STAT1. Die Ergebnisse sind in Abbildung 15 dargestellt. Das STAT1-Protein wird in allen Zellen exprimiert. Allerdings ist das Niveau in den BL2-Zellen, welche LMP1 exprimieren, deutlich erhöht. Die gleiche Beobachtung kann bei der Untersuchung des Aktivierungszustan-

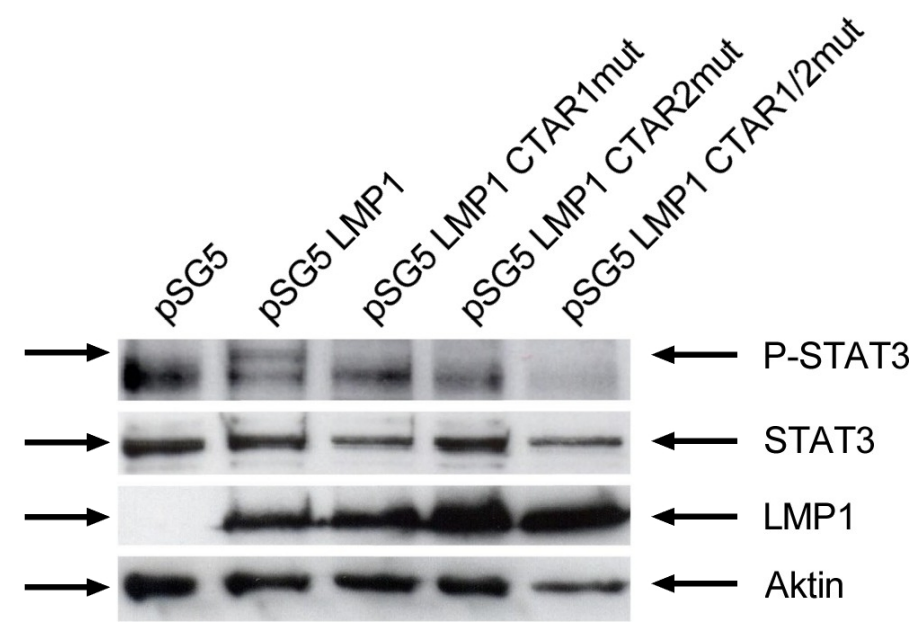

Abb. 14: Analyse der STAT3-Expression in mit LMP1-Mutanten transfizierten BL2Zellen. Dargestellt ist die Western Blot-Analyse der EBV-negativen Burkitt-Lymphomzelllinie BL2, die mit LMP1 wt und LMP1 mit Mutationen im C-terminalen Bereich transfiziert wurde. Nach MACS und Proteinisolation wurden die Proben mittels SDS-PAGE und Immunfärbung mit spezifischen Antikörpern analysiert. Zusätzlich zu P-STAT3 und STAT3 wurden auch Aktin und LMP1 gefärbt. 


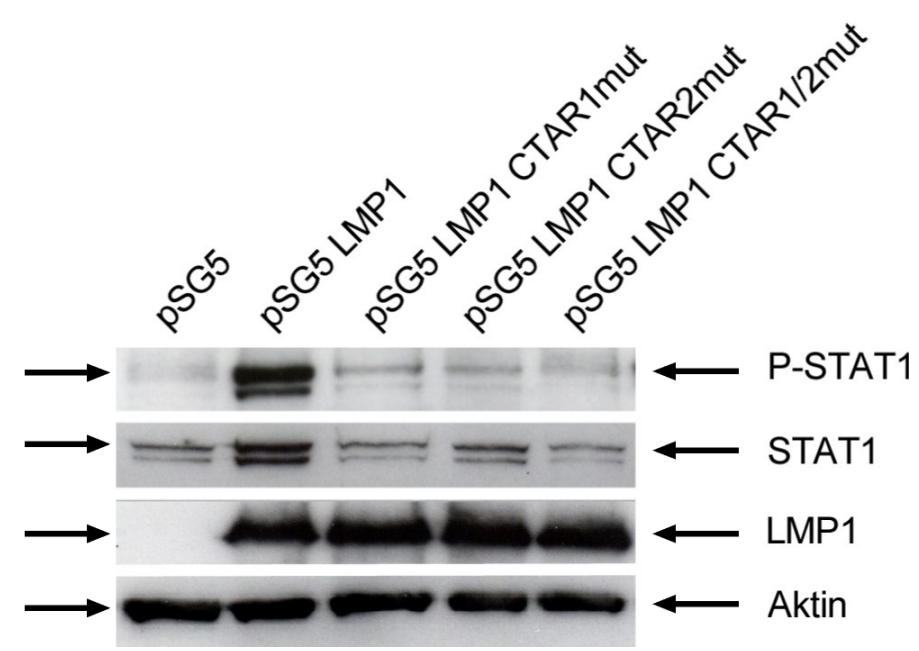

Abb. 15: Analyse der STAT1-Expression in mit LMP1-Mutanten transfizierten BL2Zellen. Dargestellt ist die Western Blot-Analyse der EBV-negativen Burkitt-Lymphomzelllinie BL2, die mit LMP1 wt und LMP1 mit Mutationen im C-terminalen Bereich transfiziert wurde. Nach MACS und Proteinisolation wurden die Proben mittels SDS-PAGE und Immunfärbung mit spezifischen Antikörpern analysiert. Neben P-STAT1 und STAT1 wurde auch auf Aktin und LMP1 gefärbt.

des von STAT1 gemacht werden. Eine deutlich ausgeprägte Tyrosin-Phosphorylierung zeigt lediglich die LMP1 wt-Probe. Sowohl Protein als auch Phosphorylierung von STAT1 sind bei allen anderen Proben auf vergleichbarem Niveau. Der Nachweis von Aktin bestätigte eine gleichmäßige Beladung des Gels.

Im Anschluss an diese Untersuchungen wurde der Frage nachgegangen, ob SOCS3 als Negativregulator des Jak/STAT-Signalweges über die LMP1-vermittelte Aktivierung von Jak/STAT in Lymphomzellen induziert wird. 


\subsection{Die Analyse der SOCS3-Expression in Lymphomzell- linien}

Bei der negativen Regulation des Jak/STAT-Signalweges spielen die SOCS-Proteine eine wesentliche Rolle. Sie inhibieren diesen Weg in Form einer negativen Rückkopplungsschleife. Sie werden durch STAT-Moleküle aktiviert und interagieren entweder mit den Januskinasen oder den Zytokinrezeptoren. Aus der Familie der SOCSMoleküle wird SOCS3 durch STAT3 aktiviert und steht daher im Fokus dieser Analyse. Um den Status von SOCS3 in den Lymphomzelllinien zu bestimmen, wurden diese auf RNA- und Protein-Ebene hinsichtlich der Expression von SOCS3 untersucht. Die Zellen wurden hierfür, wie unter 4.1.1 und 4.1.9 beschrieben, kultiviert und geerntet. Im Anschluss an die Isolation von RNA und Protein (siehe 4.3.3, 4.2.1) wurden diese dann mittels Western Blot-Analyse, Real-Time-PCR und konventioneller PCR (siehe 4.2.2, 4.3.5, 4.3.6) untersucht.

\subsubsection{SOCS3 wird in EBV-positiven Burkitt-Lymphomzelllinien expri- miert}

Abbildung 16 zeigt die Analyse der SOCS3-mRNA-Expression der EBV-negativen Burkitt-Lymphomzelllinie Ramos, der EBV-positiven Zelllinien BL60, L660, BL36 und BL74 sowie der EBV-positiven lymphoblastoiden Zelllinie (LCL) IARC304, wobei die vier letztgenannten das virale Protein LMP1 exprimieren. Die Zelllinien BL60 und Ramos weisen nach der PCR mit SOCS3-spezifischen Primern kein spezifisches SOCS3-Produkt auf, während in IARC304, L660, BL36 und BL74 SOCS3 nachgewiesen werden kann. Die Intensität der SOCS3-Bande ist bei L660 und IARC304 schwächer als bei BL36 und BL74, bei vergleichbarer Stärke des spezifischen PCRProduktes für das sogenannte „housekeeping”-Gen ABL, dessen Nachweis als Kontrolle dient. Die Ergebnisse verdeutlichen ebenfalls den Zusammenhang zwischen der Expression des viralen Onkoproteins LMP1 und dem Vorhandensein von SOCS3mRNA in den Burkitt-Lymphomzelllinien.

Bei der Analyse weiterer Burkitt-Lymphomzellinien konnte dies ebenfalls beobachtet werden. Dargestellt sind in Abb. 17 die Zelllinien BL2, BL2P3HR1, BL2B95-8, 


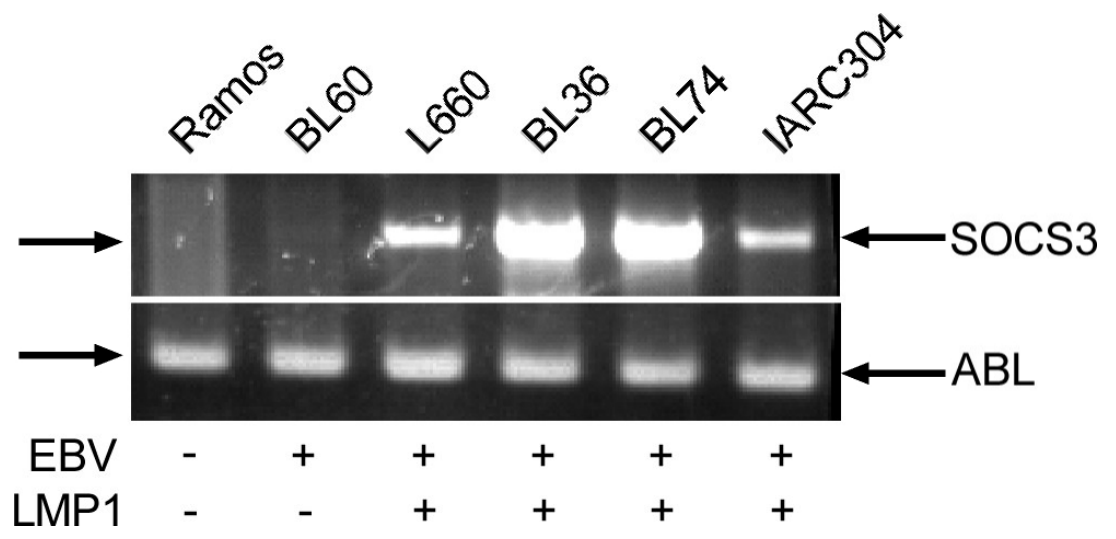

Abb. 16: SOCS3-Expression auf RNA-Ebene in Burkitt-Lymphomzelllinien. Dargestellt sind die Ergebnisse einer PCR mit SOCS3- bzw. mit ABL-spezifischen Primern, die mit aus BurkittLymphomzellinien gewonnener cDNA durchgeführt wurde. Die hier verglichenen Zellen zeigen deutliche Unterschiede in der Menge an vorhandener SOCS3-mRNA in den Zellen. Dies verdeutlicht auch die PCR mit dem Kontrollgen ABL.

BL30, BL30P3HR1, BL30B95-8, BL41, BL41P3HR1 und BL41B95-8. Bei BL2B95-8 (Abb. 17a) und BL30B95-8 (Abb. 17b) ist sehr deutlich eine Induktion der SOCS3mRNA erkennbar, während BL41B95-8 (Abb. 17c) eine nur sehr schwache SOCS3Bande aufweist. Ein spezifisches SOCS3-PCR-Produkt ist bei den parentalen Zellen und denen, die mit dem insuffizienten Virusstamm P3HR1 infiziert sind, nicht oder nur äußerst schwach nachweisbar.

Neben der konventionellen PCR wurden die cDNA-Proben ebenfalls mittels RealTime-PCR analysiert. Die so gewonnenen Daten bestätigen die bereits beobachtete SOCS3-Induktion auf RNA-Ebene in Abhängigkeit von EBV in den untersuchten Burkitt-Lymphomzelllinien. In Tabelle 22 sind die Daten in Form der Differenz aus dem Mittelwert der Zyklenzahl, bei der das SOCS3-Produkt im Laufe der PCRReaktion auftritt, und dem Mittelwert der Zyklenzahl des internen Standards $(\beta 2 \mathrm{M})$ dargestellt $\left(\Delta C_{T}\right.$-Wert). Zusätzlich sind in Spalte 2 die Mittelwerte der Zyklenzahl von SOCS3 $\left(C_{T}\right.$-Werte) aufgelistet, wobei ab einem $C_{T}$-Wert von $\geq 40$ oder einem „unbestimmt” davon auszugehen ist, dass sich in dieser Probe keine nachweisbare Menge an SOCS3 befunden hat. Es gilt somit: Je geringer der $C_{T}$-Wert, desto schneller konnte während der PCR-Reaktion das Produkt detektiert werden.

Die vorliegenden Daten (Tab. 22) lassen den Schluss zu, dass die untersuchten Zelllinien BL2, BL2P3HR1, BL30, BL30P3HR1, BL41, BL41P3HR1, Ramos und BL60 

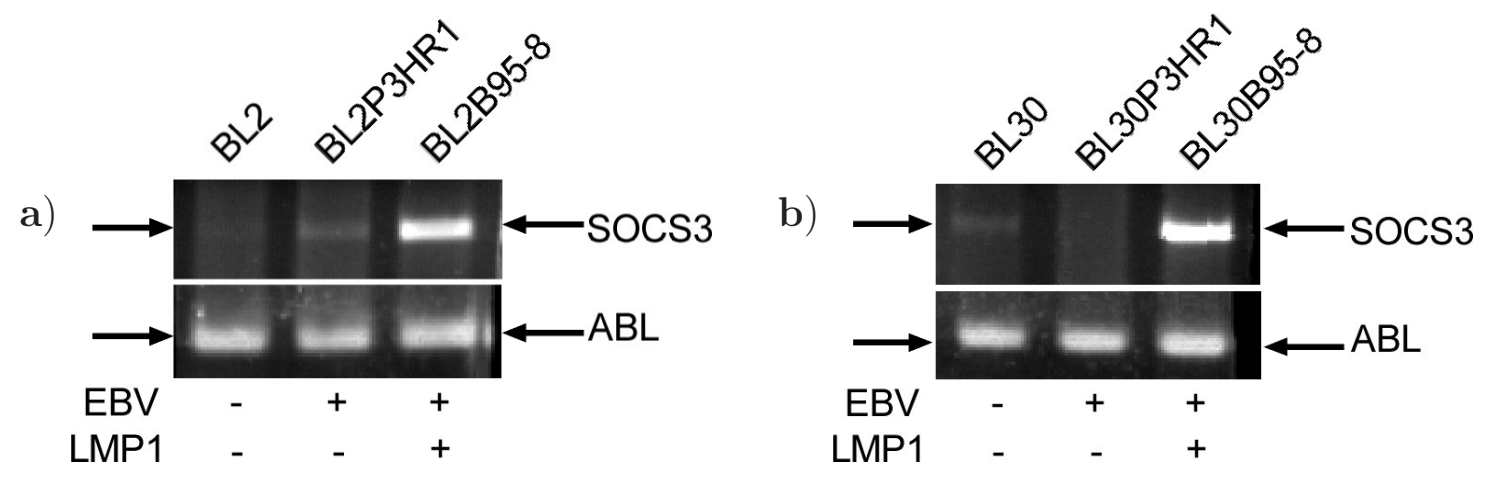

c)

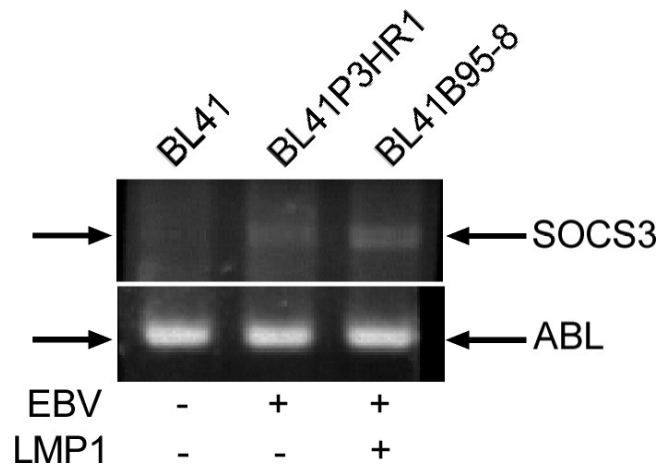

Abb. 17: SOCS3-Nachweis auf RNA-Ebene mittels PCR. Die aus den BurkittLymphomzelllinien isolierte RNA wurde mit Hilfe der reversen Transkription in cDNA umgeschrieben und in einer PCR-Reaktion mit SOCS3-spezifischen Primern eingesetzt. Die Ergebnisse für die Zelllinien BL2, BL2P3HR1 und BL2B95-8 sind in Abb. a), die für BL30, BL30P3HR1 und BL30B95-8 in Abb. b) sowie die für BL41, BL41P3HR1 und BL41B95-8 in Abb. c) dargestellt. Als Kontrolle wurde parallel eine PCR durchgeführt, um das ABL-Genprodukt mit einer Größe von 296bp nachzuweisen. Die gleichmäßige Bandenintensität des ABL-Genprodukts lässt somit einen Vergleich der SOCS3-Banden untereinander zu.

keine nachweisbare SOCS3-mRNA enthalten. Dieser Befund gilt jedoch auch für BL41B95-8, obwohl die Zelllinien BL2B95-8 und BL30B95-8 wie erwartet positiv für SOCS3 waren. Die Unterschiede in der SOCS3-Expression in BL41B95-8, die zwischen der Real-Time-PCR und der konventionellen PCR zu beobachten sind, können aufgrund der unterschiedlichen eingesetzten cDNA-Mengen zustande gekommen sein. Die Zelllinien BL74, BL36, L660 und IARC304 liegen mit ihren Zyklenzahlen deutlich unterhalb von 40, was einem Nachweis von SOCS3-mRNA entspricht. Mit Hilfe der Real-Time-PCR konnte somit mit Ausnahme von BL41B95-8 in allen LMP1-exprimierenden Zellen SOCS3-mRNA nachgewiesen werden. Der Vergleich der Zyklenzahl zeigt auch unter Berücksichtigung des Standards (Tab. 22, Spalte 2 
Tab. 22: Analyse der Burkitt-Lymphomzelllinien mittels Real-Time-PCR

\begin{tabular}{lll}
\hline Zelllinie & $C_{T}$-Wert SOCS3 & $\Delta C_{T}$-Wert \\
\hline BL2 & "unbestimmt” & "unbestimmt” \\
BL2P3HR1 & 41,9 & 21,17 \\
BL2B95-8 & 37,2 & 17,85 \\
BL30 & 40,03 & 19,5 \\
BL30P3HR1 & 43,9 & 23,8 \\
BL30B95-8 & 35,06 & 14,52 \\
BL41 & 39,69 & 19,88 \\
BL41P3HR1 & 41,24 & 21,52 \\
BL41B95-8 & 41,13 & 21,5 \\
Ramos & 40,59 & 19,66 \\
BL60 & 40,1 & 19,37 \\
L660 & 36,3 & 17,97 \\
IARC304 & 36,36 & 18,04 \\
BL36 & 31,28 & 11,6 \\
BL74 & 26,6 & 7,99 \\
\hline
\end{tabular}

und 3), dass BL74 die größte Menge an SOCS3-mRNA enthält.

Die Abhängigkeit der Expression des SOCS3-Proteins von EBV und der Expression von LMP1 wird in Abbildung 18 am Beispiel der Burkitt-Lymphomzelllinien BL2 und BL30 bzw. deren mit den Virusstämmen P3HR1 und B95-8 infizierten Zellen weiter verdeutlicht. Die relativ schwache, aber noch erkennbare SOCS3-Proteinbande von 25kDa ist nur in den B95-8-konvertierten Zellen erkennbar. Zusätzlich auftretende Banden sind als Unspezifität des Antikörpers zu betrachten. Als Kontrolle für eine starke SOCS3-Expression wurde die Hodgkin-Lymphomzelllinie HDLM2 zusätzlich aufgetragen. Die starke Bande für SOCS3 bei HDLM2 zeigt allerdings auch, dass für den Nachweis im Western Blot eine gewisse Menge an SOCS3 vorhanden sein muss. Dies war insbesondere bei schwach-SOCS3-exprimierenden Zellen mit dem uns zur Verfügung stehenden, relativ unspezifischen Antikörper nicht immer möglich. 
a)

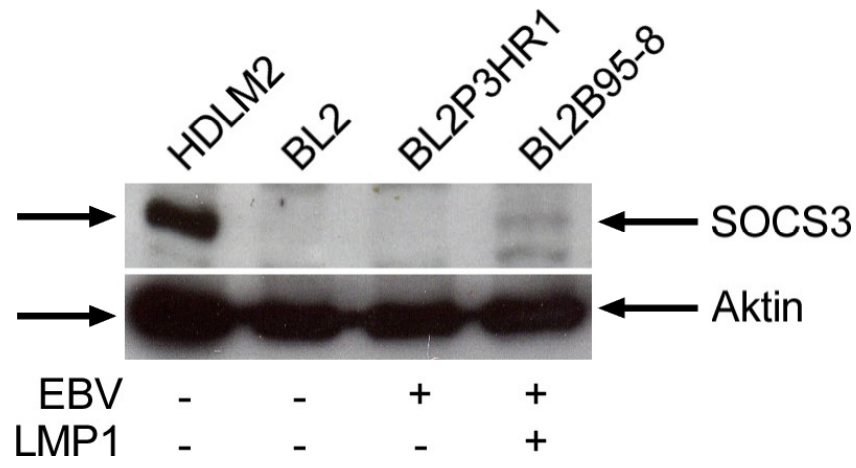

b)

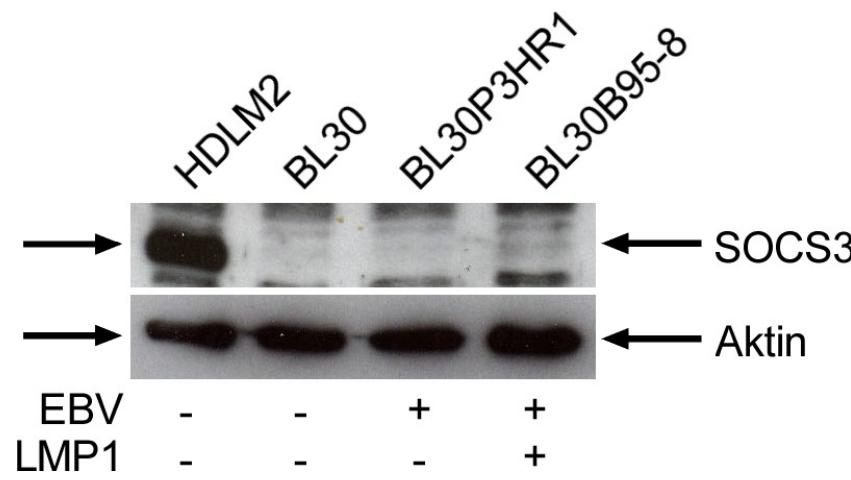

Abb. 18: SOCS3-Western Blot-Analyse in BL2- und BL30-Zellen. Das aus den Zellen isolierte Protein wurde mit Hilfe von Western Blot und Immunfärbung mit spezifischen Antikörpern auf SOCS3 und Aktin gefärbt. Unter a) ist die Analyse von BL2, BL2P3HR1 und BL2B95-8 dargestellt, wobei nur BL2B95-8 eine SOCS3-Proteinbande zeigt. Unter b) ist die Analyse von BL30, BL30P3HR1 und BL30B95-8 dargestellt, wobei sich auch hier nur bei BL30B95-8 eine SOCS3Proteinbande nachweisen lässt. Die Hodgkin-Lymphomzelllinie HDLM2 diente als Positivreferenz für eine SOCS3-Expression.

\subsubsection{Die Januskinasen 2 und 3 sind in die Aktivierung von SOCS3 involviert}

In Kapitel 5.1.3 wurde der Einfluss der Inhibitoren AG490 und WHI-P131 auf die Januskinasen 2 und 3 und auf die Aktivierung von STAT3 untersucht. Für die EBVpositive Burkitt-Lymphomzelllinie BL74 werden hier die Abbildungen 8 und 11 erneut dargestellt, jedoch erweitert um die Analyse von SOCS3. Da die Abbildungen in Kapitel 5.1.3 bereits ausführlich beschrieben wurden, wird im Folgenden lediglich auf die Expression von SOCS3 in Abhängigkeit vom jeweilig eingesetzten Jak-Inhibitor eingegangen.

In Abbildung 19a wird deutlich, dass bereits nach einstündiger AG490-Behandlung 
der BL74-Zellen die Proteinmenge an SOCS3 reduziert ist. Dieser Effekt verstärkt sich zusätzlich, wenn die Zellen für 3h oder 6h mit dem Jak2-Inhibitor AG490 behandelt werden. Der Nachweis von SOCS3-Protein ist dann im Western Blot nicht mehr möglich. In Abbildung 19b ist die Untersuchung der EBV-positiven BurkittLymphomzellinie BL74 nach Behandlung mit dem Jak3-Inhibitor WHI-P131 dargestellt. Für SOCS3 ergibt sich das gleiche Bild wie bei der Behandlung der Zellen mit AG490. Die Menge an SOCS3-Protein nimmt nach einstündiger WHI-P131Behandlung ab und ist nach $3 \mathrm{~h}$ oder $6 \mathrm{~h}$ mittels Immunoblot nicht mehr nachweisbar.

a)

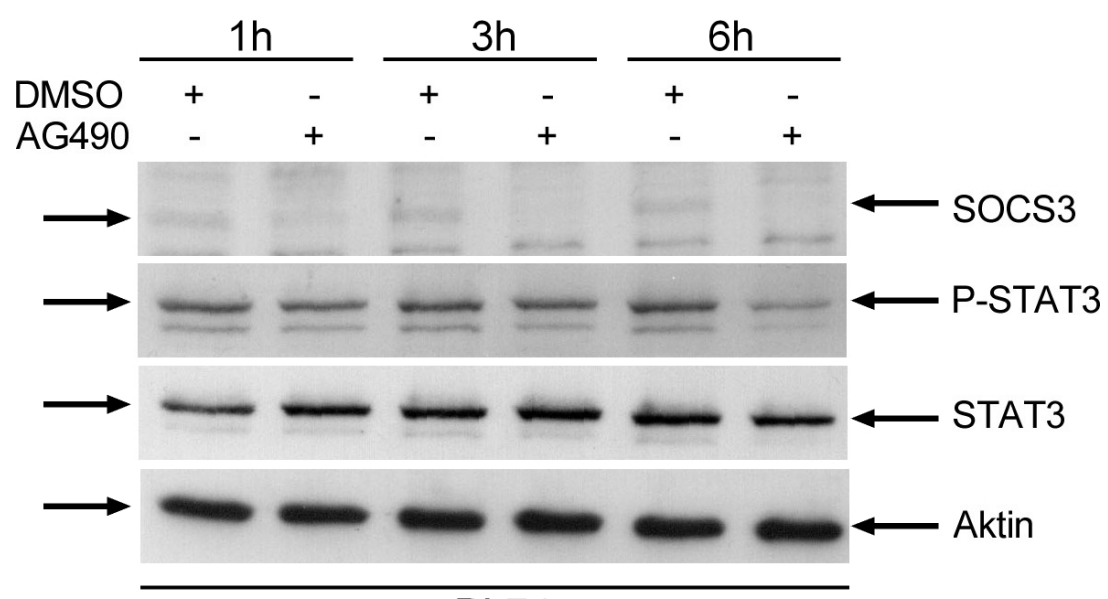

\section{$\mathrm{BL} 74$}

b)

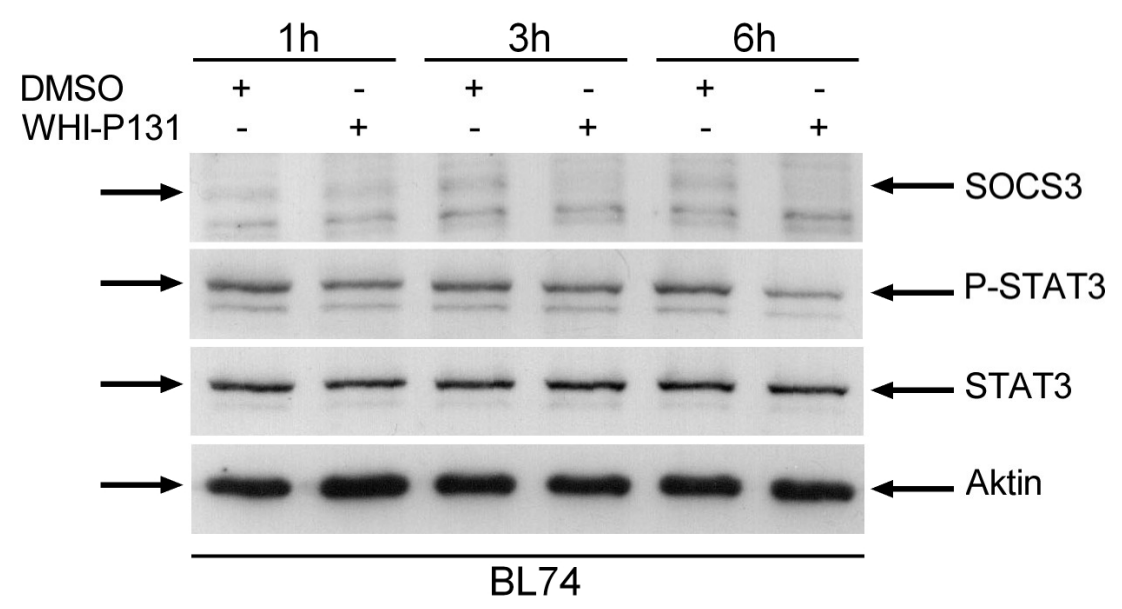

Abb. 19: Die Hemmung der Januskinasen 2 und 3 durch AG490 und WHI-P131 in BL74-Zellen. Die Burkitt-Lymphomzellinie BL74 wurde für eine, drei oder sechs Stunden mit dem Jak2-Inhibitor AG490 bzw. dem Jak3-Inhibitor WHI-P131 und als Kontrolle mit dem Lösungsmittel DMSO behandelt. Anschließend wurde das zelluläre Protein isoliert und mittels Western Blot analysiert. 


\subsubsection{SOCS3 wird in Hodgkin-Lymphomzelllinien exprimiert}

Die Untersuchung der SOCS3-Expression wurde auf Hodgkin-Lymphomzelllinien ausgeweitet. Die Hodgkinzellen sind unter anderem durch eine permanente Aktivierung von STAT3 gekennzeichnet (Kube et al., 2001). Das Ergebnis der Untersuchung der SOCS3-Expression auf RNA- bzw. cDNA-Ebene in den HodgkinLymphomzellinien mittels SOCS3-spezifischer PCR ist in Abbildung 20 dargestellt.

Die Analyse zeigt, dass in allen untersuchten Zellen SOCS3-Transkript nachgewiesen werden kann. Vergleicht man die Hodgkin-Lymphomzelllinien untereinander, so weist HDLM2 das höchste und KM-H2 das niedrigste Niveau an spezifischem SOCS3-PCR-Produkt bei gleicher Bandenintensität des Kontrollgens ABL auf.

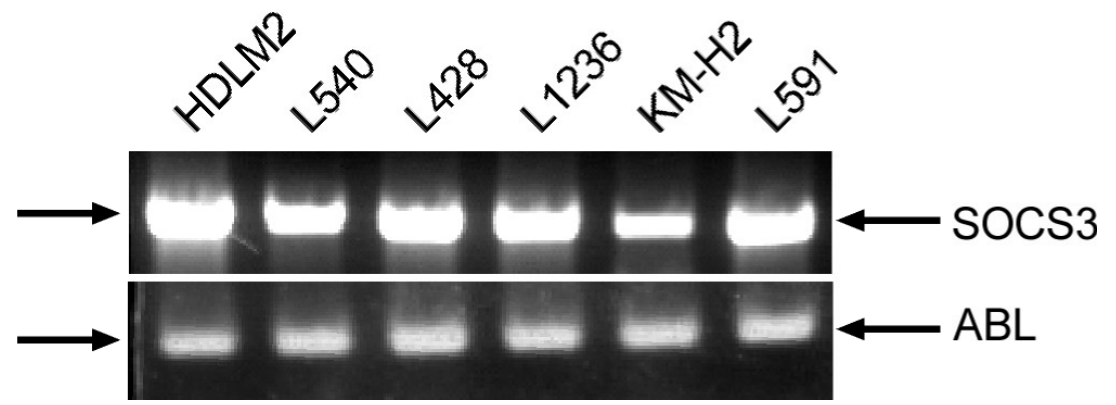

Abb. 20: SOCS3-Expression auf RNA-Ebene in Hodgkin-Lymphomzellinien. Die aus den Hodgkin-Lymphomzelllinien gewonnene RNA wurde in cDNA umgeschrieben und diese für eine konventionelle PCR-Reaktion mit SOCS3-spezifischen Primern eingesetzt. Das entstandene PCR-Produkt hat eine Größe von 678bp und ist in allen untersuchten Zellen nachweisbar. Um die Proben untereinander vergleichen zu können, wurde eine zweite PCR mit ABL-spezifischen Primern durchgeführt. Das entstandene PCR-Produkt hat eine Größe von 296bp und zeigte keine Unterschiede zwischen den einzelnen Proben.

Die cDNAs wurden ebenfalls mittels Real-Time-PCR auf das Vorhandensein von SOCS3 untersucht. Die gewonnenen Daten sind in Tabelle 23 aufgelistet. Wie anhand der $C_{T^{-}}$und $\Delta C_{T^{-}}$Werte deutlich wird, erweist sich wiederum HDLM2 als die Zelllinie mit dem höchsten Niveau an SOCS3-mRNA und KM-H2 als diejenige mit dem niedrigsten Niveau. Die Proben wurden zusätzlich zu SOCS3 auch hinsichtlich der SOCS1-, SOCS2- und SOCS5-Expression analysiert (Daten nicht gezeigt). Für SOCS2 und SOCS5 konnte in den Zellen keine mRNA nachgewiesen werden, wohingegen die Auswertung für SOCS1 ergab, dass in allen Zellen eine große Menge dieser mRNA vorliegt. 
Tab. 23: Analyse der Hodgkin-Lymphomzelllinien mittels Real-Time-PCR

\begin{tabular}{lll}
\hline Zelllinie & $C_{T}$-Wert SOCS3 & $\Delta C_{T}$-Wert \\
\hline HDLM2 & 25,34 & 5,83 \\
L428 & 29,42 & 7,25 \\
L1236 & 29,19 & 8,85 \\
KM-H2 & 34,8 & 15,06 \\
L591 & 29,44 & 10,22 \\
\hline
\end{tabular}

Abbildung 21 zeigt die Western Blot-Analyse der Hodgkin-Lymphomzelllinien. Es ist zu erkennen, dass in fünf der sechs untersuchten Zelllinien eine Expression von SOCS3 nachweisbar ist. Die Hodgkin-Lymphomzelllinie KM-H2 zeigt als einzige kein nachweisbares SOCS3-Protein, während HDLM2 das höchste Niveau an SOCS3Protein in den Zellen aufweist. Der Abgleich mit Aktin zeigt Unterschiede in den aufgetragenen Proteinmengen. Werden diese Unterschiede berücksichtigt, ergibt sich ein ähnliches Bild wie das der RNA-Analyse. Durch die starke SOCS3-Proteinexpression in einigen Hodgkin-Lymphomzellinien war es möglich, diese auch mittels Western Blot-Analyse nachzuweisen.

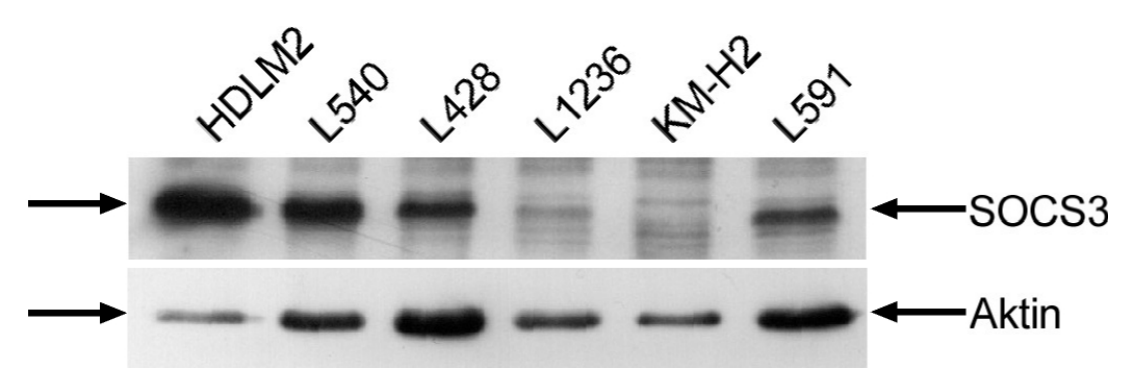

Abb. 21: SOCS3-Expression auf Protein-Ebene in Hodgkin-Lymphomzellinien. Zur Analyse der SOCS3-Proteinexpression wurde das aus den Zellen isolierte Protein mittels SDSPAGE, Western Blot und anschließender Immunfärbung untersucht. Die detektierte SOCS3-Bande von $25 \mathrm{kDa}$ konnte mit unterschiedlicher Intensität in allen Proben nachgewiesen werden. Als Kontrolle diente die Immunfärbung gegen Aktin (43kDa).

Zusammenfassend lässt sich anhand beider Abbildungen (Abb. 20 und 21) feststellen, dass in den Hodgkin-Lymphomzelllinien sowohl auf Protein- als auch auf RNA-Ebene eine signifikante Menge an SOCS3 vorhanden ist. 


\subsubsection{Die Expression von LMP1 ist ausreichend, um SOCS3 zu induzie- ren}

Um der Frage nachzugehen, ob die Expression von LMP1 neben der Aktivierung von STAT3 (siehe 5.2) auch für die Induktion von SOCS3 ausreichend ist, wurde die EBV-negative Burkitt-Lymphomzelllinie BL2 mit dem Expressionsplasmid für LMP1 transfiziert. Aufgrund der geringen Transfektionseffizienz wurden die Zellen 24h nach der Elektroporation mittels MACS (4.1.6) angereichert, um eine ausreichende Anzahl LMP1-exprimierender Zellen zu erhalten. Nach weiteren 24h wurden die Zellen geerntet und RNA bzw. Protein isoliert. Abbildung 22a zeigt deutlich die Tyrosin-Phosphorylierungsbande von STAT3 bei gleichbleibender STAT3Proteinkonzentration in den mit LMP1 transfizierten Zellen. Im Kontrollansatz wurde hingegen nur der Leervektor pSG5 exprimiert, was nicht zu einer Aktivierung von STAT3 führt.

a)

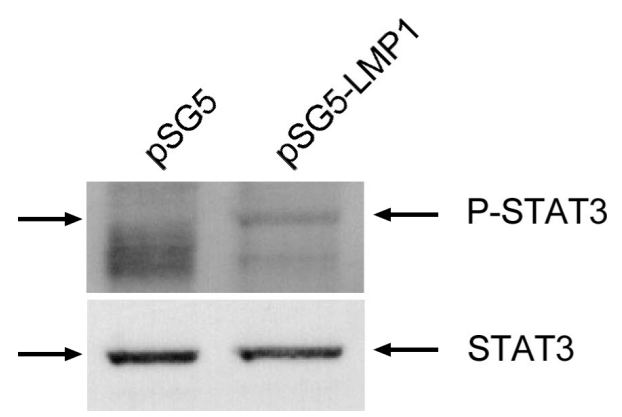

b)

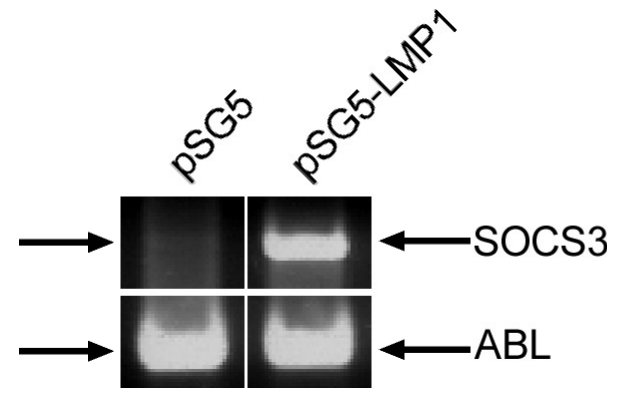

Abb. 22: Induktion von P-STAT3 und SOCS3 durch LMP1. Die Burkitt-Lymphomzelllinie BL2 wurde mit LMP1 transfiziert. Nach 24h wurden die Zellen angereichert und für weitere 24h kultiviert. Nach der Zellernte wurde Protein und RNA isoliert. a) zeigt die Western Blot-Analyse und die Immunfärbung mit spezifischen Antikörpern gegen P-STAT3 und STAT3. In b) ist die PCR mit SOCS3-Primern dargestellt. Die spezifische Produktbande hat eine Größe von 678bp. Als Kontrolle wurde mittels PCR das ABL-Gen amplifiziert, welches ein Produkt mit einer Größe von $298 \mathrm{bp}$ lieferte.

Um zu überprüfen, ob eine Transfektion von LMP1 ebenfalls zu einer Induktion von SOCS3-RNA führt, wurde die aus den Zellen isolierte RNA in cDNA umgeschrieben und mit Hilfe der Real-Time-PCR sowie der konventionellen PCR analysiert. Die Daten der Real-Time-PCR in Tabelle 24 zeigen, dass das SOCS3-Produkt in LMP1-exprimierenden Zellen viel schneller detektiert werden kann als in Zellen, die nur den Leervektor exprimieren. Der $C_{T^{-}}$Wert für BL2pSG5 von 40,77 zeigt an, 
dass sich in diesen Zellen kein SOCS3 nachweisen lässt. Der Wert von 33,11 für die LMP1-exprimierenden Zellen weist hingegen deutlich auf ein Vorhandensein von SOCS3-Transkript hin. Dies konnte auch, wie in Abbildung 22b dargestellt, mittels konventioneller PCR beobachtet werden. Die SOCS3-spezifische PCR ergibt in den LMP1-exprimierenden Zellen eine Produktbande, welche in den Leervektortransfizierten Zellen nicht nachweisbar ist. Als Standard wurde die PCR mit ABLPrimern durchgeführt. Das Transkript des ABL-Gens zeigt keinen Unterschied in seiner Bandenintensität.

Tab. 24: Analyse der veränderten SOCS3-Expression mittels Real-Time-PCR

\begin{tabular}{lll}
\hline Zelllinie & $C_{T}$-Wert SOCS3 & $\Delta C_{T}$-Wert \\
\hline BL2pSG5 & 40,77 & 20,32 \\
BL2pSG5-LMP1 & 33,11 & 12,46 \\
\hline
\end{tabular}

\subsubsection{Die Überexpression von SOCS3 führt nicht zu einer vollständigen Hemmung von STAT3 in der EBV-positiven Burkitt-Lymphom- zelllinie BL36}

Um zu überprüfen, welchen Effekt eine Überexpression von SOCS3 auf die STAT3Aktivierung hat, wurde in BL36-Zellen SOCS3 exprimiert. Hierfür wurden die Zellen mit einem Expressionsplasmid für SOCS3 bzw. mit dem Leervektor transfiziert. 24h nach der Transfektion wurden die positiv-transfizierten Zellen mittels MACS angereichert und für weitere $24 \mathrm{~h}$ kultiviert. Anschließend wurden die Zellen geerntet und Protein isoliert, welches dann im Western Blot analysiert wurde. Das Ergebnis der Untersuchung ist in Abbildung 23 dargestellt. Die Überexpression ist deutlich an der starken SOCS3-Proteinbande erkennbar. Die Probe, die mit dem Kontrollvektor transfiziert wurde, zeigt eine nur sehr schwache Expression von SOCS3. Betrachtet man nun die Tyrosin-Phosphorylierung von STAT3, so ist zu erkennen, dass die Intensität der Proteinbande in der SOCS3-überexprimierenden Probe im Vergleich zur Kontrolle etwas schwächer ist. Die Proteinmenge von STAT3 ist bei beiden Proben vergleichbar, ebenso die Menge an Aktin. 


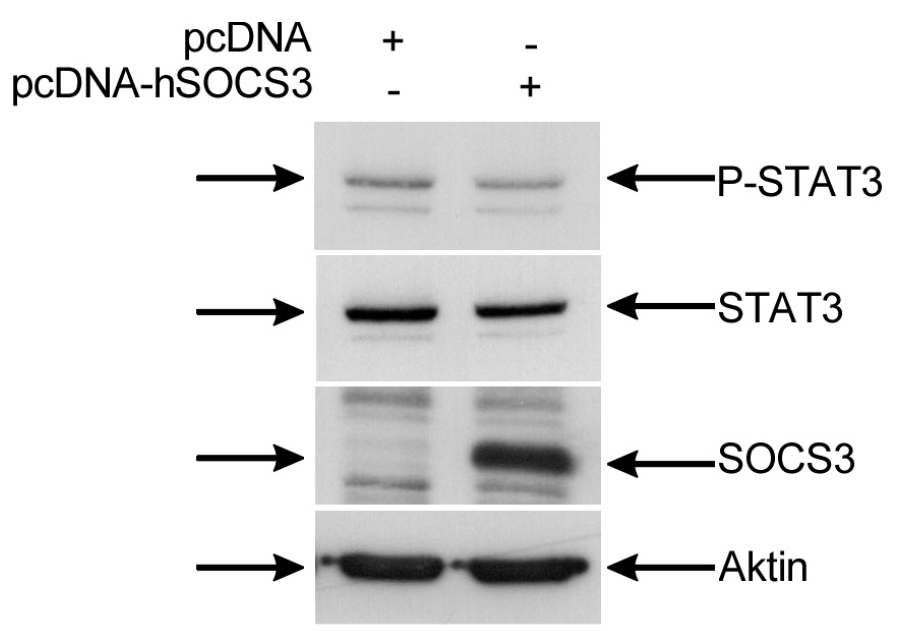

Abb. 23: SOCS3-Überexpression in BL36. Zur Analyse der SOCS3-Überexpression wurde die EBV-positive Burkitt-Lymphomzellinie BL36 mit einem Expressionsplasmid für humanes SOCS3 bzw. einem Kontrollplasmid transfiziert. Das aus den Zellen isolierte Protein wurde dann mittels SDS-PAGE, Western Blot und anschließender Immunfärbung untersucht. Die spezifischen Antikörper waren gegen P-STAT3, STAT3, SOCS3 und Aktin gerichtet.

\subsection{Der LMP1-abhängig aktivierte p38/MAPK-Signalweg beeinflusst die Regulation des Chemokins IP-10 und des Jak/STAT-Signalweges in Burkitt-Lymphomzelllinien}

Aus der Literatur ist bekannt, dass eine Expression von LMP1 in Burkitt-Lymphomzellen zur Induktion von IL-10 führt und dabei der p38/MAPK-Signalweg involviert ist (Vockerodt et al., 2001). Für das Chemokin IP-10 (Interferon- $\gamma$ induzierbares Protein-10kDa) wurde in Vorarbeiten gezeigt, dass eine Hemmung des p38/MAPKSignalweges einen Einfluss auf die LMP1-vermittelte IP-10-Aktivierung hat (Vockerodt et al., 2004) und dass NF- $\kappa$ B bei der Aktivierung des IP-10-Promotors durch LMP1 eine wichtige Rolle spielt.

\subsubsection{CD40 als funktionelles Homolog zu LMP1 reguliert NF- $\kappa$ B-abhän- gig den Promotor des Chemokins IP-10}

Es konnte ebenfalls gezeigt werden, dass es durch die LMP1-Expression zu einer Induktion von IP-10 in Lymphomzellen kommt (Vockerodt et al., 2004). Die Produktion von IP-10, die auch durch CD40 aktiviert wird, motivierte die Frage, ob 
CD40 als funktionelles Homolog zu LMP1 ebenfalls einen vergleichbaren Einfluss auf den IP-10-Promotor hat.

Um diese Frage zu klären, wurde die Burkitt-Lymphomzelllinie BL2 mit dem Repor-

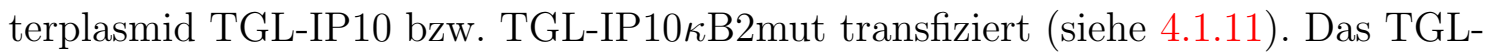
IP10-Plasmid kodiert für ein 435bp-Fragment des humanen IP-10-Promotors und enthält neben einer ISRE- auch zwei Bindungsstellen für NF- $\kappa$ B. Im Falle des TGLIP10 $\kappa$ B2mut-Reporterplasmids ist eine der beiden Bindungsstellen für NF- $\kappa \mathrm{B}$ mutiert (Majumder et al., 1998). Nach der Transfektion wurden die BL2-Zellen auf den adhärent wachsenden BHK- bzw. BHK-CD40L-Zellen für 24h kultiviert. Die BHK-CD40L-Zellen sekretieren den CD40-Liganden ins Medium, der dann auf der Oberfläche der BL2-Zellen binden und den CD40-Signalweg aktivieren kann. Die BHK-Zellen dienen hier der Kontrolle. Im Anschluss daran wurden die Zellen geerntet, das Pellet in Lysepuffer aufgenommen und die Luciferaseaktivität bestimmt (siehe 4.1.12). Die gemessene Luciferaseaktivität ist proportional zur Promotoraktivität. Das Ergebnis dieser Analyse ist in Abbildung 24 dargestellt. Die Höhe der

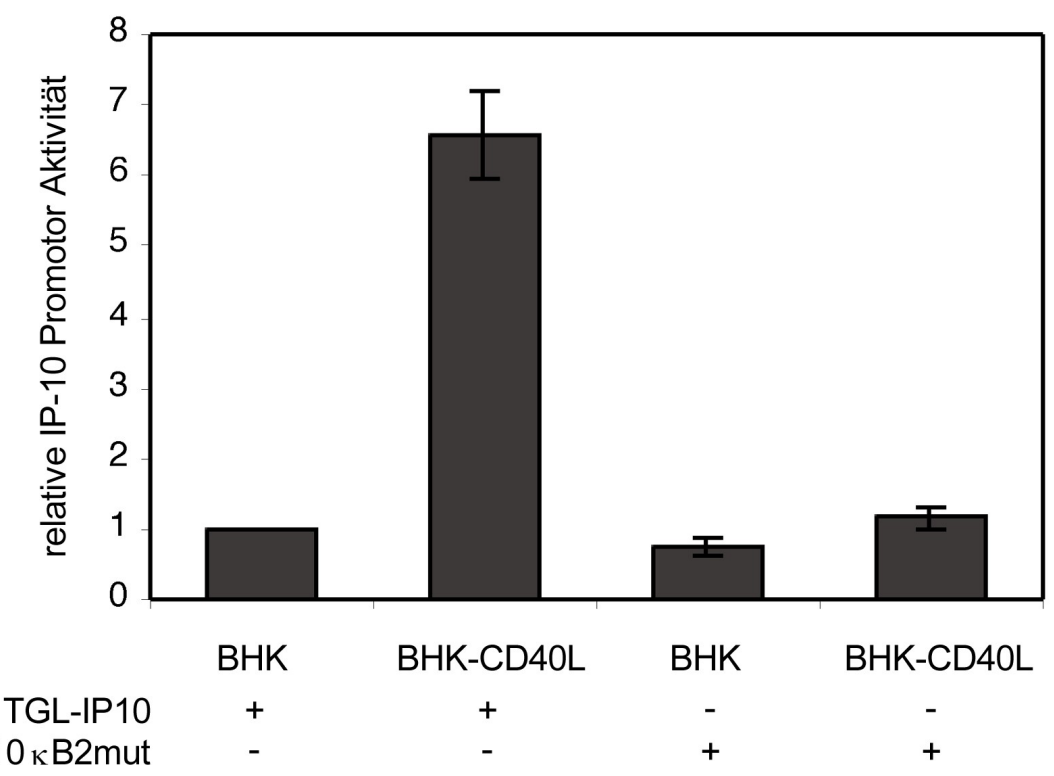

Abb. 24: CD40 reguliert NF- $\kappa$ B-abhängig den IP-10-Promotor. Die EBV-negative Burkitt-Lymphomzellinie BL2 wurde mit dem Reportergenplasmid für den IP-10-Promotor (TGLIP10) bzw. einem Plasmid mit einer Mutation in der NF- $\kappa$ B-Bindestelle innerhalb des Promotors (TGL-IP10 $\kappa$ B2mut) transfiziert. Anschließend wurden die Zellen für 24h in Anwesenheit von BHKbzw. BHK-CD40L-Zellen kultiviert. Nach der Zellernte erfolgte der Zellaufschluss und die Bestimmung der Promotoraktivität mit Hilfe des Luciferaseassays. 
einzelnen Balken zeigt die relative Promotoraktivität von IP-10 an. Die Transfektion der BL2-Zellen mit TGL-IP10 und die Kultivierung in Anwesenheit von BHKCD40L führt zur Aktivierung des Promotors im Vergleich zur Kultivierung auf den BHK-Zellen. Werden die BL2-Zellen hingegen mit TGL-IP10 $\kappa$ B2mut transfiziert, dann kommt es durch die mutierte NF- $\kappa$ B-Bindestelle im IP-10-Promotor nicht zu einer Aktivierung, wenn die Zellen mit BHK-CD40L kultiviert werden. Dieses Ergebnis deckt sich mit den Untersuchungen von Vockerodt et al. (2004) in Bezug auf die NF- $\kappa$ B-abhängige IP-10-Promotoraktivierung durch LMP1. Es konnte ebenfalls gezeigt werden, dass eine Inhibierung von p38/MAPK durch SB202190 keinen Einfluss auf die durch LMP1 induzierte Promotoraktivität von IP-10 hat (Vockerodt et al., 2004).

\subsubsection{LMP1 reguliert p38/MAPK-abhängig die mRNA-Stabilität von IP-10}

Der p38/MAPK-Signalweg spielt für die Aktivierung des IP-10-Promotors durch LMP1 keine Rolle (Vockerodt et al., 2004). Aufbauend auf diesen Daten sollte die Wirkung der LMP1-vermittelten p38/MAPK-Aktivierung auf die mRNA-Stabilität von IP-10 untersucht werden. Hierfür wurden BL2-Zellen mit LMP1 transfiziert und für 24h mit $2 \mu \mathrm{M}$ p38/MAPK-Inhibitor SB202190 bzw. als Kontrollansatz mit dessen Lösungsmittel DMSO kultiviert. Anschließend wurde die Transkription mit Hilfe von Actinomycin D $(10 \mu \mathrm{g} / \mathrm{ml})$ gestoppt und die Zellen zu definierten Zeitpunkten geerntet. Nach der Isolation der Gesamt-RNA aus den Zellen wurde diese in cDNA umgeschrieben und die Menge an IP-10-Transkript mittels Real-TimePCR bestimmt. Abbildung 25a zeigt den zeitlichen Verlauf der IP-10-RNA-Menge. Es ist deutlich zu erkennen, dass die mit SB202190 behandelten Proben bereits nach 15min nur noch 30\% der ursprünglichen IP-10-RNA-Menge aufweisen und sich nach 90min bei nur noch 10\% RNA befinden. Die Halbwertszeit der RNA beträgt somit weniger als 15min. Proben, die mit DMSO behandelt wurden, zeigen hingegen erst nach 240min eine Reduktion der IP-10-RNA um 40\%. Dieses Experiment wurde mit freundlicher Unterstützung von Dr. Dieter Kube durchgeführt.

Es konnte bereits gezeigt werden, dass p38/MAPK bei der IP-10-Aktivierung durch 
CD40 eine untergeordnete Rolle spielt (Vockerodt et al., 2004). Um zu überprüfen, ob der CD40-Signalweg die IP-10-mRNA durch p38/MAPK-vermittelte Stabilisierung beeinflusst, wurden BL2-Zellen durch die Kokultivierung mit BHK-CD40LZellen stimuliert. Diese Stimulierung von CD40 erfolgte für 3h mit SB202190 bzw. DMSO. Nach der Zugabe von Actinomycin D und der Zellernte zu definierten Zeitpunkten wurde auch hier die RNA isoliert und mittels Real-Time-PCR auf IP-10 untersucht. Das Ergebnis dieser Analyse wird in Abbildung 25b gezeigt. Die IP-10RNA der mit SB202190 behandelten Proben wird vergleichbar schnell zu der der LMP1-exprimierenden Zellen (vgl. Abb. 25a) abgebaut. Die Halbwertszeit der RNA beträgt ca. 15min. Nach 45min sind nur noch $10 \%$ der ursprünglichen RNA-Menge vorhanden. Die mit DMSO-behandelten Proben verhalten sich ganz anders als die LMP1-transfizierten BL2 Zellen. Der Abbau der RNA geht rascher voran und die Halbwertszeit beträgt weniger als eine Stunde, was deutlich macht, dass die Regulation der IP-10-mRNA-Stabilität durch CD40 nicht vorrangig über p38/MAPK läuft.

Die Spezifität des p38/MAPK-Inhibitors SB202190 wurde mit Hilfe des sogenannten „Pathfinder"-Systems untersucht. Hierbei wird indirekt die Aktivierung des p38/MAPK-Targetgens CHOP (C/EBP homologes Protein) untersucht. Hierfür wurde BL2 mit LMP1 bzw. pSG5, dem Reporterplasmid pFR-Luc oder dem Transaktivatorplasmid pFA-CHOP transfiziert. pFR-Luc besitzt ein Luciferasegen unter der Kontrolle des GAL4-Promotors. pFA-CHOP kodiert für ein Fusionsprotein bestehend aus GAL4dbd (GAL4-DNA-Bindedomäne) und CHOP. Wird dieses Fusionsprotein direkt oder indirekt durch Phosphorylierung aktiviert, dann bindet es als Dimer an den GAL4-Promotor und das Luciferasegen kann exprimiert werden. Die transfizierten BL2-Zellen wurden für 24h in Anwesenheit von SB202190 bzw. DMSO kultiviert. Nach der Zellernte wurde die Luciferaseaktivität (siehe 4.1.12) bestimmt. Das Ergebnis ist in Abbildung 26 dargestellt. Man erkennt, dass im Gegensatz zur Probe, die den Kontrollvektor pSG5 exprimiert, die Expression von LMP1 zur Aktivierung von p38 und damit auch von CHOP führt. Wurden die Proben hingegen mit SB202190 behandelt, dann reduziert sich die relative CHOP-Aktivierung sowohl in den pSG5- als auch in den LMP1-exprimierenden Zellen. Somit konnte gezeigt werden, dass die durch LMP1 aktivierte p38/MAPK durch SB202190 hemmbar ist. 
a)

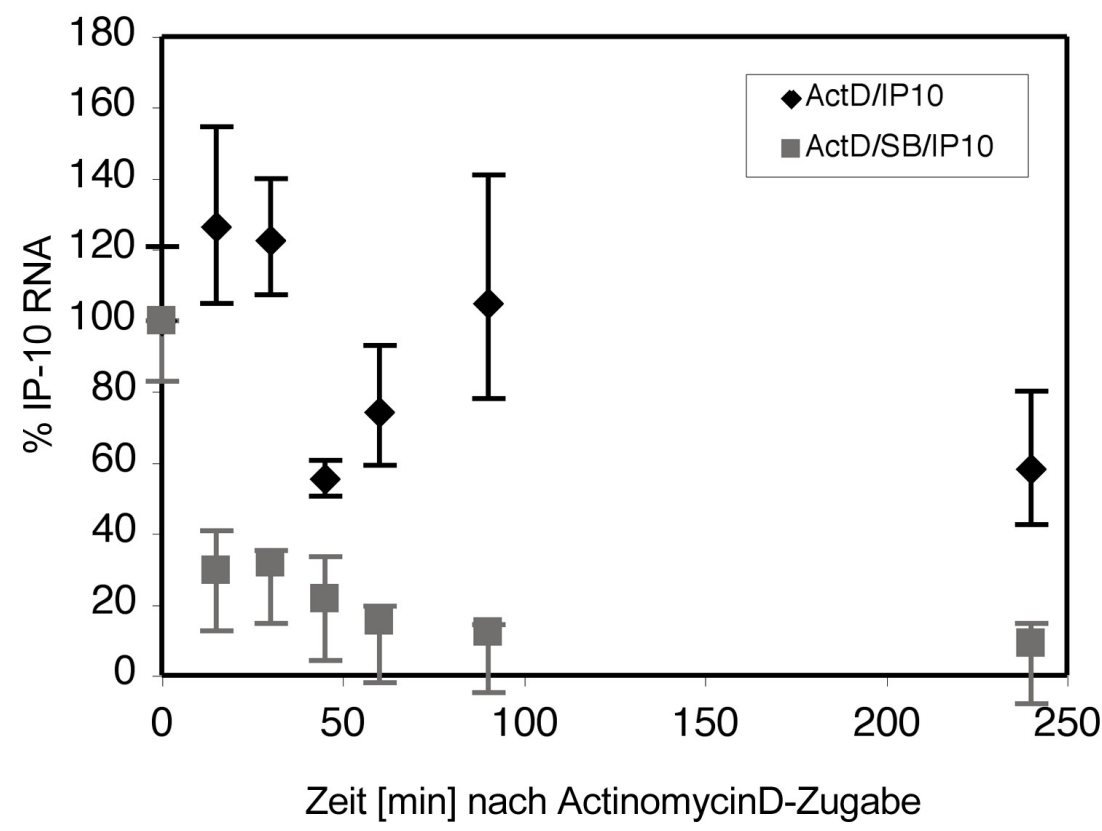

b)

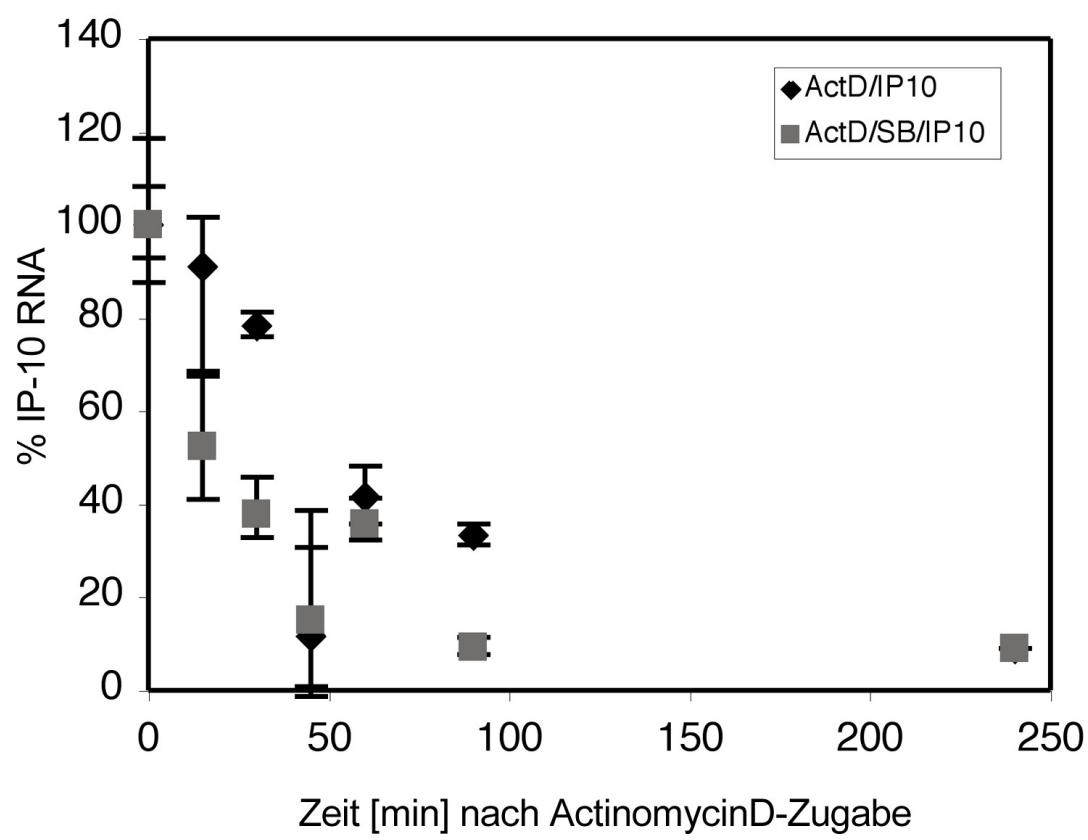

Abb. 25: LMP1-aktivierte p38/MAPK ist in die Stabilisierung der IP-10-mRNA involviert. Die EBV-negative Burkitt-Lymphomzelllinie BL2 wurde mit LMP1 transfiziert und für 24h mit SB202190 bzw. DMSO kultiviert. Anschließend wurden die Zellen für verschiedene Zeiten mit Actinomycin D behandelt und geerntet. Die isolierte RNA wurde nach der reversen Transkription mittels Real-Time-PCR auf IP-10-Transkript hin untersucht. Die Analyse der mRNA-Stabilität ist in a) dargestellt. In b) wurden die BL2-Zellen in Anwesenheit von BHK-CD40L-Zellen und SB202190 bzw. DMSO für 3h kultiviert. Nach der Actinomycin D-Zugabe wurden die Zellen, wie oben beschrieben, aufgearbeitet und ebenfalls mittels Real-Time-PCR analysiert. 


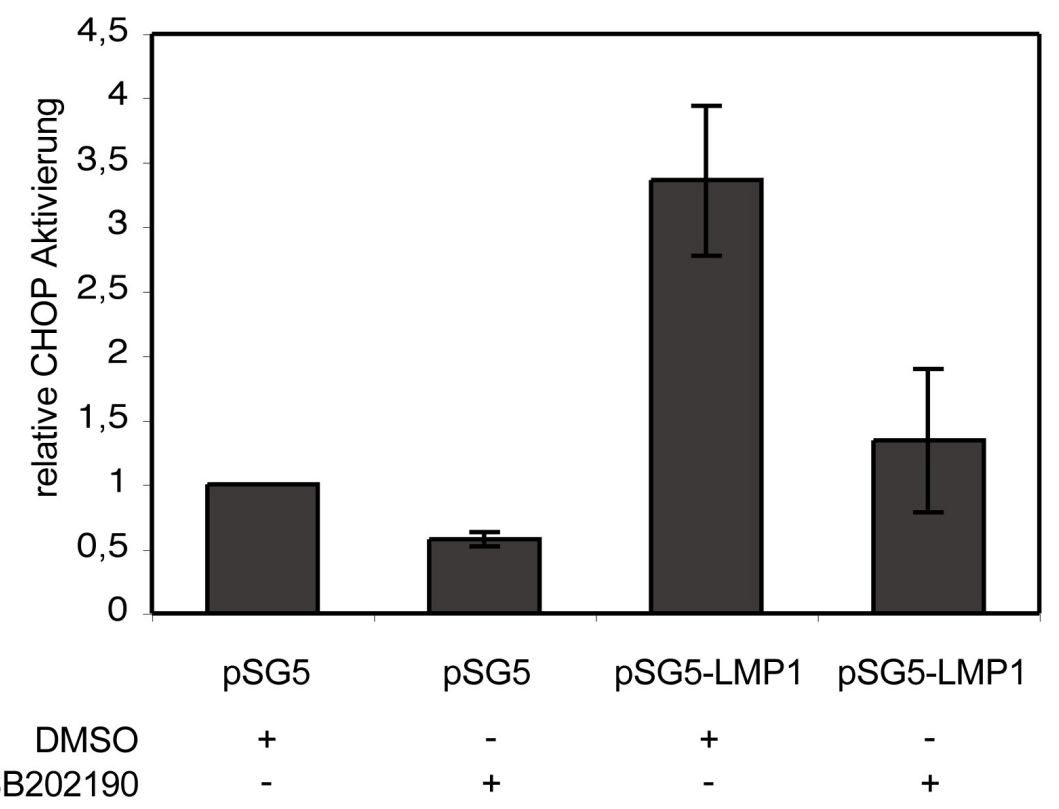

Abb. 26: Analyse der Spezifität des p38/MAPK-Inhibitors SB202190. BL2 wurde mit pSG5 (100ng) bzw. LMP1 (100ng), pFR-Luc (10 $\mu$ g) oder pFA-CHOP (500ng) transfiziert und für 24h mit SB202190 bzw. dessen Lösungsmittel DMSO kultiviert. Im Anschluss an die Zellernte wurde die Luciferaseaktivität und damit die relative CHOP-Aktivierung bestimmt.

\subsubsection{Der p38/MAPK-Inhibitor SB202190 beeinflusst den Jak/STAT- Signalweg in Burkitt-Lymphomzelllinien}

Durch den Einsatz des p38-spezifischen Inhibitors SB202190 sollte die Wirkung von fehlendem p38 auf verschiedene Proteine in EBV-positiven und -negativen BurkittLymphomzelllinien untersucht werden. Der Inhibitor wurde wie in 4.1 .7 beschrieben verwendet. In Abbildung 27 ist der Einfluss des p38-Inhibitors SB202190 auf die Expression von SOCS3 und die Aktivierung von STAT3 in verschiedenen EBVpositiven Burkitt-Lymphomzelllinien dargestellt. Um einen Einfluss des Lösungsmittels auszuschließen, wurden die Kontrollproben mit DMSO behandelt. Die HodgkinLymphomzelllinie HDLM2 diente als Positivreferenz für die SOCS3-Expression. Die vorhandene, aber sehr schwache SOCS3-Bande bei BL2B95-8 ist nach der SB202190Behandlung nicht mehr detektierbar. Bei BL36 und BL74 ist durch die Inhibierung von p38 ebenfalls eine Reduktion der SOCS3-Expression festzustellen. Diese Zellen zeigen zudem eine Abnahme der Tyrosin-Phosphorylierung von STAT3 bei gleichbleibendem Proteinlevel. Diese Reduktion von P-STAT3 ist bei BL2B95-8 weniger 


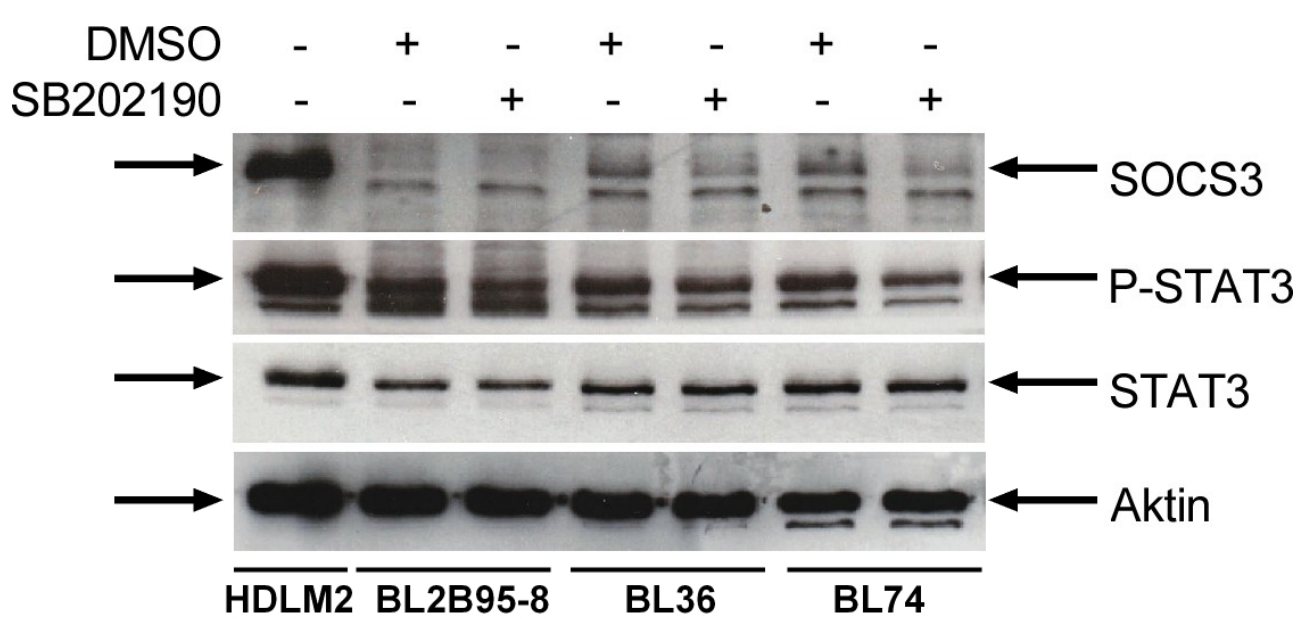

Abb. 27: Einfluss von SB202190 auf SOCS3 und P-STAT3. Die Burkitt-Lymphomzelllinien BL2B95-8, BL36 und BL74 wurden für 24 Stunden mit dem p38-Inhibitor SB202190 bzw. mit dessen Lösungsmittel DMSO behandelt. Anschließend wurden die Zellen geerntet und Protein isoliert, welches dann für die Western Blot-Analyse eingesetzt wurde. Die Immunfärbung erfolgte mit spezifischen Antikörpern gegen SOCS3, P-STAT3, STAT3 und Aktin. Die in Spur1 aufgetragene HDLM2 diente als Positiv-Kontrolle für die SOCS3-Expression.

stark ausgeprägt. Der Nachweis von Aktin in diesen Zellen diente der Kontrolle eines gleichmäßigen Probenauftrags.

\subsubsection{Der p38/MAPK-Inhibitor SB202190 beeinflusst die LMP1-indu- zierte Phosphorylierung von STAT3 und die SOCS3-Expression}

Nachdem der Einfluss von p38/MAPK auf die Expression von SOCS3 und auf die Tyrosin-Phosphorylierung von STAT3 nachgewiesen wurde (siehe Abb. 27), galt es die Rolle von LMP1 in diesem Prozess zu klären. Zu diesem Zweck wurde BL2 mit LMP1 bzw. dem entsprechenden Leervektor transfiziert und nach Anreicherung der Zellen für 24h mit dem spezifischen p38-Inhibitor SB202190 bzw. dem Lösungsmittel DMSO inkubiert. Das Ergebnis der Analyse der SOCS3-Expression auf RNA-Ebene ist in Abbildung 28 dargestellt. Die BL2-Zellen, die mit LMP1 transfiziert wurden und dieses virale Protein exprimieren, zeigen eine deutliche SOCS3-mRNAExpression. In den Zellen, die mit dem Kontrollvektor transfiziert wurden, lässt sich hingegen keine SOCS3-mRNA nachweisen. Die Intensität der SOCS3-Banden der LMP1-exprimierenden Proben weisen Unterschiede hinsichtlich ihrer Behandlung mit dem p38-Inhibitor bzw. DMSO auf. So zeigt die LMP1-exprimierende Probe 


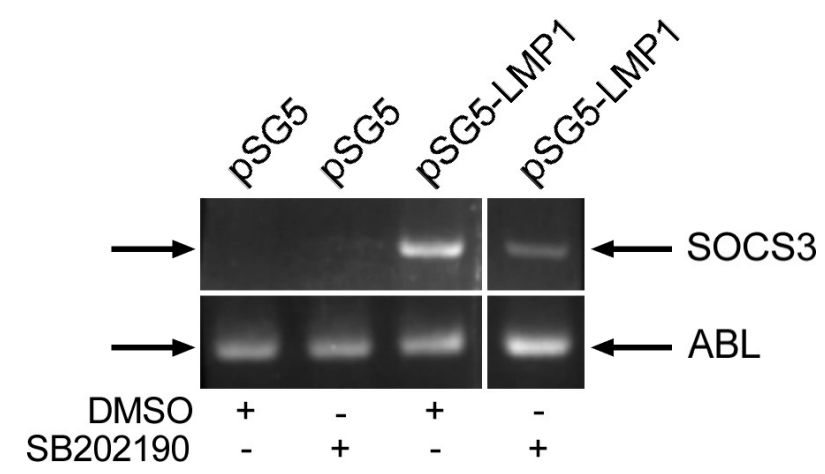

Abb. 28: Einfluss von SB202190 auf SOCS3. Die Burkitt-Lymphomzelllinie BL2 wurde mit LMP1 bzw. dem Kontrollvektor pSG5 transfiziert. Nach 24h wurden die Zellen durch MACS angereichert und für weitere 24h in Anwesenheit von SB202190 bzw. DMSO kultiviert. Die Zellen wurden geerntet und die isolierte RNA in cDNA umgeschrieben. Letztere diente als Grundlage für die PCR mit SOCS3-spezifischen Primern.

nach der SB202190-Behandlung ein deutlich schwächeres SOCS3-PCR-Produkt im Vergleich zur DMSO-behandelten Probe. Der Nachweis von ABL diente der Kontrolle und zeigt, dass das spezifische PCR-Produkt in allen Proben miteinander vergleichbar ist.

Derselbe experimentelle Ansatz wurde ebenfalls verwendet, um den Einfluss von SB202190 auf die von LMP1 induzierte Tyrosin-Phosphorylierung von STAT3 zu untersuchen. In Abbildung 29 ist das Ergebnis als Western Blot-Analyse dargestellt. Die mit LMP1-transfizierten BL2 Zellen zeigen im Gegensatz zu den Zellen, die den Kontrollvektor erhalten haben, eine Tyrosin-Phosphorylierung von STAT3 bei vergleichbarem STAT3-Proteinniveau. Die Behandlung der Zellen mit dem spezifischen p38-Inhibitor zeigt bei den LMP1-exprimierenden Zellen eine Reduktion in der Tyrosin-Phosphorylierung im Vergleich zur DMSO-behandelten Probe. Die Immunfärbung auf Aktin diente als Kontrolle für einen gleichmäßigen Probenauftrag. 


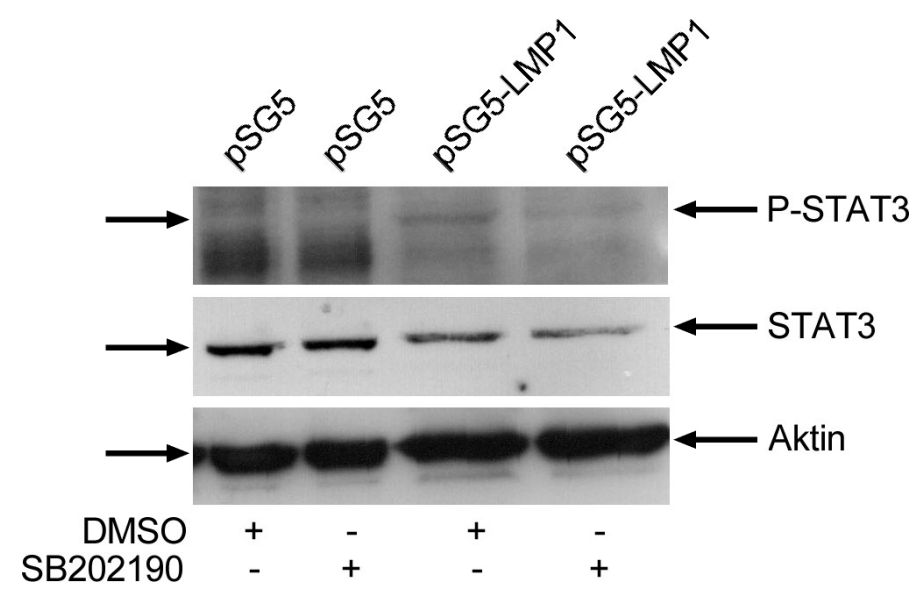

Abb. 29: Einfluss von SB202190 auf P-STAT3. Die Burkitt-Lymphomzellinie BL2 wurde mit LMP1 bzw. dem Kontrollvektor pSG5 transfiziert. Nach 24h wurden die Zellen durch MACS angereichert und für weitere 24h in Anwesenheit von SB202190 bzw. DMSO kultiviert. Die Zellen wurden geerntet und das isolierte Protein wurde für die Western Blot-Analyse eingesetzt. Die Immunfärbung erfolgte mit spezifischen Antikörpern gegen P-STAT3, STAT3 und Aktin.

\subsubsection{Die SOCS3-mRNA wird EBV-abhängig über p38/MAPK stabili- siert}

Aus der Literatur ist bekannt, dass p38/MAPK die Stabilität der mRNA beeinflussen kann (Holtmann et al., 1999; Dean et al., 1999). Es stellte sich daher die Frage, ob der durch LMP1 verstärkt induzierte p38/MAPK-Signalweg einen Einfluss auf die Stabilität der SOCS3-mRNA besitzt. Für diese Untersuchung wurde die EBV-positive, LMP1-exprimierende Burkitt-Lymphomzellinie BL36, wie in 4.1.7 beschrieben, für 24h mit SB202190 bzw. DMSO behandelt. Anschließend wurde der Transkriptionsinhibitor Actinomycin D zu den Zellen gegeben. Diese wurden nach definierten Zeitpunkten geerntet und die RNA isoliert. Nach dem Umschreiben der RNA in cDNA wurde diese sowohl für die Analyse mittels Real-Time-PCR als auch mittels konventioneller PCR eingesetzt.

Das Ergebnis der quantitativen Real-Time-PCR-Analyse ist in Abbildung 30 dargestellt. Die Graphik zeigt die prozentuale Abnahme der mRNA über die Zeit in Abhängigkeit von der Art der Behandlung der Zellen. Die hellgrauen Quadrate zeigen den Verlauf der Kontroll-Proben, die mit DMSO behandelt wurden. Die schwarzen Rhomben stellen den Verlauf für die Proben dar, die SB202190 erhalten haben. Zum Zeitpunkt Null weisen beide Proben die gleiche Menge an SOCS3-RNA auf. 


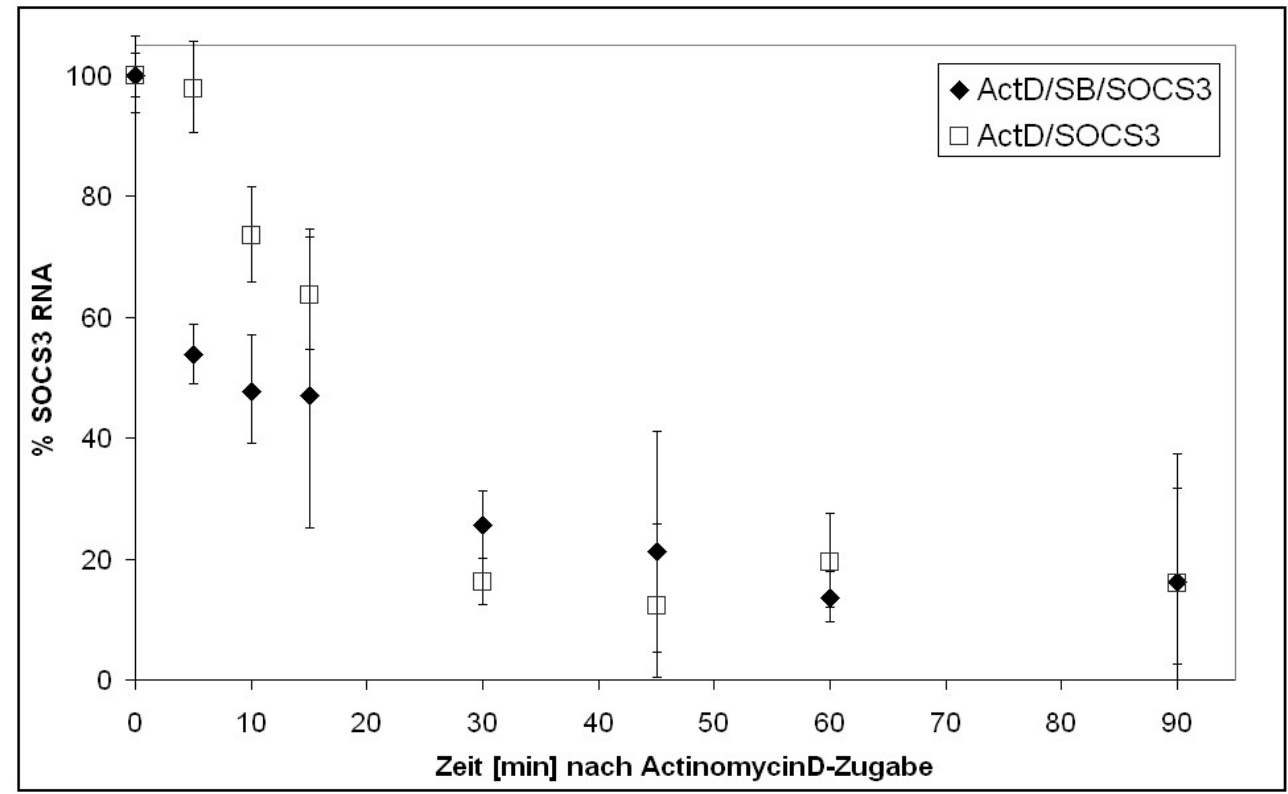

Abb. 30: p38/MAPK beeinflusst die mRNA-Stabilität von SOCS3. Nach der Behandlung der Burkitt-Lymphomzelllinie BL36 für 24h mit dem spezifischen p38/MAPK-Inhibitor SB202190 bzw. dessen Lösungsmittel DMSO wurden die Zellen mit Actinomycin D zur Inhibierung der Transkription versetzt und die Zellen nach definierten Zeitpunkten geerntet. Die aus diesen Zellen isolierte RNA wurde mittels reverser Transkription in cDNA umgeschrieben und mittels Real-Time-PCR analysiert. Die graphische Darstellung zeigt den zeitlichen Verlauf der SOCS3-mRNA-Menge. Die Abnahme der mRNA weist Unterschiede je nach Art der Behandlung der Zellen mit SB202190 oder DMSO auf.

Bereits fünf Minuten nach Inhibierung der zellulären Transkription unterscheidet sich die Menge an SOCS3-RNA deutlich. So enthält die mit SB202190 behandelte Probe $44 \%$ weniger RNA als die entsprechende Kontrolle. Nach 10min enthalten die SB202190-behandelten Zellen nur noch 50\% der ursprünglichen RNA-Menge. Während der ersten 30min ist die Menge an RNA in den SB202190-behandelten Proben stets geringer als in den DMSO-behandelten Proben. Danach nähern sich die RNA-Mengen einander an.

\subsection{Der Einfluss von LMP1 auf die Zytokinsignalwege trans- formierter B-Lymphozyten}

Das virale Protein LMP1 ist in der Lage, eine Vielzahl von Zytokinen zu aktivieren. Neben IL-6 und IL-10 sind dies die Tumor-Nekrosefaktoren $\alpha$ und $\beta$ (TNF- $\alpha$, TNF- $\beta$ ), Interferone (IFN- $\gamma$ ) und Chemokine (IL-8, IP-10) (Eliopoulos et al., 1999b; 
Nakagomi et al., 1994; Ho et al., 1999; Thompson et al., 2003; Vockerodt et al., 2001; Najjar et al., 2005).

\subsubsection{LMP1 aktiviert die IL-6- und IL-10-Produktion in Burkitt-Lym- phomzelllinien}

Die IL-6- und IL-10-Produktion wurde in Abhängigkeit von der LMP1-Expression untersucht. Die EBV-negative Burkitt-Lymphomzelllinie BL2 wurde mit WildtypLMP1 (pSG5-LMP1), den mutierten Varianten LMP1 CTAR1mut, LMP1 CTAR2mut und LMP1 CTAR1/2mut (siehe 5.2) bzw. als Kontrolle mit dem Leerplasmid pSG5 transfiziert. Nach der Anreicherung der Zellen und weiteren 24h Kultivierung wurde der Zellüberstand für die Analyse der Zytokine im ELISA (siehe 4.2.4) eingesetzt.

Tabelle 25 zeigt sehr deutlich, dass weder die Zellen, die das Kontrollplasmid erhalten, noch die, welche die LMP1-Proteine mit mutiertem C-Terminus exprimieren, eine nachweisbare Produktion von IL-6 aufweisen. Nur die Expression von WildtypLMP1 führt zu einer Induktion von IL-6 in diesen Zellen in Höhe von 63,34pg/ml.

Tab. 25: Analyse der IL-6-Produktion in transfizierten BL2-Zellen

\begin{tabular}{ll}
\hline Probe & IL-6 [pg/ml] \\
\hline BL2pSG5 & 0 \\
BL2pSG5-LMP1 & 63,34 \\
BL2pSG5-LMP1 CTAR1mut & 0 \\
BL2pSG5-LMP1 CTAR2mut & 0 \\
BL2pSG5-LMP1 CTAR1/2mut & 0 \\
\hline
\end{tabular}

Die Abhängigkeit der IL-6-Produktion von EBV bzw. der Expression von LMP1 wird deutlich, wenn man die IL-6-Produktion der Burkitt-Lymphomzelllinien BL2, BL2P3HR1, BL2B95-8, BL30, BL30P3HR1 und BL30B95-8 miteinander vergleicht. Diese Untersuchung ist in Abbildung 31 dargestellt. Von den sechs analysierten Zellen kann nur in den LMP1-exprimierenden BL2B95-8 und BL30B95-8 eine IL-6Produktion nachgewiesen werden. 


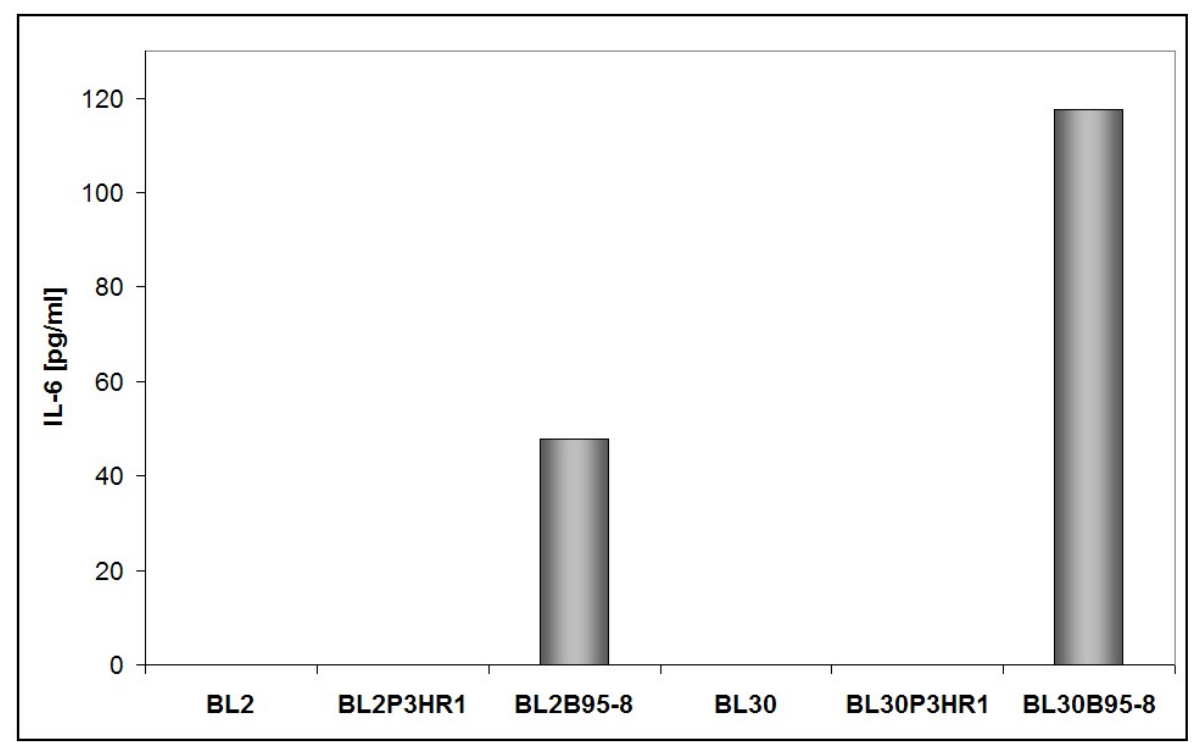

Abb. 31: IL-6-ELISA. Von den Burkitt-Lymphomzelllinien BL2, BL2P3HR1, BL2B95-8, BL30, BL30P3HR1 und BL30B95-8 wurde der Zellkulturüberstand geerntet und die Menge an IL-6 mittels ELISA bestimmt.

In der Literatur wurde bereits beschrieben, dass bei der LMP1-abhängigen IL-6-Produktion p38/MAPK eine Rolle spielt (Eliopoulos et al., 1999b). Gibt man zur EBV-positiven Burkitt-Lymphomzelllinie BL74 für 24h den spezifischen p38Inhibitor SB202190, dann reduziert sich die IL-6-Produktion drastisch. Dieses Verhalten ist in Abbildung 32 dargestellt. Die ELISA-Daten zeigen für die mit DMSO behandelte Probe eine IL-6-Menge von 62pg/ml. Nach Zugabe von SB202190 sinkt dieser Wert auf $5 \mathrm{pg} / \mathrm{ml}$ ab.

Die Analyse des zweiten Zytokins IL-10 erfolgte ebenfalls aufgrund der Fragestellung, in wie weit LMP1 dessen Aktivierung beeinflusst. Hierfür wurde die EBV-negative Burkitt-Lymphomzelllinie BL2 mit LMP1wt, den mutierten Varianten LMP1 CTAR1mut, LMP1 CTAR2mut und LMP1 CTAR1/2mut transfiziert. Als Kontrolle wurde der Leervektor pSG5 mitgeführt. Die Zellen wurden 24h nach der Transfektion angereichert und für weitere $24 \mathrm{~h}$ kultiviert. Der Zellkulturüberstand wurde dann für die Bestimmung der IL-10-Menge mittels IL-10-spezifischen ELISAs eingesetzt. Die Daten sind in Tabelle 26 zusammengefasst. Man erkennt, dass sowohl in der Kontrollprobe als auch in den Zellen, die LMP1 CTAR1mut bzw. LMP1 CTAR1/2mut exprimieren, kein IL-10 nachweisbar ist. Im Gegensatz dazu weisen die Zellen, die LMP1 CTAR2mut exprimieren, eine IL-10-Menge von 137pg/ml auf. Die Expression 


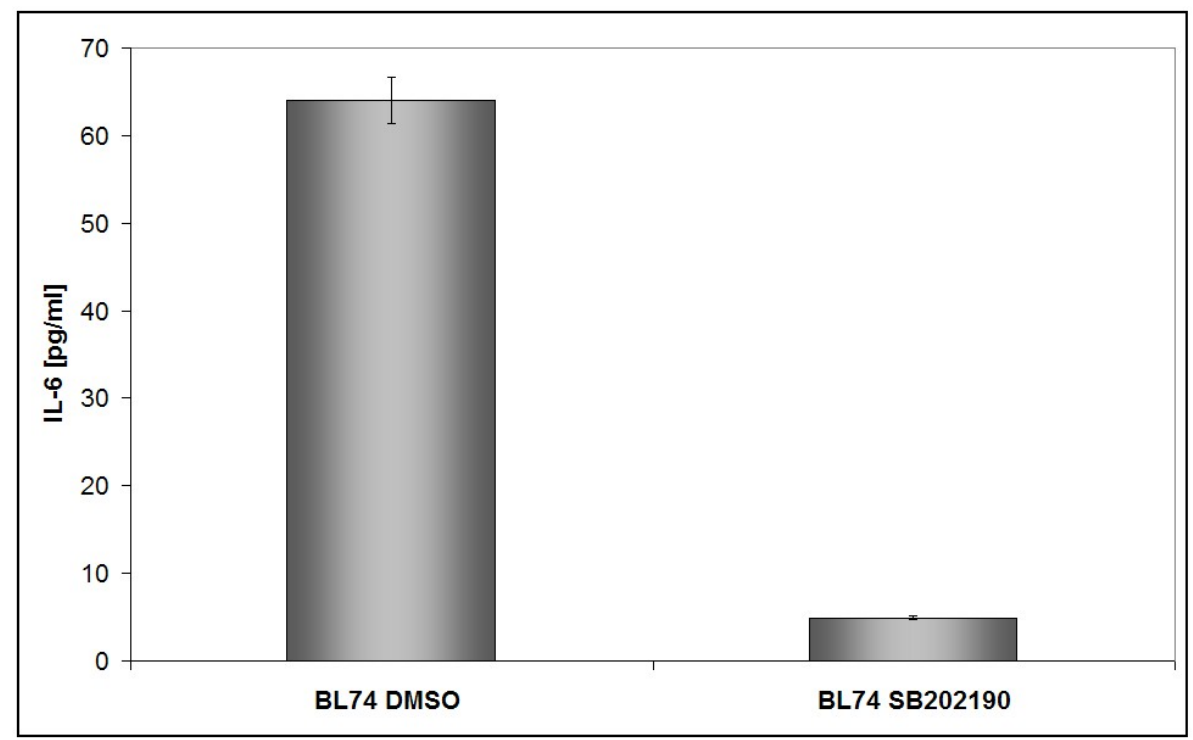

Abb. 32: p38/MAPK beeinflusst die IL-6-Produktion. Die Zelllinie BL74 wurde für 24h mit dem p38-Inhibitor SB202190 bzw. dessen Lösungsmittel DMSO als Kontrollansatz behandelt. Anschließend wurde der Zellkulturüberstand geerntet und die Menge an IL-6 mittels ELISA bestimmt.

von Wildtyp-LMP1 führt zur größten IL-10-Produktion $(337 \mathrm{pg} / \mathrm{ml})$.

Tab. 26: Analyse der IL-10-Produktion in transfizierten BL2-Zellen

\begin{tabular}{ll}
\hline Probe & $\mathrm{IL}-10[\mathrm{pg} / \mathrm{ml}]$ \\
\hline BL2pSG5 & 0 \\
BL2pSG5-LMP1 & 337,3 \\
BL2pSG5-LMP1 CTAR1mut & 0 \\
BL2pSG5-LMP1 CTAR2mut & 136,74 \\
BL2pSG5-LMP1 CTAR1/2mut & 0 \\
\hline
\end{tabular}

\subsubsection{Die Wirkung von Zytokinen auf STAT3 und SOCS3 in Burkitt- Lymphomzelllinien}

Im Anschluss an die vorangegangenen Untersuchungen galt es die Frage zu klären, welchen Einfluss eine Zugabe von IL-6 und IL-10 auf EBV-positive und -negative Burkitt-Lymphomzelllinien hat. Die Zellen wurden, wie in 4.1 .8 beschrieben, für 30min mit IL-6 bzw. IL-10 behandelt. Anschließend wurden Protein und RNA aus den Zellen isoliert und analysiert. 
In Abbildung 33a ist die Western Blot-Analyse der EBV-negativen Burkitt-Lymphomzellinie BL2 dargestellt. Die Analyse des Tyrosin-Phosphorylierungsstatus von STAT3 zeigt, dass auch nach IL-6-Zugabe keine Aktivierung von STAT3 nachweisbar ist. Der Zusatz von IL-10 führt hingegen in der EBV-negativen Zelllinie zur Tyrosin-Phosphorylierung von STAT3. Die Proteinkonzentration von STAT3 ist in dieser Probe ebenfalls etwas erhöht. Die unbehandelte und die mit IL-6 behandelte Probe weisen ein vergleichbares Niveau an STAT3 auf. In den BL2-Zellen konnte kein SOCS3-Protein detektiert werden. Als Kontrolle für einen gleichmäßigen Probenauftrag wurde Aktin in den Zellen nachgewiesen.

In Abbildung 33b ist die Analyse des SOCS3-Transkripts mittels PCR dargestellt. Bei gleichbleibender Bandenintensität des Kontrollgens ABL zeigen die BL2-Zellen nur nach IL-10-Zugabe eine SOCS3-Bande. Weder in der unbehandelten Probe noch nach IL-6-Zugabe ist SOCS3-Transkript nachweisbar.

Analog zu den EBV-negativen Burkitt-Lymphomzelllinien galt es auch für die EBVpositiven Burkitt-Lymphomzelllinien zu klären, wie diese auf die Zugabe von Zytokinen reagieren. Hierfür wurden die Zelllinien BL36 und BL74 ebenfalls mit IL-6 bzw. IL-10 behandelt und mittels Western Blot analysiert. In Abbildung 34a ist das Ergebnis für BL36 dargestellt. Diese Zelllinie weist bereits im unbehandelten Zustand
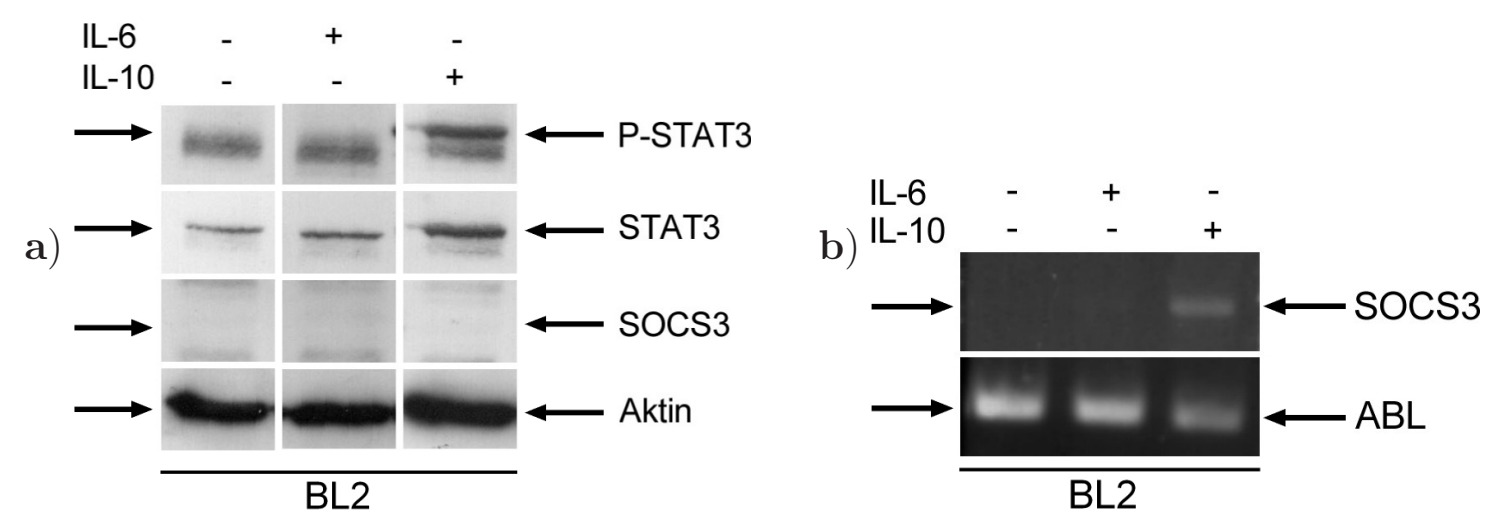

Abb. 33: Zytokinstimulation der EBV-negativen Burkitt-Lymphomzellinie BL2. Die BL2-Zellen wurden für 30min mit 100ng/ml Zytokin behandelt und anschließend geerntet, um daraus Protein und RNA zu isolieren. In a) ist die Western Blot-Analyse für unbehandelte bzw. mit IL-6 oder IL-10 behandelte BL2-Zellen dargestellt. Die Immunfärbung erfolgte mit den spezifischen Antikörpern gegen P-STAT3, STAT3, SOCS3 und Aktin. b) zeigt den Nachweis des SOCS3Transkripts mittels PCR. Der Nachweis einer gleichmäßigen Bandenintensität des ABL-Transkripts erlaubt es, die Proben untereinander zu vergleichen. 
eine Tyrosin-Phosphorylierung von STAT3 auf. Nach der Zugabe von IL-6 bzw. IL-10 wird diese Phosphorylierung noch verstärkt, wobei IL-10 eine größere Auswirkung auf die Aktivierung von STAT3 hat. Die Proteinkonzentration von STAT3 ist in allen Proben vergleichbar. Dies trifft ebenfalls auf den Nachweis von Aktin zu. SOCS3-Protein war in allen Proben nachweisbar, wobei die intensivste SOCS3Proteinbande in der mit IL-10 behandelten Probe zu finden ist.

Die Untersuchung der EBV-positiven Burkitt-Lymphomzellinie BL74, welche analog zu den Analysen für BL2 und BL36 durchgeführt wurde, wird in Abbildung 34b gezeigt. Auch diese Zelllinie weist bereits ohne Zytokinzugabe eine Aktivierung

a)
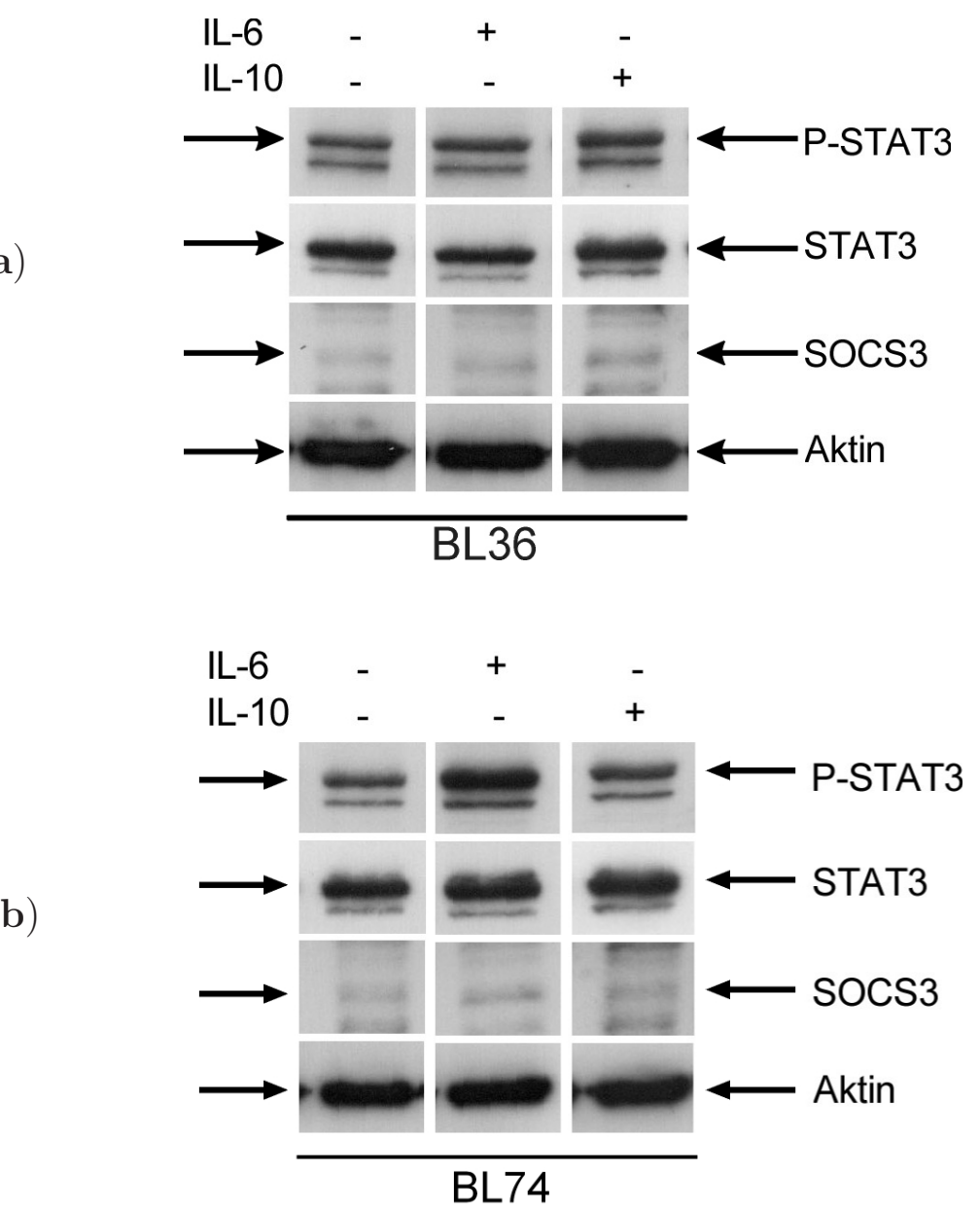

Abb. 34: Zytokinstimulation der EBV-positiven Burkitt-Lymphomzellinien BL36 und BL74. Die EBV-positiven Burkitt-Lymphomzelllinien BL36 und BL74 wurden für 30min mit 100ng/ml IL-6 bzw. IL-10 behandelt. Aus den geernteten Zellen wurde das Gesamtprotein isoliert und mittels Western Blot analysiert. Der Proteinnachweis erfolgte mit spezifischen Antikörpern gegen P-STAT3, STAT3, SOCS3 und Aktin. 
von STAT3 auf. Diese lässt sich jedoch durch die Zugabe der Zytokine IL-6 und IL-10 noch verstärken. Im Gegensatz zu BL36 ist die Tyrosin-Phosphorylierung von STAT3 bei BL74 nach der Zugabe von IL-6 am stärksten. Die STAT3-Proteinkonzentration ist in allen Proben vergleichbar. Auch der Nachweis von Aktin als Kontrolle für einen gleichmäßigen Probenauftrag zeigt in allen Proben eine vergleichbare Bandenintensität. Das SOCS3-Protein konnte ebenfalls in allen Proben nachgewiesen werden, wobei die SOCS3-Bande bei der mit IL-6 behandelten Probe am stärksten ausgeprägt scheint.

\subsubsection{Der Einfluss von neutralisierenden Antikörpern in EBV-positiven Burkitt-Lymphomzelllinien}

Nachdem untersucht wurde, welche Effekte die Stimulation mit den Zytokinen IL-6 und IL-10 auf EBV-positive und EBV-negative Zellinien hat, schließt sich konsequenterweise die Frage an, was eine Hemmung dieser Signalwege bewirkt. Dafür wurden, wie in 4.1.8 beschrieben, neutralisierende Antikörper eingesetzt. Um den IL-6-Signalweg zu hemmen, wurde ein Antikörper verwendet, der gegen die signalgebende $\beta$-Untereinheit (gp130) des IL-6-Rezeptors gerichtet ist. Für die Inhibierung des IL-10-Signalweges wurde ebenfalls ein neutralisierender Antikörper verwendet. Als Kontrollansatz diente die so genannte Isotyp-Kontrolle. Hierbei handelt es sich um einen Antikörper, der unspezifisch gegen $\operatorname{IgG}$ gerichtet ist. Somit lassen sich unspezifische Effekte der neutralisierenden Antikörper ausschließen. Für diese Untersuchung wurden die EBV-positiven Burkitt-Lymphomzellinien BL36 und BL74 eingesetzt. Die Zellen wurden 24h mit den neutralisierenden Antikörpern behandelt. Anschließend wurde aus den geernteten Zellen Protein und RNA isoliert.

Die Western Blot-Analyse der beiden Zelllinien ist in Abbildung 35 dargestellt. Der Western Blot für BL74 in Abb. 35a zeigt nach Inhibierung des IL-10-Signalweges eine Reduktion der Tyrosin-Phosphorylierung und des Proteinlevels von STAT3. Sowohl die Isotyp-Kontrolle als auch die zur Inhibierung des IL-6 Signalweges mit dem anti-gp130-Antikörper behandelten Zellen weisen keine Veränderungen in der Aktivierung oder der Proteinkonzentration von STAT3 auf. Dies trifft ebenfalls für den Nachweis von SOCS3 zu. Lediglich in der anti-IL-10-behandelten Probe kommt es 
zu einer leichten Reduktion der SOCS3-Proteinbande. Die Immunfärbung auf Aktin, die für alle drei Proben die gleiche Intensität aufweist, bestätigt den gleichmäßigen Probenauftrag während der Untersuchung.

In Abbildung 35b ist die Analyse der EBV-positiven Burkitt-Lymphomzelllinie BL36 dargestellt. Die Zelllinie wurde mit neutralisierenden Antikörpern (anti-IL-10, antigp130) bzw. der Isotyp-Kontrolle behandelt. Eine deutliche Reduktion der TyrosinPhosphorylierung von STAT3 kann nach der Zugabe von anti-IL-10 beobachtet werden. Eine Abnahme von SOCS3-Protein ist durch die Gabe von anti-IL-10 ebenfalls erkennbar. Die STAT3-Proteinmenge ist in allen Proben unverändert. Es ist ebenfalls zu sehen, dass sowohl die Inhibierung des IL-6-Signalweges als auch die Behandlung

a)
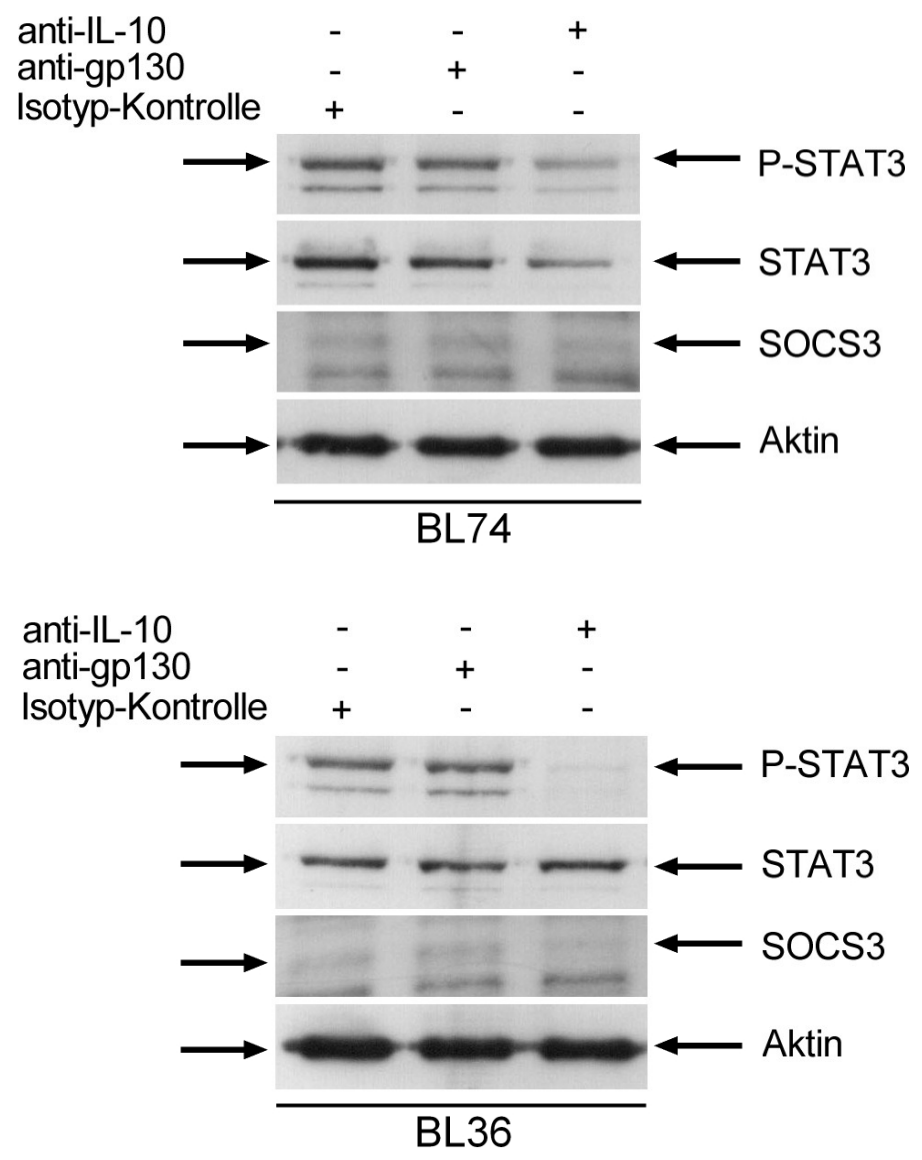

Abb. 35: Inhibierung der Zytokinsignalwege durch neutralisierende Antikörper. Die EBV-positiven Burkitt-Lymphomzelllinien BL36 und BL74 wurden für 24h mit $200 \mu \mathrm{g} / \mathrm{ml}$ antiIL-10-, anti-gp130-neutralisierenden Antikörpern bzw. der Isotyp-Kontrolle behandelt. Nach der Zellernte wurde das Gesamtprotein isoliert und mittels Western Blot analysiert. Die Immunfärbung erfolgte mit spezifischen Antikörpern gegen P-STAT3, STAT3, SOCS3 und Aktin. 
der Zellen mit der Isotyp-Kontrolle zu keiner Änderung der Aktivierung von STAT3 oder der Proteinmenge von SOCS3 führt. Der Nachweis von Aktin weist auf einen gleichmäßigen Probenauftrag hin, da keine Intensitätsunterschiede sichtbar sind.

Der Einfluss der neutralisierenden Antikörper auf das Transkript von SOCS3 wurde ebenfalls in den beiden Zelllinien BL36 und BL74 untersucht. Nach Behandlung und Ernte der Zellen wurde die RNA isoliert. Diese wurde mittels reverser Transkription in cDNA umgeschrieben und das SOCS3-Gen mit spezifischen Primern in einer PCR-Reaktion amplifiziert. Das Ergebnis dieser Analyse ist in Abbildung 36 dargestellt. Abbildung 36a zeigt für die BL36-Zellen eine Abnahme der SOCS3Transkriptmenge nach Zugabe des anti-IL-10-Antikörpers zur Zellkultur. Die Inhibierung des IL-6-Signalweges hat keinen Einfluss auf die SOCS3-Transkriptmenge, wenn man diese mit den Zellen, die die Isotyp-Kontrolle erhalten haben, vergleicht. In Abbildung 36b wird dieselbe Untersuchung für die BL74-Zellen gezeigt. Es wird deutlich, dass weder die Behandlung der Zellen mit anti-gp130 noch mit anti-IL-10 eine Änderung der SOCS3-Bandenintensität bewirkt. Die Amplifikation des ABLGens diente dem Nachweis, dass alle PCR-Ansätze die gleiche Konzentration an cDNA enthielten. Die gleichmäßige Bandenstärke des ABL-Transkripts in beiden Zelllinien zeigt, dass diese Voraussetzung erfüllt war.
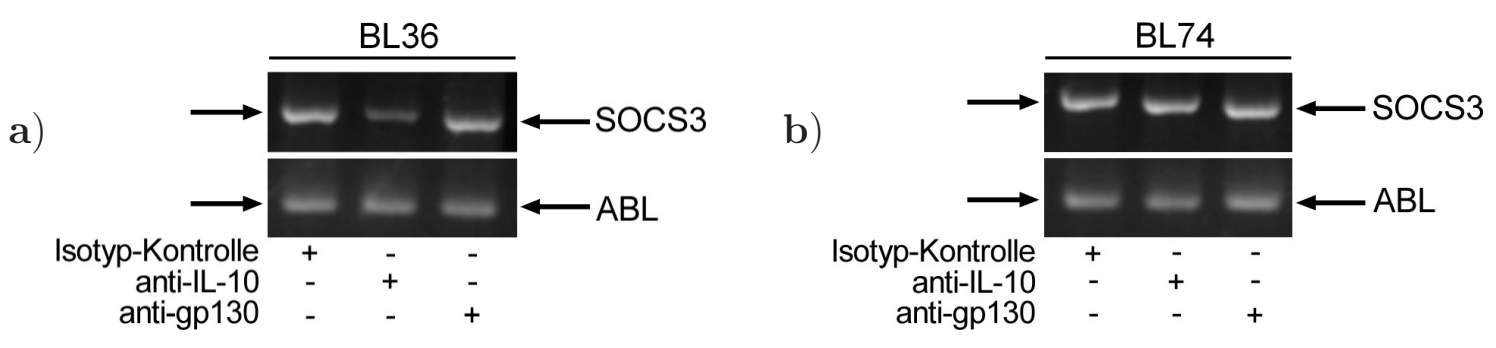

Abb. 36: Inhibierung der Zytokinsignalwege durch neutralisierende Antikörper: Analyse des SOCS3-Transkripts. Die EBV-positiven Burkitt-Lymphomzelllinien BL36 und BL74 wurden für 24h mit $200 \mu \mathrm{g} / \mathrm{ml}$ anti-IL-10- oder anti-gp130-neutralisierenden Antikörpern bzw. der Isotyp-Kontrolle behandelt. Nach der Zellernte wurde die Gesamt-RNA isoliert und mittels reverser Transkription in cDNA umgeschrieben. Diese wurde daraufhin mit spezifischen Primern in einer PCR-Reaktion auf das Vorhandensein von SOCS3 und ABL hin untersucht. 


\section{Diskussion}

Ein Zusammenhang zwischen einer EBV-Infektion und dem Auftreten einer Tumorerkrankung kann vor allem in Burkitt-Lymphomen, Hodgkin-Lymphomen und Nasopharynx-Karzinomen beobachtet werden. Eine entscheidende Rolle bei der Transformation von EBV-infizierten Zellen spielt das virale Onkogen Latentes Membran Protein 1 (LMP1). LMP1 besitzt funktionelle Homologien zu den TNF- und Toll-like-Rezeptoren und aktiviert Signalwege, die unter anderem die Apoptoseneigung, Wachstum und Differenzierung der Zelle beeinflussen. Zu den bereits intensiv erforschten Signalwegen gehören der NF- $\kappa$ B-Signalweg und die Signalwege der MAPK-Familie. Zu Beginn dieser Arbeit gab es in der Literatur Hinweise, dass der Jak/STAT-Signalweg EBV-abhängig aktiviert werden kann. So konnten beispielsweise Gires et al. (1999) eine direkte Interaktion von Jak3 mit LMP1 zeigen, was eine verstärkte STAT1-DNA-Bindungsaktivität zur Folge hatte. Die Jak3-Bindung an LMP1 konnte in anderen Untersuchungen nicht bestätigt werden (Higuchi et al., 2002). Chen et al. (2003) postulieren eine LMP1-vermittelte STAT3-Aktivierung in Nasopharynx-Karzinomzellen als Folge eines aktivierten IL-6-Signalweges. Dies zeigte deutlich, dass die Aktivierung des Jak/STAT-Signalweges vor allem in EBVpositiven Lymphomzellen noch nicht vollständig verstanden ist. Zur Aufklärung des Mechanismus ist es daher notwendig, die Vorgänge in EBV-positiven Tumorzellen genauer zu analysieren, um den Zusammenhang zwischen den EBV-abhängig aktivierten Signalwegen und dem Entstehen eines Tumors besser verstehen zu können. Aufbauend auf diesem Wissen könnten dann neue und effizientere Strategien in der Tumortherapie entwickelt werden.

Ziel dieser Arbeit war es deshalb, den Einfluss des Epstein-Barr-Virus auf den Jak/STAT-Signalweg in Burkitt-Lymphomzellen zu charakterisieren, vor allem im Hinblick auf die Aktivierung des Negativregulators SOCS3. 


\subsection{Der Jak/STAT-Signalweg wird EBV-abhängig in Bur- kitt-Lymphomzellen aktiviert}

Um der Frage nachzugehen, ob der Jak/STAT-Signalweg in Burkitt-Lymphomzelllinien EBV-abhängig aktiviert wird, wurden verschiedene Zelllinien untersucht. Es zeigte sich, dass unabhängig von der STAT3-Proteinexpression die Tyrosin-Phosphorylierung und somit der Aktivierungszustand von STAT3 nur in EBV-positiven Burkitt-Lymphomzellen nachzuweisen ist (Abb. 3). Diese Beobachtung konnte jedoch nur gemacht werden, wenn die EBV-positiven Burkitt-Lymphomzellen das virale Onkogen LMP1 exprimierten. War dies nicht der Fall, dann kam es nicht zu einer Tyrosin-Phosphorylierung von STAT3. Dieser Zusammenhang wird besonders deutlich, wenn man EBV-negative Burkitt-Lymphomzelllinien mit ihren EBV-konvertierten Analoga vergleicht (Abb. 5). Diese Zellen besitzen den gleichem genetischen Hintergrund unterscheiden sich jedoch in der Expression von LMP1.

Bei der Expression des ebenfalls untersuchten STAT1-Moleküls wurden Unterschiede zwischen den einzelnen Burkitt-Lymphomzelllinien festgestellt. Diese betrafen sowohl die Proteinexpression als auch die Tyrosin-Phosphorylierung von STAT1 (Abb. 4). Die Menge an STAT1-Protein war in den EBV-positiven und LMP1exprimierenden Zellinien bedeutend größer als in den Zelllinien, die kein LMP1 exprimierten. Eine Aktivierung von STAT1 war ebenfalls nur in den LMP1-exprimierenden Burkitt-Lymphomzellen nachzuweisen. Auch für STAT1 wurden die Untersuchungen auf Zelllinien mit gleichem genetischen Hintergrund, aber unterschiedlichen EBV-Stämmen ausgedehnt (Abb. 6). Die Analyse zeigte, dass es durch die LMP1-Expression sowohl zu einer Zunahme der Proteinexpression als auch zu einer verstärkten Tyrosin-Phosphorylierung von STAT1 kommt.

Um einen direkten Zusammenhang zwischen der LMP1-Expression und der Aktivierung von STAT1 bzw. STAT3 zu zeigen, wurde Wildtyp-LMP1 in einer EBVnegativen Burkitt-Lymphomzellinie exprimiert und die STAT-Moleküle anschließend analysiert. Der Frage, welche C-terminale Aktivierungsregion (CTAR) von LMP1 für diese Aktivierung verantwortlich ist, wurde anhand der Expression von verschiedenen LMP1-Mutanten in diesen Zellen nachgegangen. Die Untersuchung 
von STAT3 zeigte, dass es in den Wildtyp-LMP1-exprimierenden Zellen zu einer Tyrosin-Phosphorylierung von STAT3 kommt. In den LMP1-Mutanten-exprimierenden Zellen, in denen die CTARs mutiert vorlagen, konnte diese Phosphorylierung hingegen nicht nachgewiesen werden (Abb. 14). Die Analyse von STAT1 zeigte eine sehr starke STAT1-Proteinexpression in der Wildtyp-LMP1-exprimierenden Probe, während die anderen Proben ein niedrigeres Niveau an STAT1-Protein aufwiesen. Analog zur Proteinexpressionshöhe zeigte die Tyrosin-Phosphorylierung von STAT1 ebenfalls in den LMP1 exprimierenden Zellen den höchsten Wert (Abb. 15).

Aufbauend auf diesen Analysen lässt sich feststellen, dass in Burkitt-Lymphomzellen sowohl die Tyrosin-Phosphorylierung von STAT1 und STAT3 als auch die Proteinexpression von STAT1 EBV-abhängig ist. Die Untersuchungen zeigen ebenfalls, dass die Expression des viralen Onkoproteins LMP1 in Burkitt-Lymphomzellen ausreicht, um STAT3 zu phosphorylieren und sowohl die STAT1-Proteinexpression als auch die Tyrosin-Phosphorylierung von STAT1 zu steigern. Weiterhin wurde gezeigt, dass für die Tyrosin-Phosphorylierung von STAT3 alle CTARs von LMP1 benötigt werden.

Die Beobachtung, dass die Expression von LMP1 in Burkitt-Lymphomzellen ausreicht, um STAT3 zu phosphorylieren, korreliert mit der von Chen et al. (2003) nachgewiesenen LMP1-vermittelten STAT3-Aktivierung in EBV-positiven epithelialen Zellen. Eine LMP1-abhängige, NF- $\kappa$ B-Signalweg-vermittelte STAT1-Expression konnte in Latenztyp III-Zelllinien beobachtet werden (Zhang et al., 2004; Richardson et al., 2003). Gezeigt wurde auch, dass es in EBV-immortalisierten Zellen zu einer Aktivierung von STAT1 kommt (Richardson et al., 2003). Die Gruppe um Najjar et al. (2005) konnte eine Phosphorylierung von STAT1 in den von ihnen untersuchten Zelllinien (LCLs) zeigen und diese auf die durch den NF- $\kappa$ B-Signalweg aktivierten Interferone IFN- $\alpha$ und IFN- $\gamma$ zurückführen. Die in dieser Arbeit gezeigte Abhängigkeit der STAT1-Proteinexpression von einem funktionsfähigen LMP1-CTerminus korreliert gleichfalls mit den Daten von Zhang et al. (2004). Eine EBVabhängige Tyrosin-Phosphorylierung von STAT1 und STAT3, wie sie in der vorliegenden Arbeit gezeigt wurde, konnte von Zhang et al. (2004) allerdings nicht nachgewiesen werden.

Die nachgewiesene, aber relativ schwache LMP1-vermittelte Phosphorylierung von 
STAT3 macht deutlich, dass die alleinige Expression von LMP1 nicht ausreicht, um den Phänotyp der EBV-positiven Latenztyp III-Zelllinien auszuprägen. Dies weist darauf hin, dass noch andere Mechanismen, beispielsweise die Rolle von Zytokinsignalwegen bei der EBV-vermittelten Aktivierung des Jak/STAT-Signalweges, beteiligt sind.

Es bleibt jedoch festzuhalten, dass sowohl für die Expression von STAT1 als auch für die Aktivierung von STAT3 und STAT1 LMP1 voll funktionsfähig in den Zellen exprimiert werden muss.

Die Aktivierung der STAT-Moleküle erfolgt durch Übertragung von Phosphat-Gruppen durch die Januskinasen. Die Mitglieder dieser Kinase-Familie sind mit den meisten Zytokinrezeptoren assoziiert, die für die Signalweiterleitung auf zelluläre Tyrosinkinasen angewiesen sind. Im Gegensatz zu den 3 ubiquitär exprimierten Jaks (Jak1, Jak2, Tyk2) ist die Expression von Jak3 auf Zellen hämatopoetischen Ursprungs beschränkt (Leonard et al., 1998). Im Rahmen dieser Arbeit wurden die Januskinasen in EBV-positiven und -negativen Burkitt-Lymphomzelllinien analysiert. Es wurde gezeigt, dass die Januskinasen Jak2, Jak3 und Tyk2 in EBV-positiven Burkitt-Lymphomzelllinien Tyrosin-phosphoryliert vorliegen.

In wie weit die Aktivierung von STAT3 durch die Januskinasen 2 und 3 erfolgt, sollte durch Inhibitionsversuche geklärt werden. Die Behandlung der primär-EBVpositiven Zelllinien mit dem Jak2-Inhibitor AG490 zeigte eine deutliche Reduktion der Tyrosin-Phosphorylierung von STAT3 (Abb. 8 und 9). Die Hemmung der Januskinase 3 erfolgte mit Hilfe des spezifischen Jak3-Inhibitors WHI-P131. Für die in dieser Arbeit untersuchten EBV-positiven Zelllinien konnte gezeigt werden, dass die Inhibierung der Januskinase $3 \mathrm{zu}$ einer deutlichen Reduktion der STAT3-TyrosinPhosphorylierung führt (Abb. 11 und 12).

Der Tyrosin-Kinase-Inhibitor AG490 hemmt Jak2 und STAT3 (Meydan et al., 1996; Nielsen et al., 1997). Ebenso ist aus der Literatur eine Beeinflussung von Jak3 durch AG490 bekannt (Wang et al., 1999). Dies konnte für die in dieser Arbeit untersuchten Zelllinien jedoch nicht gezeigt werden. Der Hemmstoff WHI-P131 hat keinen Einfluss auf Jak1 und Jak2 (Sudbeck et al., 1999). Allerdings gibt es Hinweise in der Literatur, dass WHI-P131 nicht ausschließlich Jak3 hemmt, sondern auch andere Kinasen, 
wie p38/MAPK und JNK, beeinflusst (Linwong et al., 2005). Die unvollständige Inhibierung der STAT3-Phosphorylierung durch die eingesetzten Hemmstoffe kann aber auch Folge einer zu kurzen Inkubationszeit mit AG490 bzw. WHI-P131 sein. Es ist daher notwendig, die Zellen über einen längeren Zeitraum mit den Hemmstoffen zu behandeln. Auch eine Kombination beider Inhibitoren ist denkbar.

Die Januskinasen 2 und 3 sind somit in die EBV-vermittelte Aktivierung des Jak/STAT-Signalweges involviert. Im Zusammenhang mit dem Auftreten von Leukämien, Lymphomen und Karzinomen konnte bereits eine Fehlregulation von Januskinasen beobachtet werden (Verma et al., 2003).

Die Analyse von Jak1 konnte aus technischen Gründen nicht durchgeführt werden. Es ist jedoch notwendig, diese Untersuchung nachzuholen, um einen Überblick über das Verhalten aller Januskinasen im Zusammenhang mit EBV-infizierten Zellen zu erhalten, da Jak1 bei der Aktivierung von STAT1 und STAT3 ebenfalls eine wichtige Rolle spielen kann (Scott et al., 2002).

\subsection{Der Negativregulator SOCS3 wird in Abhängigkeit von EBV in Lymphomzelllinien exprimiert}

Ziel dieser Arbeit war es der Frage nachzugehen, ob die durch EBV vermittelte Aktivierung des Jak/STAT-Signalweges ebenfalls zu einer Aktivierung negativer Rückkopplungsmechanismen in Form von SOCS-Molekülen führt. In der EBVinfizierten Zelle könnte so die Aufrechterhaltung des Gleichgewichts zwischen Aktivierung und Inhibierung von Signalwegen zur Regulation von Viruslatenz und zellulärer Transformation beitragen. In den analysierten EBV-positiven, LMP1exprimierenden Burkitt-Lymphomzelllinien wurde eine eindeutige Induktion der SOCS3-mRNA sowie die Expression von SOCS3-Protein nachgewiesen. Es wurde erstmals gezeigt, dass die Expression von LMP1 ausreichend ist, um die SOCS3Transkription zu induzieren (Abb. 22).

Untersucht wurde auch, ob die Inhibierung der Januskinasen 2 und 3 eine Auswirkung auf die Expression von SOCS3 hat. In den untersuchten EBV-positiven Burkitt-Lymphomzelllinien war bereits drei Stunden nach der Inhibition von Jak2 
und Jak3 kein SOCS3 mehr nachweisbar (Abb. 19). Sowohl die Hemmung der Januskinase 2 als auch der Januskinase 3 führt in kürzester Zeit zur vollständigen Inhibierung der SOCS3-Expression. Dies zeigt, dass die EBV-vermittelte Phosphorylierung der Januskinasen 2 und 3 in die Aktivierung der SOCS3-Expression involviert ist. Die gleichzeitig beobachtete unvollständige Dephosphorylierung von STAT3 gibt einen Hinweis darauf, dass die Aktivierung der SOCS3-Proteinexpression nicht ausschließlich über STAT3 erfolgt. So wurde bereits eine Aktivierung der SOCS3-Expression durch STAT1 beschrieben (Ramana et al., 2005; Gatto et al., 2004). Ob die in den EBV-positiven Zellen beobachtete SOCS3-Expression auf STAT1 zurückzuführen ist, muss in zukünftigen Experimenten geklärt werden.

\subsection{LMP1 reguliert die mRNA-Stabilität von IP-10 und SOCS3}

Unter der Vielzahl von Signalwegen, die durch das virale Onkoprotein LMP1 in den EBV-infizierten Zellen aktiviert werden, ist der p38/MAPK-Signalweg von besonderem Interesse. Es gibt Hinweise in der Literatur, dass eine Expression von LMP1 in Burkitt-Lymphomzellen zur Induktion von IL-10 führt und dabei der p38/MAPKSignalweg involviert ist (Vockerodt et al., 2001). Wie der p38/MAPK-Signalweg durch LMP1 beeinflusst wird, ist jedoch noch nicht vollständig geklärt. Aus der Literatur ist bekannt, dass der p38/MAPK-Signalweg eine Rolle bei der mRNAStabilisierung, beispielsweise von TNF- $\alpha$, IL-6, IL-8 und Cyclooxygenase-2 (COX2), spielen kann (Holtmann et al., 1999; Neininger et al., 2002; Dean et al., 1999). Diese Gene werden unter anderem durch LMP1 reguliert.

Für das Chemokin IP-10 wurde in Vorarbeiten gezeigt, dass die Hemmung des p38/MAPK-Signalweges einen Einfluss auf die LMP1-vermittelte IP-10-Aktivierung hat, sich jedoch nicht auf den IP-10-Promotor auswirkt (Vockerodt et al., 2004). Daraufhin wurde die Wirkung der LMP1-vermittelten p38/MAPK-Aktivierung auf die mRNA-Stabilität untersucht. Im Rahmen dieser Arbeit wurde eindeutig gezeigt, dass die IP-10-mRNA durch den LMP1-aktivierten p38/MAPK-Signalweg stabilisiert wird (Abb. 25). Der IP-10-Promotor wird sowohl durch LMP1 als auch durch 
CD40 aktiviert, wobei NF- $\kappa$ B eine wichtige Rolle spielt (Vockerodt et al., 2004). Im Gegensatz zu LMP1 hat CD40 jedoch nur einen geringen Einfluss auf die mRNAStabilisierung von IP-10 (Abb. 25). Somit unterscheiden sich die als funktionelle Homologe gesehenen CD40 und LMP1 in der Regulation der IP-10-mRNA-Stabilität.

Mit der vorliegenden Arbeit wurde gezeigt, dass die Hemmung des p38/MAPKSignalweges in EBV-positiven, LMP1-exprimierenden Burkitt-Lymphomzellen ebenfalls einen Einfluss auf die Tyrosin-Phosphorylierung von STAT3 sowie auf die Expression von SOCS3 hat (Abb. 27 und 28). Im Rahmen dieser Arbeit wurde daraufhin untersucht, welchen Einfluss die EBV-abhängige Induktion von p38/MAPK und damit LMP1 auf die Halbwertszeit der SOCS3-mRNA hat. Die Untersuchungen ergaben einen stabilisierenden Effekt für die SOCS3-mRNA, wenn p38/MAPK nicht inhibiert wurde (Abb. 30). Um zu überprüfen, dass dieser Effekt ausschließlich auf LMP1 und dessen Aktivierung von p38/MAPK zurückzuführen ist, sollte in zukünftigen Experimenten die SOCS3-mRNA-Stabilität in einer EBV-negativen, LMP1-exprimierenden Burkitt-Lymphomzellinie untersucht werden.

Die Regulation der mRNA-Stabilität erfordert AU-reiche-Elemente (AREs) im 3'Bereich. Diese AREs sind auch in der SOCS3-mRNA zu finden (Ehlting et al., 2007). Für TNF- $\alpha$ konnte im 3'-Bereich der mRNA neben ARE ein weiteres destabilisierendes Element, das so genannte CDE (engl.: constitutive decay element), nachgewiesen werden (Stoecklin et al., 2003). Der genaue Mechanismus der durch p38/MAPK vermittelten mRNA-Regulation ist noch nicht vollständig geklärt. Es gibt Hinweise, dass das p38/MAPK-Substrat MK2 (MAPK-aktivierte Proteinkinase 2) eine Rolle spielt (Winzen et al., 1999). Ehlting et al. (2007) konnten dies bestätigen und gleichzeitig zeigen, dass für die Regulation der SOCS3-mRNA durch TNF- $\alpha$ p38/MAPK durch MKK6 aktiviert wird, welches dann seinerseits MK2 aktiviert. In Fibroblasten und Makrophagen wurde gezeigt, dass p38/MAPK für die Induktion von SOCS3 TNF- $\alpha$ benötigt und dass die mRNA von SOCS3 durch TNF$\alpha$ reguliert wird (Bode et al., 1999; Ehlting et al., 2007).

Inzwischen sind auch verschiedene mRNA-bindende Proteine bekannt, die in der Regulation der mRNA-Stabilität eine Rolle spielen. Diese binden AU-reiche Regionen in der 3'-UTR und können sowohl stabilisierende (HuR) als auch destabilisierende 
(TTP, AUF-1, TIA-1) Wirkung haben (Peng et al., 1998; Zhang et al., 1993; Lai et al., 1999; Piecyk et al., 2000). Der genaue Mechanismus, mit dem p38/MAPK die mRNA verschiedener Zielgene beeinflusst, ist noch nicht geklärt und sollte Anlass zukünftiger Untersuchungen sein.

Die Regulation der Genexpression über die Stabilisierung der mRNA stellt somit eine Möglichkeit eines direkten Mechanismus dar, wie SOCS3 EBV-abhängig reguliert werden kann.

\subsection{EBV beeinflusst den Jak/STAT-Signalweg durch Zyto- kine}

Noch immer ist ungeklärt, wie der Jak/STAT-Signalweg in EBV-positiven Lymphomzellen aktiviert wird. Im Rahmen dieser Arbeit wurde sowohl die Wirkung der Zytokine IL-6 und IL-10 als auch die Hemmung dieser Signalwege in EBVnegativen und -positiven Burkitt-Lymphomzelllinien untersucht. Die EBV-negative BL2 zeigte nach der Stimulation mit IL-6 weder ein aktiviertes STAT3 noch eine Induktion von SOCS3. Im Anschluss an die Stimulation der Zellen mit IL-10 konnte hingegen sowohl die Tyrosin-Phosphorylierung von STAT3 als auch SOCS3mRNA nachgewiesen werden. Die EBV-negative BL2 reagiert somit auf IL-10, nicht aber auf IL-6. Durch die Expression von LMP1 kommt es nachgewiesenermaßen zur Aktivierung beider Zytokine (Tab. 25 und 26). Auch der Vergleich von BurkittLymphomzelllinien mit gleichem genetischen Hintergrund zeigt eine nachweisbare IL-6-Produktion in den Zellen, die den Virusstamm B95-8 enthalten (Abb. 31).

Die beiden EBV-positiven Burkitt-Lymphomzelllinien BL36 und BL74 sprechen interessanterweise unterschiedlich auf die Zugabe von IL-6 und IL-10 an. In BL36Zellen führt die Zugabe von IL-10 im Vergleich zu IL-6 zu einer stärkeren Aktivierung von STAT3. Das umgekehrte Verhalten ist für BL74-Zellen zu beobachten, wo IL-6 zu einer stärkeren Tyrosin-Phosphorylierung von STAT3 führt. Bei beiden Zelllinien kann nach der Stimulation mit den beiden Zytokinen jeweils eine erhöhte SOCS3-Expression festgestellt werden (Abb 34). Blockiert man hingegen die Zytokinsignalwege von IL-6 und IL-10, so kann der Einfluss von IL-10 auf BL36 
bestätigt werden. Dieser drückt sich in Form einer Abnahme sowohl der TyrosinPhosphorylierung von STAT3 als auch der SOCS3-Expression aus (Abb. 35). Die SOCS3-mRNA wird ebenfalls deutlich reduziert. Die Zelllinie BL74 zeigte allerdings nicht die erwartete Reaktion auf die Hemmung der IL-6- bzw. IL-10-Signalwege. Die Aktivierung von STAT3 wurde nur minimal gehemmt, wobei der Effekt des neutralisierenden anti-IL-10-Antikörpers stärker scheint. Auf SOCS3 zeigte die Hemmung der IL-6- und IL-10-Signalwege in BL74 keinerlei Einfluss.

Das unterschiedliche Verhalten der EBV-negativen und -positiven Zellen infolge der Stimulation mit IL-6 lässt vermuten, dass durch die Expression von LMP1 die Expression der Rezeptoren verändert wird. Dies sollte in weiterführenden Experimenten überprüft werden. Das unterschiedliche Ansprechen der EBV-positiven Burkitt-Lymphomzellen auf die beiden Zytokine ist bei der derzeitigen Datenlage nicht zu erklären. Die Versuche zeigen aber deutlich, dass die EBV-positiven Burkitt-Lymphomzellen in der Lage sind, auf Zytokine, wie IL-6 und IL-10, mit der Aktivierung von STAT3 und SOCS3 zu reagieren. Sowohl die Analysen der Stimulierung mit Zytokinen als auch der neutralisierenden Antikörper sollten auf weitere EBV-positive Burkitt-Lymphomzellinien ausgeweitet werden.

LMP1 ist in der Lage, verschiedene Interleukine (IL-6, IL-10), Tumor-Nekrosefaktoren (TNF- $\alpha$, TNF- $\beta$ ), Interferone (IFN- $\gamma$ ) und Chemokine (IL-8, IP-10) zu aktivieren (Eliopoulos et al., 1999b; Nakagomi et al., 1994; Ho et al., 1999; Thompson et al., 2003; Vockerodt et al., 2001; Najjar et al., 2005). So postuliert die Arbeitsgruppe um Chen et al. (2003) eine Aktivierung des Jak/STAT-Signalweges durch eine positiv regulierte Rückkopplungsschleife in Nasopharynx-Karzinomzellen. Dabei ist auch das durch LMP1 aktivierte IL-6 für die Aktivierung des Jak/STAT-Signalweges verantwortlich. Nepomuceno et al. (2002) vermuten hingegen einen Zusammenhang zwischen dem Auftreten von konstitutiv aktivem STAT3 und einer autokrinen IL-10Produktion in LCLs. Die gezeigten Daten lassen einen durch die LMP1-vermittelte IL-10-Produktion aktivierten Jak/STAT-Signalweg vermuten. Somit ist ebenfalls eine EBV-vermittelte Aktivierung des Jak/STAT-Signalweges und von SOCS3 über einen indirekten Mechanismus denkbar.

Neben der in der Literatur beschriebenen Aktivierung des Jak/STAT-Signalweges 
durch Zytokine konnten Gires et al. (1999) zeigen, dass Jak3 in der Lage ist, direkt an LMP1 zu binden. In der vorliegenden Arbeit wurde gezeigt, dass die Aktivierung des Jak/STAT-Signalweges in EBV-positiven Burkitt-Lymphomzellinien durch LMP1aktivierte Zytokine erfolgen kann. Dennoch kann zu diesem Zeitpunkt eine direkte Interaktion der in den EBV-positiven Lymphomzellen vorliegenden aktivierten Januskinasen nicht ausgeschlossen werden. Um diese Frage eindeutig beantworten zu können, bedarf es weiterer Untersuchungen.

\subsection{Mögliche Funktionen von SOCS3 in EBV-positiven Bur- kitt-Lymphomzellen}

Die nachgewiesene Expression von SOCS3 in EBV-positiven Burkitt-Lymphomzellen lässt die Frage nach dessen Bedeutung in diesen Zellen aufkommen. Es wurde deshalb untersucht, welchen Einfluss eine Überexpression von SOCS3 auf die Tyrosin-Phosphorylierung von STAT3 hat. Diese führte unerwartet nicht zu einer vollständigen Inhibierung der STAT3-Aktivierung in der EBV-positiven BurkittLymphomzelllinie BL36 (Abb. 23). Das lässt vermuten, dass nicht das gesamte phosphorylierte STAT3 in dieser Zelllinie durch Januskinasen aktiviert wurde. So können auch andere Kinasen für die Aktivierung von STAT3 verantwortlich sein (Bowman et al., 2000; Wang et al., 1999). Beispielsweise kommt es nach der Stimulation von Zellen mit Interferon- $\gamma$ zur Aktivierung von STAT3 durch Src-Kinasen, wobei die Januskinasen 1 und 2 ebenfalls eine Rolle spielen (Qing et al., 2004). Es sollte außerdem überprüft werden, ob eine SOCS3-Überexpression einen Einfluss auf STAT1 hat, da STAT1 ebenfalls die SOCS3-Proteinexpression beeinflussen kann (Ramana et al., 2005; Gatto et al., 2004). Es ist bekannt, dass die Aktivierung des IL-10-Signalweges zur Induktion von STAT1 und STAT3 führt (Finbloom et al., 1995). In neutrophilen Zellen konnte aber auch eine STAT-unabhängige Induktion von SOCS3 durch den IL-10-Signalweg gezeigt werden (Cassatella et al., 1999). Aus der Literatur ist weiterhin bekannt, dass ein durch IL-10 aktiviertes STAT3 zwar SOCS3 aktiviert, SOCS3 diesen Signalweg aber nicht durch eine direkte Bindung an den IL-10-Rezeptor hemmen kann (Niemand et al., 2003). 
Die Bedeutung, die den SOCS-Molekülen als Negativregulatoren des Jak/STATSignalweges in der Regulation des zellulären Gleichgewichts in einer gesunden Zelle zukommt, wird deutlich, wenn diese Moleküle nicht mehr ihrer Funktion nachkommen können. In verschiedenen Tumorentitäten konnte bereits eine Methylierung von SOCS-Genen in Zusammenhang mit dem Auftreten maligner Tumoren gebracht werden (He et al., 2003; Sutherland et al., 2004; Weber et al., 2005; Tokita et al., 2007). Bei der EBV-vermittelten SOCS3-Aktivierung stellt sich daher die Frage, ob das Virus durch die Expression von SOCS3 das Ansprechen der Tumorzelle auf bestimmte Zytokine beeinflussen kann und somit den transformierten Zustand der Zelle aufrechterhält.

\subsection{Ausblick}

Weiterführend sollte geklärt werden, welche Rolle die Januskinasen bei der EBVabhängigen Aktivierung des Jak/STAT-Signalweges spielen. Daran könnten sich Bindungsstudien anschließen, die Aufschluss über eine direkte Bindung der Januskinasen an LMP1 in Burkitt-Lymphomzellen geben. In Bezug auf die Aktivierung der STAT-Moleküle sollte die Rolle anderer Kinasen, wie die Scr-Kinasen, näher beleuchtet werden.

Bezugnehmend auf die EBV-vermittelte SOCS3-Aktivierung in EBV-positiven Burkitt-Lymphomzellen, sollte der Frage nachgegangen werden, ob und wenn ja wie der SOCS3-Promotor reguliert wird. Die Arbeitsgruppe um Gatto et al. (2004) analysierte den SOCS3-Promotor in Makrophagen und konnte zeigen, dass die Induktion von SOCS3 von STAT-Bindungsstellen innerhalb des SOCS3-Promotors abhängt. Es gibt ebenfalls Studien zur STAT3-Bindung innerhalb des SOCS3-Promotors im IL-6-induzierten Signalweg (Zhang et al., 2006). Eine andere Arbeitsgruppe konnte zeigen, dass für die IL-6-vermittelte Aktivierung von SOCS3 die Bindung von SP3 an GC-reiche Regionen des SOCS3-Promotors notwendig ist (Ehlting et al., 2005). In weiterführenden Projekten sollte deshalb auch die Rolle von Interferon- $\gamma$, STAT1 und STAT3 in Bezug auf das LMP1-induzierte SOCS3 untersucht werden.

Weiterhin sollten die Untersuchungen zur mRNA-Stabilisierung von SOCS3 auf wei- 
tere Zelllinien ausgeweitet werden, um eine zusätzliche Bestätigung für den direkten Effekt von LMP1 auf die Halbwertszeit von SOCS3 zu erhalten.

Aufgrund der vorliegenden Daten sollte geklärt werden, ob sich durch die EBVvermittelte SOCS3-Aktivierung das Ansprechverhalten der transformierten B-Zelle auf verschiedene Zytokine ändert. Dies stellt eine Möglichkeit dar, wie das virale Onkoprotein LMP1 zur Transformation und zur Aufrechterhaltung des transformierten Zustandes der Zelle beiträgt. 


\section{$7 \quad$ Zusammenfassung}

Zielsetzung dieser Arbeit war es zu zeigen, dass eine durch das Epstein-Barr-Virus vermittelte Aktivierung des Jak/STAT-Signalweges zu einer Aktivierung von SOCS3 als Negativregulator des Jak/STAT-Signalweges in Burkitt-Lymphomzellen führt und welche Mechanismen dem zugrunde liegen können.

Im ersten Teil der Arbeit wurde gezeigt, dass in EBV-positiven, LMP1-exprimierenden Burkitt-Lymphomzelllinien eine Aktivierung des Jak/STAT-Signalweges vorliegt. In diesen Prozess sind die Januskinasen 2 und 3 involviert. Es konnte gezeigt werden, dass in den untersuchten EBV-positiven, LMP1-exprimierenden BurkittLymphomzellinien STAT3 aktiviert vorliegt und dass sowohl die Expression als auch die Phosphorylierung von STAT1 gesteigert wird. Die Aktivierung der STATMoleküle erfordert jedoch einen vollständig funktionsfähigen C-Terminus von LMP1. Das vom Epstein-Barr-Virus exprimierte LMP1 ist somit ausreichend, um den Jak/STAT-Signalweg zu aktivieren.

Im zweiten Teil der Arbeit wurden verschiedene EBV-positive und -negative BurkittLymphomzellen hinsichtlich ihrer Fähigkeit, SOCS3 zu exprimieren, untersucht. Hierbei konnte die eingangs formulierte Hypothese eindeutig bestätigt werden. In EBV-positiven Burkitt-Lymphomzellen ist SOCS3 exprimiert. Es konnte weiterhin der Nachweis erbracht werden, dass eine Expression von LMP1 ausreichend ist, um SOCS3 zu induzieren.

Die EBV-vermittelte Expression von SOCS3 ist als direkter Mechanismus unter anderem auf die Stabilisierung der SOCS3-mRNA durch den LMP1-aktivierten p38/MAPK-Signalweg zurückzuführen.

Eine wichtige Rolle bei der Aktivierung des Jak/STAT-Signalweges spielen die Zytokine IL-6 und IL-10. In dieser Arbeit konnte gezeigt werden, dass die Aktivierung des Jak/STAT-Signalweges indirekt, das heißt über EBV-abhängig aktivierte Zytokinsignalwege, reguliert wird. Eine zusätzliche direkte Aktivierung durch eine Interaktion von Komponenten des Jak/STAT-Signalweges mit LMP1 kann derzeit jedoch noch nicht völlig ausgeschlossen werden. 


\section{Literatur}

Babcock GJ, Hochberg D, Thorley-Lawson DA. The expression pattern of Epstein-Barr virus latent genes in vivo is dependent upon the differentiation stage in the infected B cell. Immunity 13, 497-506 (2000)

Bertrand S, Berger R, Philip T, Bernheim A, Bryon PA, Bertoglio J, Dore JF, Brunat-Mentigny M, Lenoir GM. Variant translocation in a non endemic case of Burkitt's lymphoma: t(8:22) in an Epstein-Barr virus negative tumour and in a derived cell line. Eur. J. Cancer 17, 577-584 (1981)

Bode JG, Nimmesgern A, Schmitz J, Schaper F, Schmitt M, Frisch W, HÄUssinger D, Heinrich PC, Graeve L. LPS and TNF- $\alpha$ induce SOCS3 mRNA and inhibit IL-6-induced activation of STAT3 in macrophages. FEBS Lett. 463, 365-370 (1999)

Bowman T, Garcia R, Turkson J, Jove R. STATs in oncogenesis. Oncogene 19, 2474-2488 (2000)

Boxer LM, Dang CV. Translocations involving c-myc and $c$-myc functions. Oncogene 20, 5595-5610 (2001)

Brodeur SR, Cheng G, Baltimore D, Thorley-Lawson DA. Localization of the major NF- $\kappa$ B-activating site and the sole TRAF3 binding site of LMP-1 defines two distinct signaling motifs. J. Biol. Chem. 272, 19777-19784 (1997)

Bromberg J. Stat proteins and oncogenesis. J. Clin. Invest. 109, 1139-1142 (2002)

Burkitt D. A sarcoma involving the jaw in African children. Brit. J. Surg. 46, 218-223 (1958)

Calender A, Billaud M, Aubry JP, Banchereau J, Vuillaume M, LeNOIR GM. Epstein-Barr virus (EBV) induces expression of B-cell activation markers on in vitro infection of EBV-negative B-lymphoma cells. Proc. Natl. Acad. Sci. USA 84, 8060-8064 (1987)

Cassatella MA, Gasperini S, Bovolenta C, Calzetti F, Vollebregt M, Scapini P, Marchi M, Suzuki R, Suzuki A, Yoshimura A. Interleukin-10 (IL-10) selectively enhances CIS3/SOCS3 mRNA expression in human neutrophils: Evidence for an IL-10-induced pathway that is independent of STAT protein activation. Blood 94, 2880-2889 (1999)

Chen H, Hutt-Fletcher L, CaO L, Hayward SD. A positive autoregulatory loop of LMP1 expression and STAT activation in epithelial cells latently infected with Epstein-Barr virus. J. Virol. 77, 4139-4148 (2003)

Chung CD, Liao J, Liu B, Rao X, Jay P, Berta P, Shuai K. Specific inhibition of Stat3 signal transduction by PIAS3. Science 278, 1803-1805 (1997) 
Dean JL, Sully G, Clark AR, Saklatvala J. The involvement of AUrich element-binding proteins in p38 mitogen-activated protein kinase pathwaymediated mRNA stabilisation. Cell. Signal. 16, 1113-1121 (2004)

Dean JL, Brook M, Clark AR, Saklatvala J. p38 mitogen-activated protein kinase regulates cyclooxygenase-2 mRNA stability and transcription in lipopolysaccharide-treated human monocytes. J. Biol. Chem. 274, 264-269 (1999)

Devergne O, Cahir McFarland E, Mosialos G, Izumi KM,Ware CF, KIEFF E. Role of TRAF binding site and NF- $\kappa$ B activation in Epstein-Barr virus Latent Membrane Protein 1-induced cell gene expression. J. Virol. 72, 7900-7908 (1998)

Devergne O, Hatzivassiliou E, Izumi KM, Kaye KM, Kleijnen MF, KiefF E, Mosialos G. Association of TRAF1, TRAF2 and TRAF3 with an Epstein-Barr virus LMP1 domain important for B-Lymphocyte transformation: Role in NF- $\kappa$ B activation. Mol. Cell. Biol. 16, 7098-7108 (1996)

Diehl V, Kirchner HH, Burrichter H, Stein H, Fonatsch C, Gerdes J, Schandt M, Heit W, Uchanka-Ziegler B, Ziegler A, Heintz F, Sueno K. Characteristics of Hodgkin's disease-derived cell lines. Cancer Treat. Rep. 66, 615-632 (1982)

Diehl V, Kirchner HH, Schaadt M, Fonatsch C, Stein H, Gerdes J, BoIE C. Hodgkin's disease: establishment and characterization of four in vitro cell lines. J. Cancer Res. Clin. Oncol. 101, 111-124 (1981)

Diehl V, Pfreundschuh M, Fonatsch C, Stein H, Falk M, Burrichter H, SchaAdT M. Phenotypic and genotypic analysis of Hodgkin's disease derived cell lines: histopathological and clinical implications. Cancer Surv. 4, 399-419 (1985)

Eliopoulos AG, Blake SMS, Floettmann JE, Rowe M, Young LS. The Epstein-Barr virus-encoded Latent Membrane Protein 1 activates the JNK Pathway through its extreme $\mathrm{C}$ terminus via a mechanism involving TRADD and TRAF2. J. Virol. 73, 1023-1035 (1999a)

Eliopoulos AG, Gallagher NJ, Blake SMS, Dawson W, Young LS. Activation of the p38 mitogen-activated protein kinase pathway by Epstein-Barr virusencoded Latent Membrane Protein 1 coregulates Interleukin-6 and Interleukin-8 production. J. Biol. Chem. 274, 16085-16096 (1999b)

Eliopoulos AG, Young LS. LMP1 structure and signal transduction. Cancer Biol. 11, 435-444 (2001)

Elting C, HÄussinger D, Bode JG. Sp3 is involved in the regulation of SOCS3 gene expression. Biochem. J. 387, 737-745 (2005) 
Elting C, Lai WS, Schaper F, Brenndörfer ED, Matthes RJ, Heinrich PC, Ludwig S, Blackshear PJ, Gaestel M, Häussinger D, Bode JG. Regulation of Suppressor of Cytokine Signaling 3 (SOCS3) mRNA stability by TNF- $\alpha$ involves activation of the MKK6/p38 178, 2813-2826 (2007)

Epstein MA, Achong BG, BARR YM. Virus particles in cultured lymphoblasts from Burkitt's Lymphoma. Lancet 15, 702-703 (1964)

Finbloom DS, Winestock KD. IL-10 induces the tyrosin phosphorylation of Tyk2 and Jak1 and the differential assembly of STAT $1 \alpha$ and STAT3 complexes in human T cells and monocytes. J. Immunol. 155, 1079-1090 (1995)

Gatto L, Berlato C, Poli V, Tininini S, Kinjyo I, Yoshimura A, CassaTELLA MA, BAzZONi F. Analysis of SOCS-3 promotor responses to interferon- $\gamma$. J. Biol. Chem. 279, 13746-13754 (2004)

Gires O, Kohlhuber F, Kilger E, Baumann M, Kieser A, Kaiser C, Zeidler R, Schaffer B, Ueffing M, Hammerschmidt W. Latent membrane protein 1 of Epstein-Barr virus interacts with JAK3 and activates STAT proteins. EMBO J. 18, 3064-3073 (1999)

Gires O, Zimber-Strobl U, Connella R, Ueffing M, Marschall G, ZeidLER R, Pich D, Hammerschmidt W. Latent membrane protein 1 of EpsteinBarr virus mimics a constitutively active receptor molecule. EMBO J. 16, 61316140 (1997)

Goh KC, Haque SJ, Williams BRG. p38 MAP kinase is required for STAT1 serine phosphorylation and transcriptional activation induced by interferons. EMBO J. 18, 5601-5608 (1999)

Haan S, Ferguson P, Sommer U, Hiremath M, McVicar DW, Heinrich PC, Johnston JA, Carcalano NA. Tyrosin phosphorylation disrupts elongin interaction and accelerates SOCS3 degradation. J. Biol. Chem. 278, 31972-31979 (2003)

He B, You L, Uematsu K, Zang K, Xu Z, Lee AY, Costello JF, McCorMICK F, JABLONS DM. SOCS-3 is frequently silenced by hypermethylation and suppresses cell growth in human lung cancer. PNAS 100, 14133-14138 (2003)

Hess S, Kurrle R, Lauffer L, Riethmüller G, Engelmann H. A cytotoxic CD40/p55 tumor necrosis factor receptor hybrid detects CD40 ligand on Herpesvirus saimiri transformed T cells. Eur. J. Immunol. 25, 80-86 (1995)

Higuchi M, KiefF E, Izumi KM. The Epstein-Barr virus latent membrane protein 1 putative janus kinase 3 (Jak3) binding domain does not mediate JAK3 association or activation in B-lymphoma or lymphoblastoid cell lines. J. Virol. 76, 455-459 (2002) 
HiLton DJ. Negative regulators of cytokine signal transduction. Cell. Mol. Life Sci. 55, 1568-1577 (1999)

Ho JWY, Liang RHS, Srivastava G. Differential cytokine expression in EBV positive peripheral T cell lymphomas. J. Clin. Pathol. 52, 269-274 (1999)

Holtmann H, Winzen R, Holland P, Eickemeier S, Hoffmann E, WalLach D, Malinin NL, CoOper JA, Resch K, Kracht M. Induction of Interleukin-8 synthesis integrates effects on transcription and mRNA degradation from at least three different cytokine- or stress-activated signal transduction pathway. Mol. Cell. Biol. 19, 6742-6753 (1999)

Hörtner M, Nielsch U, Mayr LM, Heinrich PC, HaAn S. A new high affinity binding site for suppressor of cytokine signaling- 3 on the erythropoietin receptor. Eur. J. Biochem. 269, 2516-2526 (2002)

Huen DS, Henderson SA, Croom-Carter D, Rowe M. The Epstein-Barr virus latent membrane protein 1 (LMP1) mediates activation of NF- $\kappa \mathrm{B}$ and cell surface phenotype via two effector regions in its carboxy-terminal cytoplasmatic domain. Oncogene 10, 549-560 (1995)

Izumi KM, Cahir McFarland E, Ting AT, Riley EA, Seed B, Kieff E. The Epstein-Barr virus oncoprotein latent membrane protein 1 engages the tumor necrosis factor receptor-associated proteins TRADD and receptor-interacting protein (RIP) but does not induce apoptosis or require RIP for NF- $\kappa$ B activation. Mol. Cell. Biol. 19, 5759-5767 (1999a)

Izumi KM, Cahir McFarland E, Riley EA, Rizzo D, Chen Y, Kieff E. The residues between the two transformation effector sites of Epstein-Barr virus latent membrane protein 1 are not critical for B-lymphocyte growth transformation. $J$. Virol. 73, 9908-9916 (1999b)

Izumi KM, KaYe KM, KIEFF E. The Epstein-Barr virus LMP1 amino acid sequence that engages tumor necrosis factor receptor associated factors is critical for primary B-lymphocyte growth transformation. Proc. Natl. Acad. Sci. USA 94, 1447-1452 (1997a)

Izumi KM, KIEFF E. The Epstein-Barr virus oncogene product latent membrane protein 1 engages the tumor necrosis factor receptor-associated death domain protein to mediate B-lymphocyte growth transformation and active NF- $\kappa \mathrm{B}$. Proc. Natl. Acad. Sci. USA 94, 12592-12597 (1997b)

Jarrett RF, Gallagher A, Jones DB, Alexander FE, Krajewski AS, Kelsey A, Adams J, Angus B, Gledhill S, Wright DH, Cartwright RA, Onions DE. Detection of Epstein-Barr virus genomes in Hodgkins's disease: Relation to age. J. Clin. Pathol. 44, 844-848 (1991)

Janeway CA, Travers P, Walport M, Shlomchik MJ. Immuno Biology. Garland Science Publishing (2005) 
Joseph, AM, Babcock GJ, Thorley-Lawson DA. Cells expressing the Epstein-Barr virus growth program are present in and restricted to the naive B-cell subset of healthy tonsils. J. Virol. 74, 9964-9971 (2000)

Kamesaki H, Fukuhara S, Tatsumi E, Uchino H, Yamabe H, Miwa H, Shirakawa S, Hatanaka M, Honjo T. Cytochemical, immunologic, chromosomal, and molecular genetic analysis of a novel cell line derived from Hodgkin's disease. Blood 68, 285-292 (1986)

Kamura T, Sato S, Haque D, Liu L, Kaelin WG, Conaway RC, ConaWAY JW. The Elongin BC complex interacts with the conserved SOCS-box motif present in members of the SOCS, ras, WD-40 repeat, and ankyrin repeat families. Genes Dev. 12, 3872-3881 (1986)

Kaye KM, Izumi KM, KiefF E. Epstein-Barr virus latent membrane protein 1 is essential for B-lymphocyte growth transformation. Proc. Natl. Acad. Sci. USA 90, 9150-9154 (1993)

Kaye KM, Izumi KM, Mosialos G, KiefF E. The Epstein-Barr virus LMP1 cytoplasmic carboxy terminus is essential for B-lymphocyte transformation; fibroblast cocultivation complements a critical function within the terminal 155 residues. J. Virol. 69, 675-683 (1995)

Kaye KM, Izumi KM, Li H, Johannsen E, Davidson D, Longnecker R, KIEFF E. An Epstein-Barr virus that expresses only the first 231 LMP1 amino acids efficiently initiates primary B-lymphocyte growth transformation. J. Virol. 73, 10525-10530 (1999)

Kaykas A, Worringer K, Sugden B. CD40 and LMP-1 both signal from lipid rafts but LMP-1 assembles a distinct, more efficient signaling complex. EMBO J. 20, 2641-2654 (2001)

KiefF E And Rickinson AB. Epstein-Barr virus and its replication; chapter 34 aus dem Buch: KNIPE DM, Howley PM. Fundamental Virology. Lippincott Williams \& Wilkins; 4th edition (2001)

Kieser A, Kaiser C, Hammerschmidt W. LMP1 signal transduction differs substantially from TNF receptor 1 signaling in the molecular functions of TRADD and TRAF2. EMBO J. 18, 2511-2521 (1999)

Kieser A, Kilger E, Gires O, Ueffing M, Kolch W, Hammerschmidt W. Epstein-Barr virus latent membrane protein-1 triggers AP-1 activity via the c-Jun N-terminal kinase cascade. EMBO J. 16, 6478-6485 (1997)

Klein G, Giovanella B, Westman A, Stehlin JS, Mumford D. An EBVgenome-negative cell line established from an American Burkitt Lymphoma; receptor characteristics. EBV infectibility and permanent conversion into EBVpositive sublines by in vitro infection. Intervirology $\mathbf{5}, 319-334$ (1975) 
Kloosterman WP, Plasterk RHA. The Diverse function of MicroRNAs in animal development and disease. Developmental Cell 11, 441-450 (2006)

KREBS DL, HiLton DJ. SOCS: physiological suppressors of cytokine signaling. J. Cell Sci. 113, 2813-2819 (2000)

Kube D, Holtick U, Vockerodt M, Ahmadi T, Haier B, Behrmann I, Heinrich PC, Dienl V, Tesch H. STAT3 is constitutively activated in Hodgkin cell lines. Blood 98, 762-770 (2001)

KüPPERS R. B cells under influence: Transformation of B cells by Epstein-Barr Virus. Nat. Rev. Immunol. 3, 801-812 (2003)

Lacronique V, Boureaux A, Valle VD, Poirel H, Quang C, Mauchaffe M, Berthou C, Lessard M, Berger R, Ghysdeal J, Bernard OA. A TEL-JAK2 fusion protein with constitutive kinase activity in human leukemia. Science 278, 1309-1312 (1997)

Lai WS, Carballo E, Strum JR, Kennington EA, Phillips RS, BlacksHEAR PJ. Evidence that tristetraprolin binds to AU-rich elements and promotes the deadenylation and destabilization of tumor necrosis factor alpha mRNA. Mol. Cell. Biol. 19, 4311-4323 (1999)

Lee RC, Feinbaum RL, Ambros V. The C. elegans heterochronic Gene lin-4 encodes small RNAs with antisense complementary to lin-14. Cell 75, 843-854 (1993)

Lenoir GM, Vuillaume M, Bonnardel C. The use of lymphomatous and lymphoblastoid cell lines in the study of Burkitt's lymphoma. IARC Sci. Publ. 60, 309-318 (1985)

LeOnard WJ, O'Shea JJ. Jaks and STATs. Biological implications. Ann. Rev. Immunol. 16, 293-322 (1998)

Liebowitz D, WAng D, KiefF E. Orientation and patching of the latent infection membrane protein encoded by Epstein-Barr virus. J. Virol. 58, 233-237 (1986)

Liebowitz D, Kopan R, Fuchs E, Sample J, Kieff E. An Epstein-Barr virus transforming protein associates with vimentin in lymphocytes. Mol. Cell. Biol. 7, 2299-2308 (1987)

Liebowitz D, Mannick J, Takada K, KiefF E. Phenotypes of Epstein-Barr virus LMP1 deletion mutants indicate transmembrane and amino-terminal cytoplasmic domains necessary for effects in B-lymphoma cells. J. Virol. 66, 4612-4616 (1992)

Lim CP, CAO X. Serine phosphorylation and negative regulation of Stat3 by JNK. J. Biol. Chem. 274, 31055-31061 (1999) 
Linwong W, Hirasawa N, Aoyama S, Hamada H, Saito T, Ohuchi K. Inhibition of the antigen-induced activation of rodent mast cells by putative Janus kinase 3 inhibitors WHI-P131 and WHI-P154 in a Janus kinase 3-independent manner. British Journal of Pharmacology 145, 818-828 (2005)

Liu B, Liao J, Rao X, Kushner Sa, Chung CD, Chang DD, Shuai K. Inhibition of Stat1-mediated gene activation by PIAS1. Proc. Natl. Acad. Sci. USA 95, 10626-10631 (1998)

Luftig M, Prinarakis E, Yasui T, Tsichritzis T, Cahir-McFarland E, Inoue JI, Nakano H, Mak TW, Yeh WC, Li X, Akira S, Suzuki N, Suzuki S, Mosialos G, KiefF E. Epstein-Barr virus latent membrane protein 1 activation of NF- $\kappa \mathrm{B}$ through IRAK1 and TRAF6. Proc. Natl. Acad. Sci. USA 100, 15595-15600 (2003)

MacPherson I, Stoker M. Polyoma transformation of hamster cell clones - an investigation of genetic factors affecting cell competence. Virology 16, 147-151 (1962)

Majumder S, Zhou LZH, Chaturvedi P, Babcock G, Aras S, Ransohoff RM. p48/STAT- $1 \alpha$-containing complexes play a predominant role in induction of IFN- $\gamma$-inducible protein, $10 \mathrm{kDa}$ (IP-10) by IFN- $\gamma$ alone or in synergy with TNF- $\alpha$. J. Immunol. 161, 4736-4744 (1998)

Meydan N, Grunberger T, Dadi H, Shahar M, Arpaia E, Lapidot Z, Leeder JS, Freedman M, Cohen A, Gazit A, Levitzki A, Roifman CM. Inhibition of acute lymphoblastic leukaemia by Jak-2 inhibitor. Nature $\mathbf{3 7 9}$, 645-648 (1996)

Mitchell T, Sugden B. Stimulation of NF- $\kappa$ B-mediated transcription by mutant derivatives of the latent membrane protein 1 of Epstein-Barr virus. J. Virol. 69, 2968-2976 (1995)

Mosialos G, Birkenbach M, Yalamanchili R, VanArsdale T, Ware C, KIEFF E. The Epstein-Barr virus transforming protein LMP1 engages signaling proteins for the tumor necrosis factor receptor family. Cell 80, 389-399 (1995)

Najuar I, Baran-Marszak F, Le Clorennec C, Laguillier C, Schischmanoff O, Marfak-Youlyouz I, Schlee M, Bornkamm GW, Raphael M, FEUILLARD J, FAGARD R. Latent membrane protein 1 regulates STAT1 through $\mathrm{NF}-\kappa \mathrm{B}$-dependent interferon secretion in Epstein-Barr virus-immortalized B cells. J. Virol. 79, 4936-4943 (2005)

Nakagomi H, Dolcetti R, Bejarano Mt, Pisa P, Kiessling R, Masucci M. Classification and biological nature of established human hematopoietic cell lines. Int. J. Cancer 57, 240-244 (1994) 
Neininger A, Kontoyiannis D, Kotlyarov A, Winzen R, Eckert R, Volk HD, Holtmann H, Kollias G, Gaestel M. MK2 targets AU-rich elements and regulates biosynthesis of tumor necrosis factor and interleukin-6 independently at different post-transcriptional levels. J. Biol. Chem. 277, 3065-3068 (2002)

Nepomuceno RR, Snow AL, Beatty PR, Krams SM, Martinez OM. Constitutive activation of Jak/STAT Proteins in Epstein-Barr virus-infected B-cell lines from patients with posttransplant lymphoproliferative disorder. Transplantation 74, 396-402 (2002)

Neri A, Barriga F, Inghirami G, Knowles DM, Neequaye J, Magrath T, Dalla-Favera R. Epstein-Barr virus infection precedes clonal expansion in Burkitt's and acquired immunodeficiency syndrome-associated lymphoma. Blood 77, 1092-1095 (1991)

Niemand C, Nimmesgern A, Haan S, Fischer P, Schaper F, Rossaint R, Heinrich PC, Muller-Newen G. Activation of STAT3 by IL-6 and IL-10 in primary human macrophages is differentially modulated by suppressor of cytokine signaling 3. J. Immunol. 170, 3263-3272 (2003)

Nielsen M, Kaltoft K, Nordahl M, Ropke C, Geisler C, Mustelin T, Dobson P, Svejgando A, Odum N. Constitutive activation of a slowly migrating isoform of STAT3 in mycosis fungoides: tyrphostin AG-490 inhibits Stat3 activation and growth of mycosis fungoides tumor cell lines. Proc. Natl. Acad. Sci. USA 94, 6764-6769 (1997)

Nilsson K, Ponten J. Classification and biological nature of established human hematopoietic cell lines. Int. J. Cancer 15, 321-324 (1975)

Ortmann RA, Cheng TC, Visconti R, Frucht DM, O'Shea JJ. Janus kinases and signal transducers and activators of transcription: their roles in cytokine signaling, development and immunoregulation. Arthritis Res. 2, 16-32 (2000)

Peeters P, Raynaud SD, Cools J, Wlodarska I, Grosgeorge J, Philip P, Monpoux F, Van Rompaey L, Baens M, Van de Berghe H, Marynen P. Fusion of Tel, the ETS-variant gene 6 (ETV6), to the receptor-associated kinase Jak2 as a result of $+(9 ; 12)$ in a lymphoid and $\mathrm{t}(9 ; 15 ; 12)$ in a myeloid leukemia. Blood 90, 2535-2540 (1997)

Peng SS, Chen CY, Xu N, Shyu AB. RNA stabilization by the AU-rich element binding protein, HuR, an ELAV protein. EMBO J. 17, 3461-3470 (1998)

Pfeffer S, Zavolan M, Grässer FA, Chien M, Russo JJ, Ju J, John B, Enright AJ, Marks D, SANDer C, Tuschl T. Identification of virus-encoded MicroRNAs. Science 304, 734-736 (2004)

Piecyk M, Wax S, Beck AR, Kedersha N, Gupta M, Maritim B, Chen S, Gueydan C, Kruys V, Streuli M, Anderson P. TIA-1 is a translational 
silencer that selectively regulates the expression of TNF- $\alpha$. EMBO J. 19, 4154$4163(2000)$

Poirier S, Ohshima H, De-The G, Hubert A, Bourgade MC, Bartsch H. Volatile nitrosamine levels in common foods from Tunisia, south China and Greenland, high-risk areas for nasopharyngeal carcinoma (NPC). Int. J. Cancer 39, 293-296 (1987)

QING Y, STARK GR. Alternative activation of STAT1 and STAT3 in response to Interferon- $\gamma$. J. Biol. Chem. 279, 41679-41685 (2004)

Ramana CV, Kumar A, Enelow R. STAT1-independent induction of SOCS-3 by interferon- $\gamma$ is mediated by sustained activation of STAT3 in mouse embryonic fibroblasts. J. BBRC 327, 727-733 (2005)

Richardson C, Fielding C, Rowe M, Brennan P. Epstein-Barr virus regulates STAT1 through latent membrane protein 1. J. Virol. 77, 4439-4443 (2003)

Rickinson AB AND KIEFF E. Epstein-Barr virus; chapter 75 aus dem Buch: Fields BN, Knipe DM, Howley PM, Chanock RM, Monath TP, MeiNick JL, Roizman B, Straus SE. Fields Virology. Lippincott Williams \& Wilkins; 3rd edition (1996)

RoITT IM. Leitfaden der Immunologie. Blackwell Wissenschaft (1993)

Sasaki A, Yasukawa H, Suzuki A, Kamizono S, Syoda T, Kinjyo I, Sasaki M, Johnston JA, Yoshimura A. Cytokine-inducible SH2 protein-3 (CIS3/SOCS3) inhibits Janus tyrosine kinase by binding through the N-terminal kinase inhibitory region as well as SH2 domain. Genes Cells 4, 339-351 (1999)

Schaadt M, Fonatch C, Kirchner H, Diehl V. Establishment of a malignant, Epstein-Barr-virus (EBV)-negative cell-line from the pleura effusion of a patient with Hodgkin's disease. Blut 38, 185-190 (1979)

Schmitz J, Weissenbach M, HaAn S, Heinrich PC, Schaper F. SOCS3 exerts its inhibitory function on interleukin-6 signal transduction through SHP2 recruitment site of gp130. J. Biol. Chem. 275, 12848-12856 (2000)

Schultheiss U, Püschner S, Kremmer E, Mak TW, Engelmann H, HamMERSCHMIDT W, KIESER A. TRAF6 is a critical mediator of signal transduction by the viral oncogene latent membrane protein 1. EMBO J. 20, 5678-5691 (2001)

Schulz WA. Molecular Biology of Human cancers. Springer (2005)

Scott MJ, Godshall CJ, Cheadle WG. Jaks, STATs, Cytokines, and Sepsis. Clinical and Diagnostic Laboratory Immunology 9, 1153-1159 (2002)

Shaulian E, Karin M. AP-1 in cell proliferation and survival. Oncogene 20, 2390$2400(2001)$ 
Shirakata M, Imadome KI, Okazaki K, Hirai K. Activation of TRAF5 and TRAF6 signal cascades negatively regulates the latent replication origin of Epstein-Barr virus through p38 mitogen-activated protein kinase. J. Virol. 75, 5059-5068 (2001)

SHUAI K. Modulation of STAT signaling by STAT-interacting proteins. Oncogene 19, 2638-2644 (2000)

Stahl, N, Faruggella TJ, Boulton TG, Zhong Z, Darnell JE, YancoPOULOS GD. Choice of STATs and other substrates specified by modular tyrosinebased motifs in cytokine receptors. Science 267, 1349-1353 (1995)

Steelman LS, Pohnert SC, Shelton JG, Franklin RA, Bertrand FE, MCCUBREy JA. JAK/STAT, Raf/MEK/ERK, PI3K/Akt and BCR-ABL in cell cycle progression and leukemogenesis. Leukemia 18, 189-218 (2004)

Stoecklin G, Lu M, Rattenbacher B, Moroni C. A constitutive decay element promotes tumor necrosis factor alpha mRNA degradation via an AU-Rich element-independent pathway. Mol. Cell. Biol. 23, 3506-3515 (2003)

SudBECK EA, UCKun FM. Recent advances in Jak3 kinase inhibitors. IDrugs. 2, 1026-1030 (1999)

Sutherland KD, Lindeman GJ, Choong DY, Wittlin S, Brentzell L, Phillips W, Campbell IG, Visvader JE. Differential hypermethylation of SOCS genes in ovarian and breast carcinomas. Oncogene 23, 7726-7733 (2004)

Thompson MP, Aggarwal BB, Shishodia S, Estrov Z, Kurzrock R. Autocrine lymphotoxin production in Epstein-Barr virus-immortalized B cells: induction via NF- $\kappa$ B activation mediated by EBV-derived latent membrane protein 1. Leukemia 17, 2196-2201 (2003)

Tokita T, Maesawa C, Kimura T, Kotani K, Takahashi K, Akasaka T, MASUDA T. Methylation status of the SOCS3 gene in human malignant melanomas. Int. J. Oncol. 30, 689-694 (2007)

Uchida J, Yasui T, TAKaOKa-Shichijo Y, Muraoka M, Kulwichit W, RaAB-Traub N, Kikutani H. Mimicry of CD40 signals by Epstein Barr virus LMP1 in B lymphocyte responses. Science 286, 300-303 (1999)

Verma A, Kambhampati S, Parmar S, Platanias LC. Jak family of kinases in cancer. Cancer and Metastasis Reviews 22, 423-424 (2003)

Vockerodt M, Haier BM Buttgereit P, Tesch H, Kube D. Epstein-Barr virus latent membrane protein 1 induces interleukin-10 in Burkitt's lymphoma cells but not in Hodgkin's lymphoma cells involving the p38/SAPK2 pathway. Virology 280, 183-198 (2001) 
Vockerodt M, Pinkert D, Smola-Hess S, Michels A, Ransohoff RM, Tesch H, KubE D. The Epstein-Barr virus oncoprotein latent membrane protein 1 induces expression of the chemokine IP-10: Importance of the mRNA half-life regulation. Int. J. Cancer 114, 598-605 (2004)

Wang D, Liebowitz D, KiefF E. An EBV membrane protein expressed in immortalized lymphocytes transforms established rodent cells. Cell 43, 831-840 (1985)

Wang D, Liebowitz D, KiefF E. The truncated form of the Epstein-Barr virus latent-infection membrane protein expressed in virus replication does not transform rodent fibroblasts. J. Virol. 62, 2337-2346 (1988)

Wang LH, Kirken RA, Erwin RA, Yu CR, FArrar WL. JAK3, STAT, and MAPK signaling pathways as novel molecular targets for the tyrphostin AG-490 regulation of IL-2-mediated T cell response. J. Immunol. 162, 3897-3904 (1999)

Weber A, Hengge UR, Bardenheuer W, Tischoff I, Sommerer F, Markwarth A, Dietz A, Wittekind C, Tannapfel A. SOCS3 is frequently methylated in head and neck squamous cell carcinoma and its precursor lesions and causes growth inhibition. Oncogene 24, 6699-6708 (2005)

Winzen R, Kracht M, Ritter B, Wilhelm A, Chen CYA, Shyu AB, Müller M, Gaestel M, Resch K, Holtmann H. The p38 MAP kinase pathway signals for cytokine-induced mRNA stabilization via MAP kinase-activated protein kinase 2 and an AU-rich region-targeted mechanism. EMBO J. 18, 4969$4980(1999)$

Wolf J, Kapp U, Bohlen H, Kornacker M, Schoch C, Stahl B, Mucke S, von Kalle C, Fonatsch C, Schaefer HE, Hansmann ML, Diehl V. Peripheral blood mononuclear cells of a patient with advanced Hodgkin's lymphoma give rise to permanently growing Hodgkin-Reed Sternberg cells. Blood 87, 3418-3428 (1996)

Wormald S, Hilton DJ. Inhibitors of Cytokine Signal Transduction. J. Biol. Chem. 279, 821-824 (2004)

Ye H, Park YC, Kreisham M, Kieff E, Wu H. The structural basis for the recognition of diverse receptor sequences by TRAF2. Mol. Cell 4, 321-330 (1999)

Yoshikawa H, Matsubara K, Qian GS, Jackson P, Groopman JD, ManNING JE, HARRIS CC, HERMAN JC. SOCS-1, a negative regulator of the Jak/STAT pathway, is silenced by methylation in human hepatocellular carcinoma and shows growth-suppression activity. Nat. Genet. 28, 29-35 (2001)

Zhang JG, Farley A, Nicholson SE, Willson TA, Zugaro LM, Simpson RJ, Moritz RL, Cary D, Richardson R, Hausmann G, Kile BJ, Kent SB, Alexander WS, Metcalf D, Hilton DJ, Nicola NA, Baca M. The 
conserved SOCS box motif in suppressors of cytokine signaling binds elongins B and $\mathrm{C}$ and may couple bound proteins to proteasomal degradation. Proc. Natl. Acad. Sci. USA 96, 2071-2076 (1999)

Zhang L, Hong K, Zhang J, PAgAno JS. Multiple siganal transducers and activators of transcription are induced by EBV LMP-1. Virology 323, 141-152 (2004)

Zhang L, Badgwell DB, Bevers III JJ, Schlessinger K, Murray PJ, LEVY DE, WATOWICH SS. IL-6 signaling via the STAT3/SOCS3 pathway: Functional analysis of the conserved STAT3 N-domain. Mol. Cell. Biol. 288, 179-189 (2006)

Zhang Q, Raghunath PN, Xue L, Majewski M, Carpentieri DF, Odum N, Morris S, Skorski T, WASIK MA. Multilevel dysregulation of STAT3 activation in anaplastic lymphoma kinase-positive T/null-cell lymphoma. J. Immunol. 168, 466-474 (2002)

Zhang W, Wagner BJ, Ehrenman K, Schaefer AW, Demaria CT, Crater D, DeHaven K, Long L, Brewer G. Purification, characterization, and cDNA cloning of an AU-rich element RNA-binding protein, AUF1. Mol. Cell. Biol. 13, 7652-7665 (1993) 


\section{Veröffentlichungen}

Pinkert D, Vockerodt M, Kieser A, Kube D. The Epstein-Barr virus oncoprotein latent membrane protein 1 affects the expression of suppressors of cytokine signaling in transformed B-lymphocytes. (Manuskript in Vorbereitung)

Schoof N, Pinkert D, von Bonin F, Wilting J, Trümper L, Kube D. Janus kinases are targets of tyrphostin AG17 and HSP90-inhibitor 17-AAG in classical Hodgkin lymphoma. (Manuskript zur Begutachtung eingereicht)

Holtick U, Vockerodt M, Pinkert D, Schoof N, Sturzenhofecker B, Kussebi N, Lauber K, Wesselborg S, Loffler D, Horn F, Trumper L, KuBE D. STAT3 is essential for Hodgkin lymphoma cell proliferation and is a target of tyrphostin AG17 which confers sensitization for apoptosis. Leukemia 19, 936-944 (2005)

Vockerodt M, Pinkert D, Smola-Hess S, Michels A, Ransohoff RM, Tesch H, Kube D. The Epstein-Barr virus oncoprotein latent membrane protein 1 induces expression of the chemokine IP-10: importance of mRNA half-life regulation. Int. J. Cancer 114, 598-605 (2005)

Teile dieser Arbeit wurden bisher öffentlich als Poster auf folgenden Tagungen präsentiert:

- Jahrestagung der Gesellschaft für Virologie; 17. - 20.03.2004 in Tübingen

- Jahrestagung der Gesellschaft für Virologie; 16. - 19.03.2005 in Hannover

- Jahrestagung der Deutschen Gesellschaft für Hämatologie und Onkologie; 01. - 05.10.2005 in Hannover

- Joint Meeting der Signal Transduction Society; 10. - 12.11.2005 in Weimar

- Jahrestagung der Gesellschaft für Virologie; 15. - 18.03.2006 in München

- EBV2006-Meeting der International Association Epstein-Barr Virus Research; 08. - 12.07.2006 in Boston 
- Genetic variation and pharmacogenomics in oncology; 14. - 15.07.2006 in Göttingen

- Joint Meeting der Signal Transduction Society; 10. - 12.11.2006 in Weimar

Teile dieser Arbeit wurden bisher öffentlich als Vortrag auf folgenden Tagungen präsentiert:

- Genetic variation and pharmacogenomics in oncology; 14. - 15.07.2006 in Göttingen 


\section{Danksagung}

Geschafft! Nun ist es endlich Zeit, mich bei all denen zu bedanken, die zum Gelingen dieser Arbeit beigetragen haben. Mein besonderer Dank gilt Herrn Prof. Dr. R. Hardeland für die Bereitschaft diese Arbeit zu betreuen und zu begutachten, sein Interesse am Fortgang derselbigen und für so manch hilfreichen Hinweis. Herrn Prof. Dr. E. Wimmer möchte ich für die Übernahme des Zweitgutachtens herzlich danken.

Für die Möglichkeit diese Arbeit anzufertigen und die hervorragende wissenschaftliche Betreuung geht ein großes Dankeschön an Herrn PD Dr. D. Kube, der mir mit Rat und Tat zur Seite stand und immer eine Lösung für Probleme aller Art hatte. Herrn Prof. Dr. L. Trümper möchte ich für die herzliche Aufnahme in die Abteilung der Hämatologie und Onkologie danken. Dem Graduiertenkolleg „Die Bedeutung genetischer Polymorphismen in der Onkologie" sei für die Unterstützung, das lehrreiche Ausbildungsprogramm und die nette Atmosphäre im Kolleg gedankt. Ein großes Lob für ihre unermüdliche Hilfsbereitschaft geht an Frederike von Bonin, die mich mit der Frage „Wieviel Proben sind es denn?” so manches Mal in moralische Bedrängnis gebracht hat. Dr. Martina Vockerodt und Nils Schoof möchte ich für ihre Hilfe beim Erlernen von Methoden und ihre ständige Diskussionsbereitschaft, auch über wissenschaftliche Themen hinaus, danken.

Ein riesiges Dankeschön gilt meiner lieben Freundin und Kollegin Jeannine MissbachGüntner für ihr ständiges Mut zusprechen und ihr offenes Ohr für alle wissenschaftlichen und privaten Probleme, für die sie immer einen passenden Rat hatte. Und nicht zu vergessen, die literarischen Stunden im Labor zusammen mit Melani Fork, rein wissenschaftlich versteht sich. Dr. Katharina Jannasch danke ich für das Korrekturlesen dieser Arbeit. Ohne sie wäre das Mensaessen nur halb so erträglich gewesen. Sarah Greco und Carmen Haak gilt mein Dank für ihre Hilfe bei der Bewältigung der Mengen an Proben, die es aufzuarbeiten galt. Hilfe beim Schreiben mit LTEX erhielt ich von Jutta Pollmann, wofür ich mich herzlich bedanken möchte. Ohne meine lieben Kolleginnen und Kollegen, die mir immer eine helfende Hand gereicht haben, wenn ich mal wieder im wissenschaftlichen Morast zu versinken drohte, wäre diese Arbeit gar nicht möglich gewesen. Und natürlich teilen wir auch so manch 
lustige Begebenheit, die so einen Laboralltag auflockert. Ein herzliches Dankeschön an dieser Stelle auch an alle, die ich hier nicht namentlich erwähnt habe.

Meinen lieben Eltern und Geschwistern danke ich für all die aufmunternden Worte, den familiären Rückhalt, den sie mir geben und die unermüdliche Unterstützung seit dem Beginn meines Studiums. Meinem Mann Roland gilt besonderer Dank für seine ganze Liebe und den Halt, den er mir gibt. Dass er selbst aus weiter Ferne unermüdlich all die technischen Tücken in den Griff bekommen hat, die scheinbar immer nur bei mir auftauchen. Er ist eine Quelle an Geduld, Ruhe und Zuversicht, aus der ich meine ganze Kraft schöpfe. 


\section{Lebenslauf}

\section{Angaben zur Person}

Name:

Diana Pinkert-Leetsch, geb. Pinkert

Geburtsdatum/-ort:

23.12.1978 in Merseburg

Staatsangehörigkeit:

deutsch

Familienstand:

verheiratet

\section{Schulbildung}

$\begin{array}{ll}1985-1989 & \text { Erich-Weinert-Grundschule, Merseburg } \\ 1989-1991 & \text { Erich-Weinert-Oberschule, Merseburg } \\ 1991-1997 & \text { Johann-Gottfried-Herder-Gymnasium, Merseburg }\end{array}$

wissenschaftlicher Werdegang

$1997-2002$

$2001-2002$

$2002-2003$

$2003-2007$
Biochemie-Studium an der Martin-Luther-Universität Halle-Wittenberg, Halle

Diplomarbeit in der Arbeitsgruppe von PD Dr. H. Taubert am Institut für Pathologie der Martin-Luther-Universität Halle-Wittenberg

Titel der Arbeit: „Expressions- und Funktionsstudien von MDM2-Spleißvarianten in Normalgewebe"

sechsmonatiger Aufenthalt als Gastwissenschaftler in der Arbeitsgruppe von Dr. G. Zambetti, Department of Biochemistry, St. Jude Children's Research Hospital, Memphis, USA

Doktorarbeit in der Arbeitsgruppe von PD Dr. D. Kube, Abteilung Hämatologie und Onkologie am Uniklinikum Göttingen der Georg-August-Universität Göttingen Titel der Arbeit: „Funktionelle Analysen deregulierter Signalwege transformierter B-Lymphozyten Das Epstein-Barr-Virus-Onkogen LMP1" 